Linköping University Medical Dissertations

No. 1537

\title{
Interplay of human macrophages and Mycobacterium tuberculosis phenotypes
}

\author{
Johanna Raffetseder
}

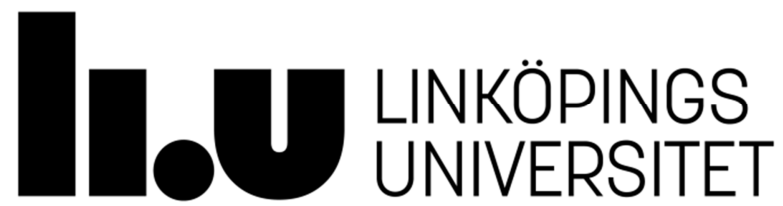

Division of Microbiology and Molecular Medicine Department of Clinical and Experimental Medicine

Faculty of Medicine and Health Sciences

Linköping University

SE-581 85 
(C) Johanna Raffetseder, 2016

All rights reserved.

Paper 1 was published in PLOS ONE under the Creative Commons CC-BY license.

Paper 2 was published in Journal of Innate Immunity under the Creative Commons CC-BYNC license.

Artwork on cover created by Elfi Raffetseder.

ISBN: 978-91-7685-690-1

ISSN: 0345-0082

Printed by LiU-Tryck, Linköping 2016 
„Ein guter Forscher muss nach der Wabrheit streben und wissen, dass er ihr immer nur nahe kommen kann. Er muss Tatsachen anerkennen, gleichgülig, ob diese seinem Denken und seinen Wünschen entgegenkommen oder nicht, das heißt, er muss selbstlos sein. Und er muss die Fähigkeit haben, sich über das Naturgeschehen zu wundern und es zu bewundern."

Lise Meitner, Austrian-Swedish physicist, 1953 


\section{Supervisor}

Maria Lerm, Linköping University, Sweden

\section{Co-supervisors}

Olle Stendahl, Linköping University, Sweden

Vesa Loitto, Linköping University, Sweden

\section{Faculty opponent}

Trude Helen Flo, Norwegian University of Science and Technology, Norway

\section{Funding}

This work was supported by the Swedish Research Council, the Bill \& Melinda Gates Foundation, the Carl Trygger Foundation, the Swedish Heart Lung Foundation, SIDA/SAREC, the County Council of Östergötland and the Oskar II Jubilee Foundation. 


\section{Table of contents}

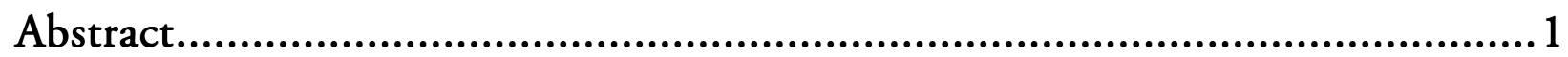

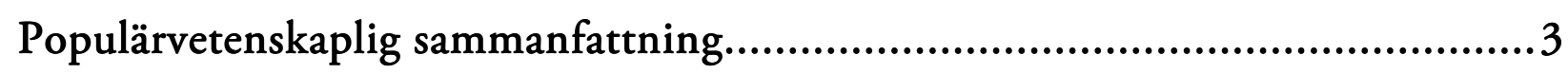

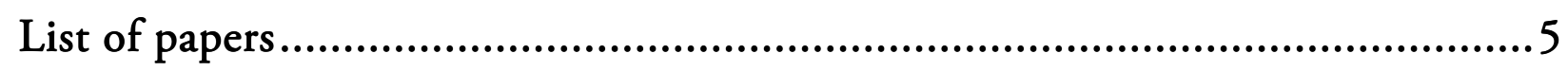

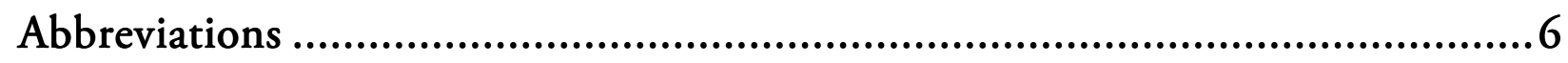

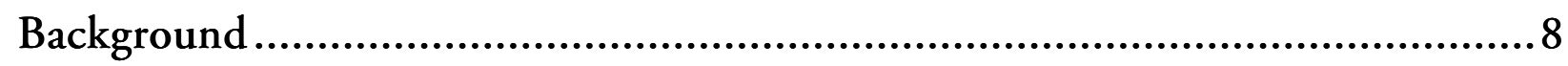

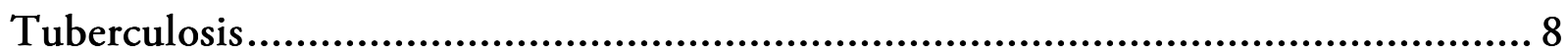

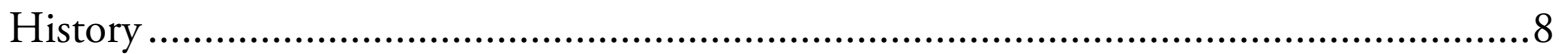

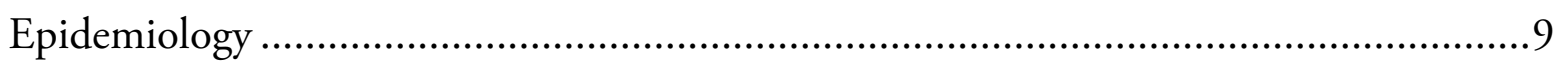

Mycobacterium tuberculosis ................................................................................ 10

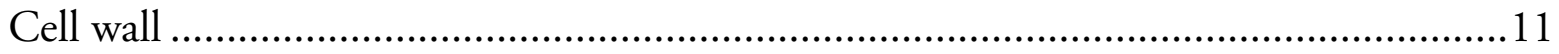

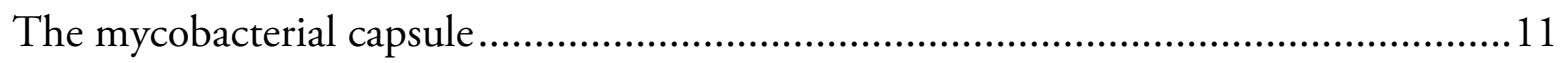

Transport across membranes, ESX-1 secretion and ESAT6 …………………….......13

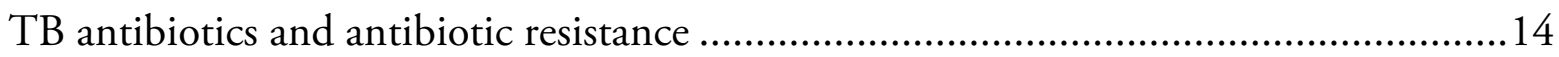

Mtb and the human immune system ............................................................. 16

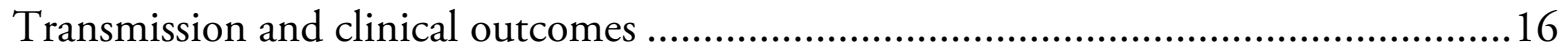

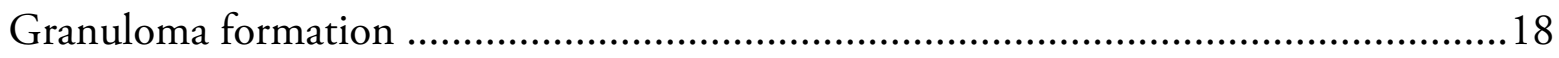

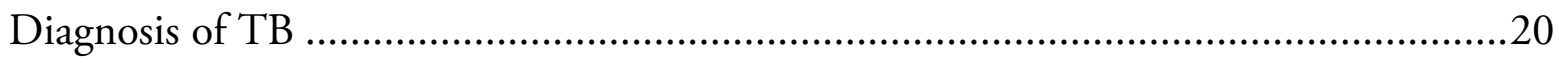

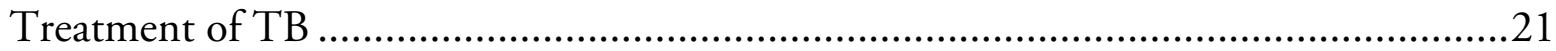

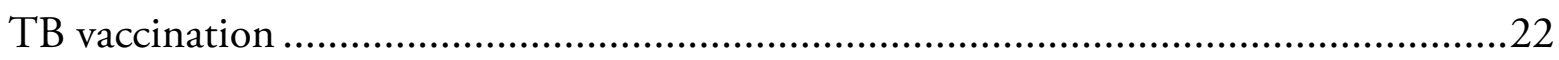

Interplay of macrophages and Mycobacterium tuberculosis ..........................................24

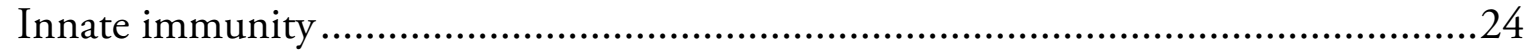

Polarization - heterogeneity of macrophages..........................................................24

Recognition and uptake of Mtb by macrophages ...................................................25

Phagolysosomal maturation and autophagy..............................................................27

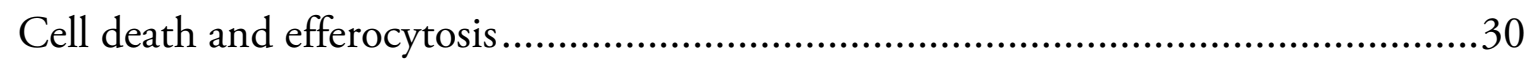

ESX-1-secreted virulence factors and the human immune system...................................31 


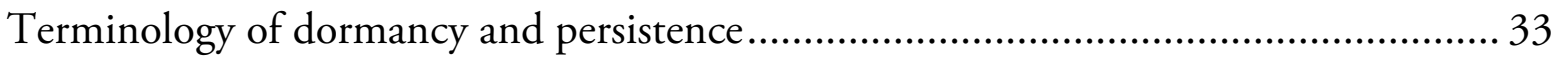

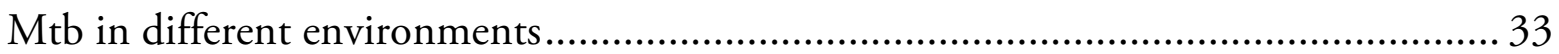

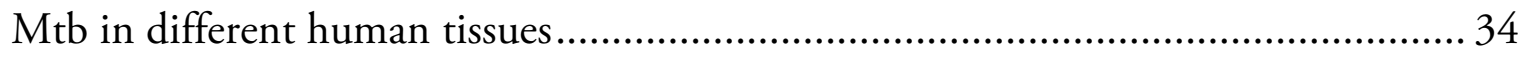

Conditions and adaptation inside the macrophage ............................................ 36

The environment in the granuloma ................................................................ 40

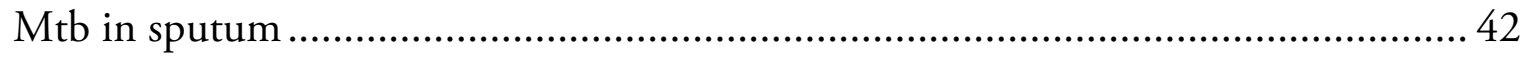

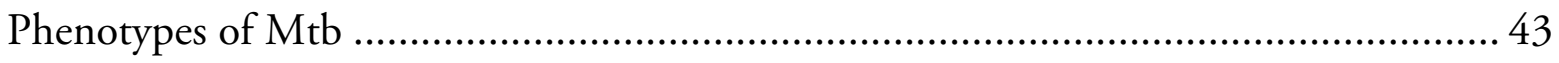

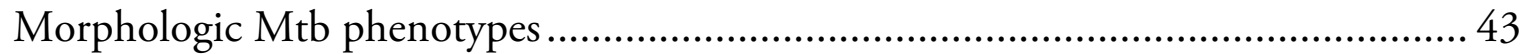

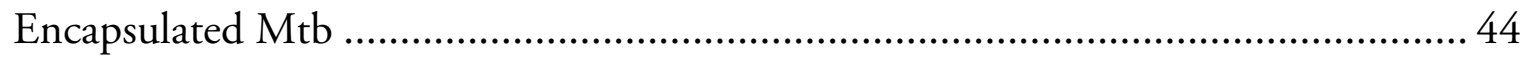

Mechanisms and models for Mtb dormancy and persistence................................ 46

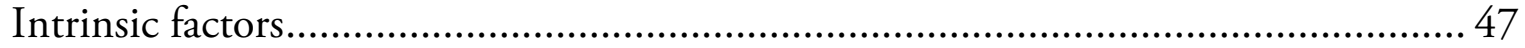

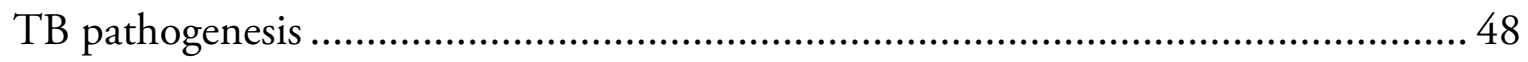

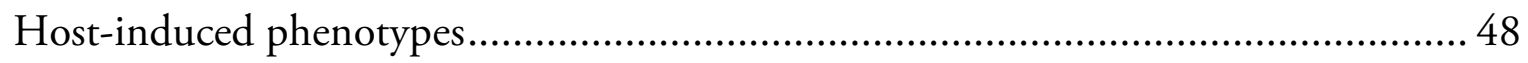

Clinical implications of dormancy and persistence .......................................... 53

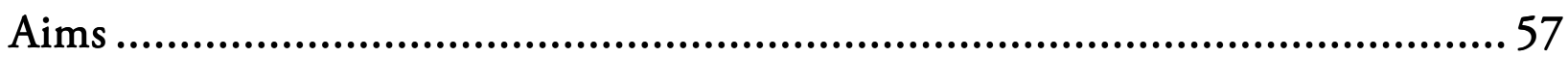

Results and Discussion .............................................................. 58

Concluding remarks and outlook ................................................. 67

References ............................................................................... 69

Acknowledgements ................................................................. 88 


\section{Abstract}

Mycobacterium tuberculosis (Mtb) is the pathogen causing tuberculosis (TB), a disease most often affecting the lung. 1.5 million people die annually due to TB, mainly in low-income countries. Usually considered a disease of the poor, also developed nations recently put TB back on their agenda, fueled by the HIV epidemic and the global emergence of drugresistant Mtb strains. HIV-coinfection is a predisposing factor for $\mathrm{TB}$, and infection with multi-drug resistant and extremely drug resistant strains significantly impedes and lengthens antibiotic treatment, and increases fatality. Mtb is transmitted from a sick individual via coughing, and resident macrophages are the first cells to encounter the bacterium upon inhalation. These cells phagocytose intruders and subject them to a range of destructive mechanisms, aiming at killing pathogens and protecting the host. Mtb, however, has evolved to cope with host pressures, and has developed mechanisms to submerge macrophage defenses. Among these, inhibition of phagosomal maturation and adaptation to the intracellular environment are important features. Mtb profoundly alters its phenotype inside host cells, characterized by altered metabolism and slower growth. These adaptations contribute to the ability of $\mathrm{Mtb}$ to remain dormant inside a host during latent TB infection, a state that can last for decades. According to recent estimates, one third of the world's population is latently infected with Mtb, which represents a huge reservoir for active TB disease. Mtb is also intrinsically tolerant to many antibiotics, and adaptation to host pressures enhances tolerance to first-line TB drugs. Therefore, TB antibiotic therapy takes 6 to 9 months, and current treatment regimens involve a combination of several antibiotics. Patient noncompliance due to therapeutic side effects as well as insufficient penetration of drugs into TB lesions are reasons for treatment failure and can lead to the rise of drugresistant populations. In view of the global spread of drug-resistant strains, new antibiotics and treatment strategies are urgently needed.

In this thesis, we studied the interplay of the primary host cell of Mtb, human macrophages, and different Mtb phenotypes. A low-burden infection resulted in restriction of Mtb replication via phagolysosomal effectors and the maintenance of an inactive Mtb phenotype reminiscent of dormant bacteria. Macrophages remained viable for up to 14 days, and profiling of secreted cytokines mirrored a silent infection. On the contrary, higher bacterial numbers inside macrophages could not be controlled by phagolysosomal functions, and intracellular Mtb shifted their phenotype towards active replication. Although slowed mycobacterial replication is believed to render Mtb tolerant to antibiotics, we did not observe such an effect. Mtb-induced macrophage cell death is dependent on ESAT6, a small 
mycobacterial virulence factor involved in host cell necrosis and the spread of the pathogen. Although well-studied, the fate of ESAT6 inside infected macrophages has been enigmatic. Cultivation of $\mathrm{Mtb}$ is commonly carried out in broth containing detergent to avoid aggregation of bacilli due to their waxy cell wall. Altering cultivation conditions revealed the presence of a mycobacterial capsule, and ESAT6 situated on the mycobacterial surface. Infection of macrophages with this encapsulated Mtb phenotype resulted in rapid ESAT6dependent host cell death, and ESAT6 staining was lost as bacilli were ingested by macrophages. These observations could reflect the earlier reported integration of ESAT6 into membranes followed by membrane rupture and host cell death.

In conclusion, the work presented in this thesis shows that the phenotype of Mtb has a significant impact on the struggle between the pathogen and human macrophages. Taking the bacterial phenotype into account can lead to the development of drugs active against altered bacterial populations that are not targeted by conventional antibiotics. Furthermore, deeper knowledge on Mtb virulence factors can inform the development of virulence blockers, a new class of antibiotics with great therapeutic potential. 


\section{Populärvetenskaplig sammanfattning}

Tuberkelbakterien Mycobacterium tuberculosis är en bakterie som orsakar en av världens vanligaste infektionssjukdomar, nämligen lungsjukdomen tuberkulos (TBC). Uppskattningsvis dör en och en halv miljoner människor årligen i TBC, framförallt i Afrika och i Asien. TBC kan behandlas med långvarig antibiotikabehandling som i okomplicerade fall tar 6-9 månader. Behandlingen har försvårats betydligt de senaste åren genom uppkomsten av antibiotikaresistenta tuberkelbakteriestammar. Dessutom har individer som även bär på HIV mycket lättare att utveckla TBC efter att ha blivit smittade med tuberkelbakterien.

Det klassiska TBC-symptomet är kronisk hosta, som gör att bakterierna kan sprida sig mellan människor. När bakterierna inhaleras i lungan så är det ätarceller, så kallade makrofager, som försöker avdöda dem innan infektionen får fäste och bakterierna hinner tillväxa. Makrofagerna åstadkommer detta genom att ta upp bakterien i en så kallad fagosom, en cellvesikel som oskadliggör bakterier genom olika mekanismer. Eftersom tuberkelbakterien antagligen har funnits lika länge som människan så har den hunnit utveckla mekanismer för att hämma immuncellens försvars- och avdödningsfunktioner. Samspelet mellan bakterier och immuncellerna kan tänkas som en dragkamp, där i vissa fall immuncellerna klarar av att avdöda smittan, medans i andra fall kan bakterierna växa till och orsaka immuncellens död. I vissa fall kan bakterierna även byta skepnad (s.k. fenotyp) och bege sig in i en slags dvala, som leder till att smittan kan vara kvar i smittade individer. Detta kallas för latent TBC.

I denna avhandling har vi haft som syfte att undersöka samspelet mellan tuberkelbakterien och makrofager, och även tagit hänsyn till olika fenotyper som bakterierna kan anta. Vi har då sett att makrofagerna kan bromsa bakteriernas tillväxt under vissa förutsättningar, vilket resulterat i att bakterierna fått egenskaper som påminner om 'lata' bakterier. Dessa bakterier växer väldigt långsamt $\mathrm{i}$ makrofagerna och makrofagernas överlevnad påverkas inte av infektionen som kan pågå i ungefär två veckor. Kontrollen av bakteriernas tillväxt är beroende av cellens förmåga att surgöra fagosomen, vilket i sin tur leder till aktiveringen av vissa enzymer som kan attackera bakterierna. Vi kunde i experimenten även efterlikna situationen där bakterierna är mer aktiva och delar sig i cellerna, med cellernas död som följd. Detta händer troligtvis i lungan när infektionen inte kan kontrolleras längre, vilket leder till smittsam TBC. 
Anledningen för att TBC-behandlingen tar så lång tid är att tuberkelbakterien är tolerant mot många antibiotika, och man trodde att den främsta mekanismen för antibiotikatolerans är att bakterien saktar ner sin delningshastighet. Vi har undersökt detta i makrofagerna, men har dock inte kunnat se ett samband mellan delningshastigheten och antibiotikatolerans.

För att kunna avdöda makrofager så utsöndrar bakterierna ett ämne som är skadligt för cellerna och som kallas ESAT6. ESAT6 gör så att bakterien kan smita från den ovänliga miljön i fagosomen genom att förstöra fagosomens membran. Tuberkelbakterier som saknar ESAT6 är mindre skadliga och saknar förmågan att sprida sig till andra celler och individer. Vi har försökt påvisa ESAT6 i makrofager, för att kunna förstå när den utsöndras. Att kunna hämmautsöndringen av ESAT6 skulle nämligen kunna leda till utvecklingen av nya sätt att bekämpa bakterien. Vi har inte lyckats att påvisa ESAT6 inuti infekterade celler, men genom att förändra odlingsförhållanden av bakterierna har vi sett att ESAT6 finns på bakteriernas yta. Vanligtvis odlas nämligen tuberkelbakterierna i buljong som innehåller ett tvålämne som förhindrar att bakterierna klumpar ihop sig under tillväxten. Tidigare har man dock sett att detergenten förstör bakteriernas kapsel, som är det yttersta, sköra lagret av cellväggen. Om man nu odlar bakterierna utan detta ämne, så finns ESAT6 kvar på bakteriernas yta. Dessa 'beväpnade' tuberkelbakterier har förmåga att avdöda makrofagerna mycket snabbare än vanliga bakterier som har odlats med detergent, som visar att ESAT6 spelar en stor roll när det gäller att avdöda cellen. Vi har dessutom belägg att ESAT6 påverkar makrofagens cellyta, vilket kan leda till att cellen förstörs.

Sammanlagt så visar dessa studier att bakteriernas fenotyp kan påverka utfallet av infektionen av makrofager. Bättre förståelse av samspelet mellan olika bakteriefenotyper och cellerna kommer att leda till utvecklingen av läkemedel som har effekt på flera olika bakteriefenotyper, eller som hämmar ett av tuberkelbakteriens mest cellskadliga ämnen. 


\section{List of papers}

\section{Paper 1}

Welin A, Raffetseder J, Eklund D, Stendahl O, Lerm M. Importance of phagosomal functionality for growth restriction of Mycobacterium tuberculosis in primary human macrophages. Journal of Innate Immunity 2011, 3(5):508-518.

\section{Paper 2}

Raffetseder J, Pienaar E, Blomgran R, Eklund D, Patcha Brodin V, Andersson H, Welin A, Lerm M. Replication Rates of Mycobacterium tuberculosis in Human Macrophages Do Not Correlate with Mycobacterial Antibiotic Susceptibility. PLOS ONE 2014, 9(11):e112426.

\section{Paper 3}

Raffetseder J, Iakobachvili N, Loitto V, Peters P, Lerm M. Retention of ESAT6 in the capsular layer of Mtb causes hypervirulence. Manuscript. 


\section{Abbreviations}

${ }^{18} \mathrm{FDG}$

AM

BAL

BCG

CFP10

CFU

DAMP

DC

DC-SIGN

DNA

DOT

EMB

ER

ESAT6

ESX

HIV

IFN

IGRA

INH

iNOS

LAM

LTBI

ManLAM

MDR-TB

MOI

MR

Mtb

NGMA

$\mathrm{NF \kappa B}$

NHP

NOX2

Nramp1

PCR

PET-CT

PPD

PRR

PZA
${ }^{18}$ F-fluorodeoxyglucose

arabinomannan

bronchoalveolar lavage

Bacille Calmette Guérin

$10 \mathrm{kDa}$ culture filtrate antigen CFP-10

colony-forming units

danger-associated molecular patterns

dendritic cell

dendritic cell-specific intercellular adhesion molecule-3 grabbing nonintegrin

deoxyribonucleic acid

directly observed therapy

ethambutol

endoplasmic reticulum

$6 \mathrm{kDa}$ early secreted antigenic target

ESAT6 secretion system

human immunodeficiency virus

interferon

IFN $\gamma$ release assay

isoniazid

inducible nitric oxide synthase

lipoarabinomannan

latent tuberculosis infection

mannosylated lipoarabinomannan

multi drug-resistant tuberculosis

multiplicity of infection

mannose receptor

Mycobacterium tuberculosis

non-growing but metabolically active

nuclear factor kappa-light-chain-enhancer of activated B cells

non-human primate

NADPH oxidase complex

natural resistance-associated macrophage protein

polymerase chain reaction

positron emission tomography-computed tomography

purified protein derivative

pattern recognition receptors

pyrazinamide 
$\mathrm{RD} 1$

RIF

Rpf

SP-A

SP-D

TAT

TB

TLR

TNF

TST

VBNC

WHO

WXG

XDR-TB region of difference 1

rifampicin

resuscitation-promoting factors

surfactant protein A

surfactant protein $\mathrm{D}$

twin-arginine transporter

tuberculosis

Toll-like receptor

tumor necrosis factor

tuberculin skin test

viable but non-culturable

world health organization

tryptophan-variable-glycine

extremely drug-resistant tuberculosis 


\section{Background}

\section{Tuberculosis}

\section{History}

Tuberculosis (TB) is a lethal infectious disease mainly affecting the lung while virtually most organs can be affected. In the human TB is caused by the bacterium Mycobacterium tuberculosis $(\mathrm{Mtb})$, which was cultured for the first time and identified by Robert Koch in 1882. However, it has been a scourge of humanity for much longer and may have killed more people than any other microbial pathogen [1]. Archeological evidence in the form of fossil bones dates back to $8000 \mathrm{BC}$ and spinal TB was found in Egyptian mummies from 3 500 BC [2]. Molecular analysis on ancient DNA extracted from mummies confirmed the presence of Mtb [3-5] and bacilli could even be detected by acid-fast staining [6]. Nevertheless, phylogenetic studies on DNA extracted from different Mtb complex strain lineages suggest that Mtb and humankind co-evolved, possibly since the emergence of the anatomically modern human 200000 years ago [7, 8]. Around the same time, humans started to use fire which fundamentally altered many areas of human life and could have implied the advent of human TB [9]. Other theories describe a connection between the appearance of one of the earliest lineages of Mtb complex and the first wave of humans migrating out of Africa, 67000 years ago, and other lineages could be dated to other migration events [10]. This is supported by findings that Mtb lineages exhibit a preference for transmission to specific human populations [11]. Ever since, TB has been a part of human society. Around 400 BC, Hippocrates described 'phthisis' as the most common disease of his time [12] and even considered it a hereditary disease as it commonly occurred within families [2]. Almost 2000 years later during the industrial revolution and with the crowding of cities, TB turned endemic in Europe accounting for $25 \%$ of deaths. Already before the introduction of antibiotics, TB cases dropped in the early $20^{\text {th }}$ century due to better living conditions [1]. This was also supported by the introduction of sanatoria where patients experienced improvement upon treatment with sunlight, fresh air and food, but after discharge often still died from the disease $[2,13]$. In the meantime, the development of X-ray allowed closer characterization and diagnosis of lung tubercles [2]. Finally, in the 1940's, streptomycin, the first antibiotic against Mtb, was isolated from Streptomyces griseus, and its discoverer, Selman Waksman considered TB soon to be eradicated in 1964, further supported by the discovery of new antibiotics [14]. Still, drug resistance was quick to appear [15] and the challenges of the contemporary TB endemic evolve around multi drug-resistant strains of Mtb and co-infections such as human immunodeficiency virus (HIV). 
Due to its constant presence and huge impact on society, TB has received a lot of attention in literature (i.e. in Astrid Lindgren's 'The Brother's Lionheart') and arts, such as in famous paintings by Claude Monet and Edvard Munch. Under the ongoing epidemic also recent artistic works were devoted to $\mathrm{TB}$, such as a series of photographs by James Nachtwey, focusing attention on multidrug-resistant TB.

\section{Epidemiology}

According to the latest annual report on tuberculosis by the World Health Organization (WHO) from 2015 [16], 2-3 billion people were estimated to be latently infected with Mtb in 2014, comprising one third of the world's population. The majority of people exposed to Mtb never develop TB disease (90-95\%) and many of them carry no immunological memory of an encounter with Mtb. This suggests that in most infected individuals, the bacilli can be eradicated before adaptive immunity is mounted, ascribing innate immune mechanisms an important role for early TB control.

Still, TB causes 1.5 million deaths annually, and the total number of incident cases of TB worldwide was 9.6 million. Many of them occurred in low income countries topped by India, Indonesia and China, accounting for $43 \%$ of all cases. Incidence rates, e.g. the number of new and relapsed cases as a ratio of population, were highest in Sub-Saharan Africa and the region of South-East Asia and Western Pacific (Figure 1) [16]. Global incidence rates are declining, but still the total burden of $\mathrm{TB}$ is increasing due to the fast growth of the global population [17]. Apparently, incidence correlates with population density and income, which highlights the importance of socioeconomic factors and living conditions [18], reminiscent of Europe during the late $18^{\text {th }}$ and $19^{\text {th }}$ century, where TB was rising due to urbanization. Besides overcrowding and poverty, the major risk factor for contracting TB is HIV infection, with a 26-fold increased risk of developing TB in HIVpositives. Most HIV-positive TB-cases occurred in Africa (74\%) [16], and HIV co-infection complicates diagnosis and treatment of TB. Other risk factors for developing TB are coinfection with helminths, diabetes mellitus, as well as alcoholism and smoking [17]. Furthermore, there is a growing number of genetic variants known to be associated with susceptibility to $\mathrm{TB}$, such as polymorphisms in the genes encoding the vitamin $\mathrm{D}$ receptor, nitric oxide synthase, natural resistance-associated macrophage protein (Nramp1) and components of interferon- $\gamma$ pathway [19].

Treatment of TB is lengthy and accompanied by many side effects, though currently successful in $86 \%$ of cases if completed. This is in strong contrast to multi drug-resistant TB 
(MDR-TB) and extremely drug-resistant TB (XDR-TB), where 50\% of MDR-TB cases could be cured [16].

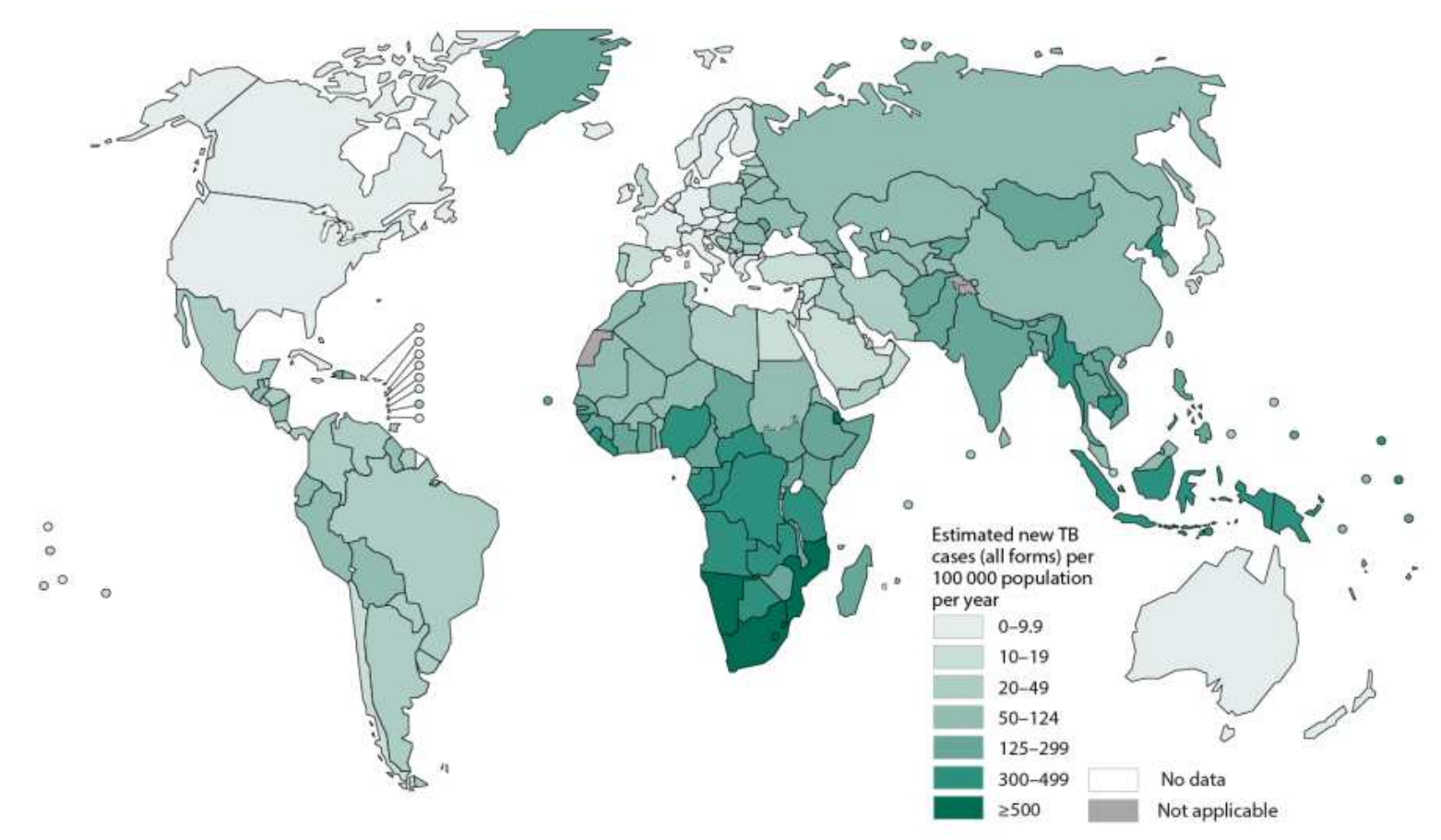

Figure 1. Estimated TB incidence rates in 2014 [16]. Figure obtained from [20]. Permission for reprint granted by WHO.

\section{Mycobacterium tuberculosis}

Mycobacteria belong to the order actinomycetes, and the majority of mycobacteria belong to the large group of non-tuberculous mycobacteria most often found in soil. These can cause opportunistic infections but are usually non-pathogenic. The organisms belonging to the Mtb complex that can cause human disease are Mycobacterium tuberculosis, Mycobacterium africanum, Mycobacterium bovis, Mycobacterium microti and Mycobacterium canetti. The most common agent of human TB, Mtb, is a slender rod-shaped bacterium with a typical size of 1-5 $\mu \mathrm{m}$ [21]. Mtb is an intracellular pathogen, aerobic and non-motile, and has originally been described as non-encapsulated and non-spore forming [17], both of which has been challenged (and will be discussed in later chapters). The generation time is 15-20 hours or even longer, strongly depending on the growth conditions and the strain. Mtb has further been shown to divide asymmetrically producing two differently sized daughter cells [22-24], as opposed to the symmetric cell division described for many other bacteria [25]. 


\section{Cell wall}

Mtb is gram-positive by phylogenetic definition, although its cell wall features an outer membrane as in gram-negative bacteria. Due to its waxy, impermeable cell wall, Gramstaining often renders inconsistent results. Instead, mycobacteria can be identified by a procedure known as acid-fast staining. Here, staining with fuchsin or the fluorescent dye auramine is enhanced by the addition of phenol, which facilitates membrane penetration. In a subsequent decolorization step, only the mycobacterial cell wall is resistant to acidic solvents, leading to retention of the dye. Other acid-fast organisms impeding diagnosis of TB are non-tuberculous mycobacteria and Nocardia. The principle of acid-fast staining was developed by Franz Ziehl and Friedrich Neelsen in the late $19^{\text {th }}$ century, and ever since constitutes the gold standard for diagnosis of Mtb in sputum [17].

The composition of the mycobacterial cell wall is complex, and has been the target of extensive research. It is composed of a plasma membrane, surrounded by a peptidoglycan layer with a periplasmic space in between. Another layer consisting of arabinogalactan is covalently attached to the peptidoglycan. In return, most arabinan residues are ligated with uncommonly long, branched fatty acids, the mycolic acids, which represent $60 \%$ of the mycobacterial cell wall forming the characteristic waxy coat of mycobacteria also referred to as the mycomembrane or mycobacterial outer membrane $[25,26]$. The mycomembrane furthermore contains various free lipids, such as glycolipids, phthiocerol dimycocerosates, cord factor or dimycolyltrehalose, sulpholipids and phosphatidylinositol mannosides. Many of these are considered virulence factors and have immunomodulatory properties, similar to lipoarabinomannan (LAM) which is present throughout the cell wall but probably covered by the capsule [27]. Finally, on the surface of the cell wall lies the capsule (see Figure 2). The mycobacterial cell wall constitutes an important barrier against the surroundings, protecting Mtb from dehydration, osmosis and drugs, much contributing to the inherent tolerance to antibiotics [26]. For the transport of secretory proteins across the mycomembrane specialized secretion systems are employed [28] (see below), and for the uptake of hydrophilic molecules such as nutrients, porins are inserted into the cell wall and membrane [26].

\section{The mycobacterial capsule}

The presence of a mycobacterial capsule was already suggested in 1959, and during the following decades it was observed in several electron microscopy studies as an electrontransparent zone around phagocytosed mycobacteria of all species, with varying thickness $[29,30]$. 
Although presumably constituting the primary 'contact zone' between Mtb and host cells, the capsule never got much attention, and is often omitted in reviews about the mycobacterial cell walls, also recently [31]. Mamadou Daffé and his group pioneered the field, developing methods for capsule extraction and analysis. Basically, this is done by mechanical treatment of unagitated cultures, with or without the addition of Tween- 80 as a detergent [32]. Biochemical analysis of the capsule of Mtb revealed that it is mainly composed of polysaccharides, with $\alpha$-glucan being the most abundant, but also arabinomannan and mannan. Small amounts of proteins and lipids have been found as well, with the latter ones mainly residing at the inner part of the capsule, probably interacting with the mycolic acids [33, 34] (Figure 2). The proteins present in the Mtb capsule comprise many enzymes, secreted proteins and peptides typically found in the culture supernatant,

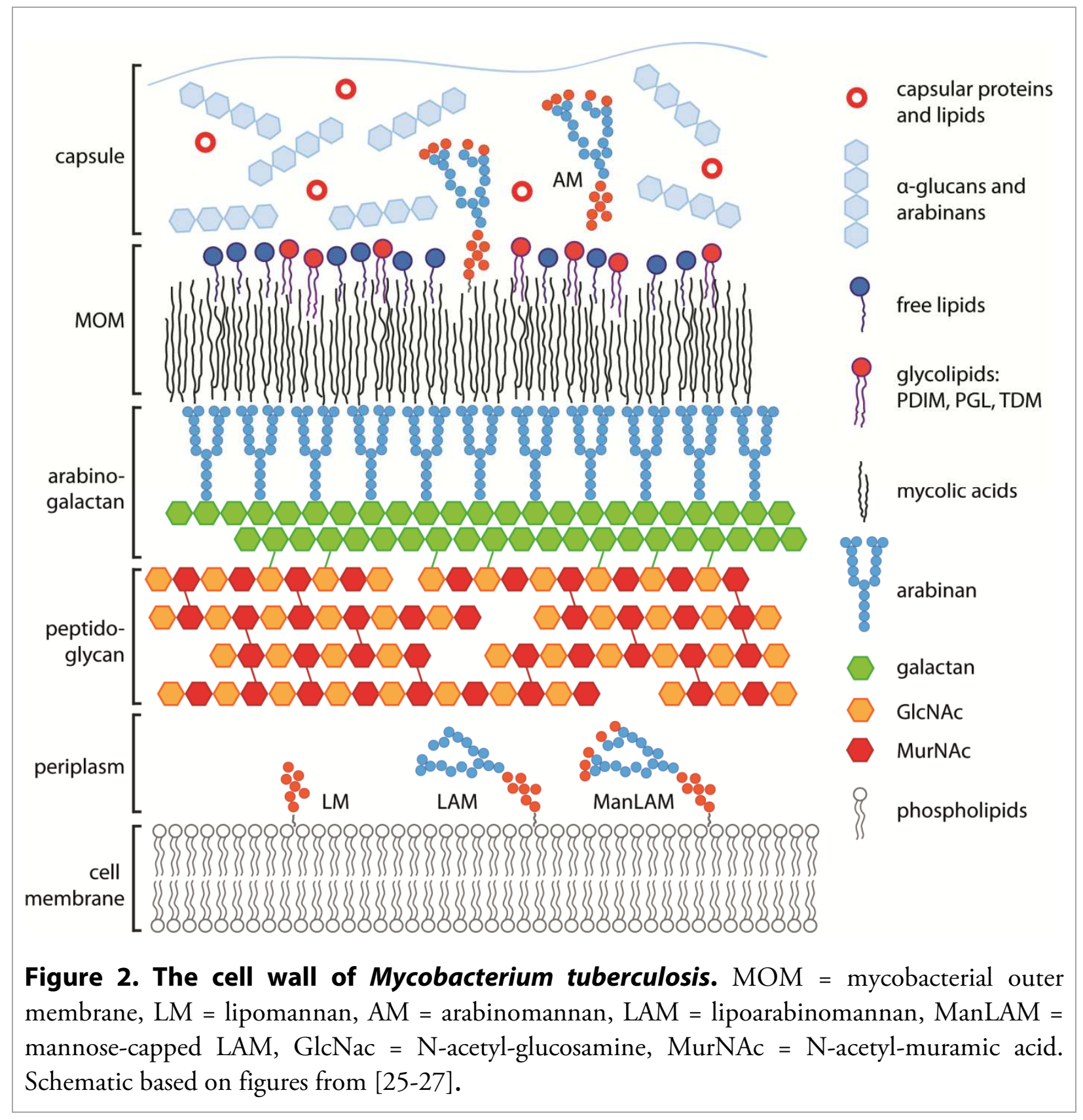


suggesting that they are shed from the surface of the bacteria into the medium [35]. Whether or not non-pathogenic mycobacteria have a thinner or no capsule at all has been debated [36-38], but the molecular composition seems to differ between pathogenic and nonpathogenic mycobacteria [39], suggesting that capsular components might play a role in virulence. Indeed, the capsule of $M$. marinum contains virulence factors secreted through the $6 \mathrm{kDa}$ early secreted antigenic target (ESAT6) secretion system 1 (ESX-1) [38]. To my knowledge, the presence of a capsule on Mtb has not been shown ex vivo, as for example on bacteria in sputum. There is evidence for its presence in vivo, such as after infection of mice with M. lepraemurium $[40,41]$ or with Mtb H37Rv [34].

\section{Transport across membranes, ESX-1 secretion and ESAT6}

Due to the extraordinary length of mycolic acids in the cell wall and their covalent attachment to the arabinogalactan-peptidoglycan layer, the mycomembrane exhibits low fluidity and therefore constitutes a highly efficient permeability barrier. This is believed to be one of the major determinants for the intrinsic antibiotic tolerance of $\mathrm{Mtb}$, and mycobacteria have evolved mechanisms to transport substances across their cell wall.

Porins are present in the outer membrane for the uptake of hydrophilic nutrients [42], and for the active secretion of proteins, and Mtb uses the Sec secretion system and the twinarginine transporter (TAT) similar to other bacteria [43]. Besides that, Mtb employs type VII secretion systems termed ESX-1 through ESX-5. These are the only secretory machines in $\mathrm{Mtb}$ that promote translocation across both membranes. ESX-5 secreting PE/PPE proteins and ESX-3 mediating the uptake of iron and zinc are essential for Mtb survival in the host, whereas less is known about ESX-2 and ESX-4 [44]. The most prominent type VII secretion system in Mtb is ESX-1 and conserved in pathogenic mycobacterial species such $M$. leprea and $M$. marinum [45], but was identified due to the absence of its coding region RD1 (region of difference 1) from $M$. bovis Bacille Calmette Guérin (BCG) [46-48]. RD1 codes for most of the proteins constituting the ESX-1 transmembrane complex and for some but not all known ESX-1 substrates. ESX-1 consists of transmembrane proteins, ATPases and essential accessory proteins [49]. The most prominent ESX-1 substrates ESAT6 and $10 \mathrm{kDa}$ culture filtrate antigen CFP-10 (CFP10), encoded by es $x A$ and esxB adjacently located on RD1, lack Sec and TAT secretion signals and both belong to the WXG-100 protein family. These proteins usually encompass around 100 amino acids and feature a central WXG (tryptophan-variable-glycine) sequence motif causing a turn in the alpha-helical structure. WXG100-proteins and ESX-secretion systems have also been identified in Staphylococcus aureus, Bacillus anthracis and other bacteria $[50,51]$. 
Mycobacterial ESAT6 and CFP10 are co-secreted through ESX1 as a 1:1 heterodimer [55, 56], which is stabilized by hydrophobic interactions between the $\alpha$-helices in the helix-turn-helix hairpinshaped structure $[55,57]$ (see Figure 3). Secretion of the heterodimer depends on a signal motif identified at the Cterminus of CFP10 [53], which later was found to be characteristic for type VIIsecreted substrates [58] and interacts with other proteins belonging to ESX-1 [28]. As for ESAT6, deletion of twelve amino acids from the $\mathrm{C}$-terminus caused attenuation of Mtb but did not abolish secretion [57]. The heterodimer was shown to dissociate under acidic conditions, hypothetically inside acidic compartments of the macrophage [59]. On the contrary, studies using recombinant ESAT6 and CFP10 expressed in Escherichia coli failed to

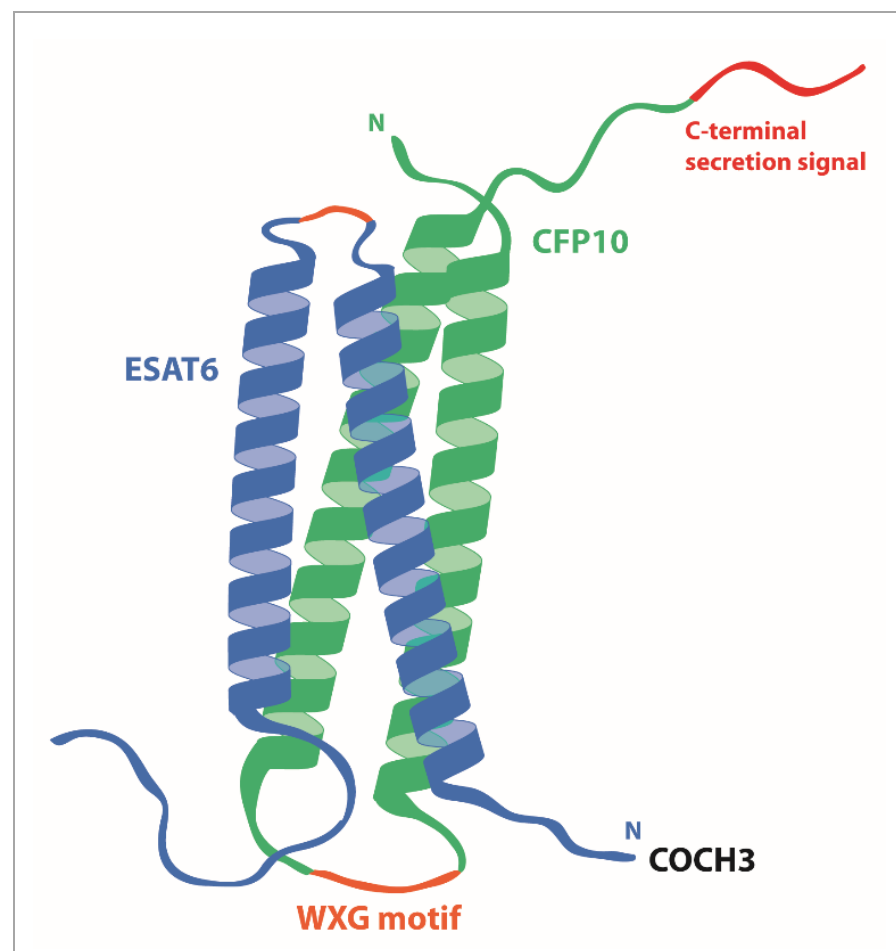

Figure 3. Schematic of the ESAT6-CFP10 heterodimer secreted through ESX-1. Both proteins feature a tryptophan-variable-glycine (WXG) motif. ESAT6 is N-terminally acetylated [52] and CFP10 carries a C-terminal secretion sequence essential for export [53]. ' $\mathrm{N}$ ' indicates the $\mathrm{N}$-termini of the proteins. Schematic drawing is based on the structures in $[28,54]$.

detect complex dissociation at acidic $\mathrm{pH}[60,61]$. This discrepancy between native and recombinant proteins could be explained by mycobacterium-specific post-translational modifications on ESAT6 [52]. Both recombinant and native ESAT6 lyse artificial membranes [59, 61-64] due to a hypothetical conformational change of ESAT6 that also facilitated membrane interaction [61]. The helix-turn-helix structure of ESAT6 was shown to insert into membranes upon acidification and to form a membrane-spanning structure, which could lead to membrane lysis [65]. As mentioned before, the RD1 region is missing in M. bovis BCG, explaining the attenuation of the strain $[46,47]$ and in the avirulent Mtb strain H37Ra, ESAT6 secretion is defective due to a point mutation in the PhoP gene [66]. Together, this highlights the importance of ESAT6 for Mtb virulence.

\section{TB antibiotics and antibiotic resistance}

Nowadays, TB is treated with a combination of up to four first-line drugs, which generally have the best activity against drug-tolerant Mtb strains. Other drugs are referred to as 
'second-line drugs'. All first-line drugs were developed about 50 years ago, and mostly target mycobacterial cell wall synthesis. Isoniazid (INH) is a pro-drug that requires conversion into its active form by the mycobacterial catalase-peroxidase kat $G$ to generate a range of reactive oxygen intermediates of INH. These attack multiple targets in Mtb involved in DNA, lipid, carbohydrate and NAD metabolism, but mainly in cell wall mycolic acid synthesis, such as the enoyl ACP reductase $(i n h A)$. Not surprisingly, mutations in $k a t G$ are the major mechanism for INH resistance [67]. As for the other first-line drugs, ethambutol (EMB) inhibits the synthesis of arabinogalactan, another cell wall component, rifampicin (RIF) inhibits RNA synthesis and pyrazinamide (PZA) disrupts membrane transport [68]. Secondline drugs comprise the injectable aminoglycosides (i.e. amikacin, streptomycin and kanamycin), fluoroquinolones (i.e. levofloxacin, moxifloxacin and ciprofloxacin) and other, less effective substances (i.e. ethionamide and cycloserin). These often have less specific antimycobacterial activity and toxic side effects [69]. After decades without any new TB drug approvals, bedaquiline and delamanid were approved for use in drug-resistant $\mathrm{TB}$, and several other substances are in clinical trials [70].

Mycobacteria exhibit intrinsic tolerance to many drugs, and genetic antibiotic resistance has increased considerably during the last decades. Antimicrobial resistance is common in bacteria capable of horizontal gene transfer, a feature that has been shown in M. canetti but probably was lost during evolution of Mtb [71]. With its limited genetic diversity and low mutation rate $\mathrm{Mtb}$ constitutes an exception among all bacteria, because resistance mutations are known for all first and second-line TB drugs [72]. One of the reasons leading to drug resistance, besides patient noncompliance, is the fact that Mtb resides in lesions with atypical conditions such as hypoxia or in lipid-rich caseum. Several TB drugs were shown to penetrate insufficiently into these lesions, leading to diminished drug concentrations in the tissue and unintentional spatial monotherapy, which could enhance emergence of drug resistance mutations [73, 74]. Similarly, mycobacterial efflux pumps could lead to submicrobicidal drug concentrations, thereby promoting resistance [75]. In line with that, TB drug discovery is impeded by the lack of appropriate models for human TB, such as for example in vitro correlates of $\mathrm{Mtb}$ persister populations. This was exemplified by moxifloxacin, a fluoroquinolone drug with faster sterilizing activity than standard treatment in the mouse model [76], which did not hold true in human clinical studies [77].

Recently, a new mechanism for antimicrobial drug resistance was revealed, namely inactivation of the compound through methylation. This methylation was exerted by a bacterial methyltransferase which was upregulated due to mutations in a transcriptional regulator protein [78]. The reasons and mechanisms for phenotypic drug tolerance (as opposed to genetically encoded drug resistance) are discussed later. 


\section{Mtb and the human immune system}

\section{Transmission and clinical outcomes}

Mtb is usually spread from one diseased individual to another via airborne transmission. Contagious droplets are typically expelled by coughing, and upon inhalation, Mtb infects the lung. Most bacteria are trapped in the upper parts of the lower airways, where mucus lining the epithelium as well as the mucociliary escalator constitute a first physical barrier against infection [79]. Mtb in droplets small enough to bypass this trap and able to enter alveoli are primarily being taken up by tissue-resident alveolar macrophages. This results in a cascade of events with different possible outcomes: active TB disease (also called primary TB), latent TB infection (with potential for a later reactivation), or eradication of the infection.

One third of the world's population is estimated to have latent TB infection (LTBI), which is defined as Mtb-specific immune memory in the absence of clinical symptoms. Around 5$15 \%$ of all individuals with LTBI progress to active TB disease during their lifetime, and most often, progression occurs within five years after initial infection [80]. The risk of progression largely increases in immunocompromised individuals, such as HIV-positives (who are 20-30 times more likely to develop TB [81]), or with other risk factors such as malnutrition, diabetes, smoking, and old age [70].

Post-primary TB can either occur due to an initial LTBI that reactivates, or upon failure to control a new infection. The immune mechanisms contributing to controlled Mtb infection in the latent state are many, and so are the bacterial mechanisms leading to resistance to killing and the maintenance of a silent infection. On the one hand, the high risk of TB disease in immunocompromised individuals suggests that adaptive immune responses play a key role for the control of infection, but in contrast to what is expected, immune responses mounted during primary $\mathrm{TB}$ do not protect from re-infection. Even worse, previous TB disease rather increases the risk of developing active TB again upon re-infection [82]. On the other hand, there is also evidence that innate immune responses can suffice to control bacterial expansion or to even eradicate the infection. Mtb DNA could be detected in lungs from individuals who had died from causes other than TB and lung tissues did not exhibit any signs of pathology [83], indicating bacterial persistence controlled by innate immunity. Also the phenomenon of eradication after transmission has baffled scientists. Although difficult to study, evidence for early clearance can be obtained from household contact studies, where the TB status of individuals frequently exposed to contagious aerosols from a coughing family member was investigated. Almost 50\% of exposed individuals test negative for Mtb-specific immune responses, although transmission clearly must have occurred [84, 
85]. Also clearance of LTBI can occur, reflected by reversion of positive tuberculin skin test (TST) or IFN $\gamma$ release assay (IGRA)-results [86].

The dynamics and different clinical outcomes of $\mathrm{Mtb}$ infections are depicted in Figure 4.

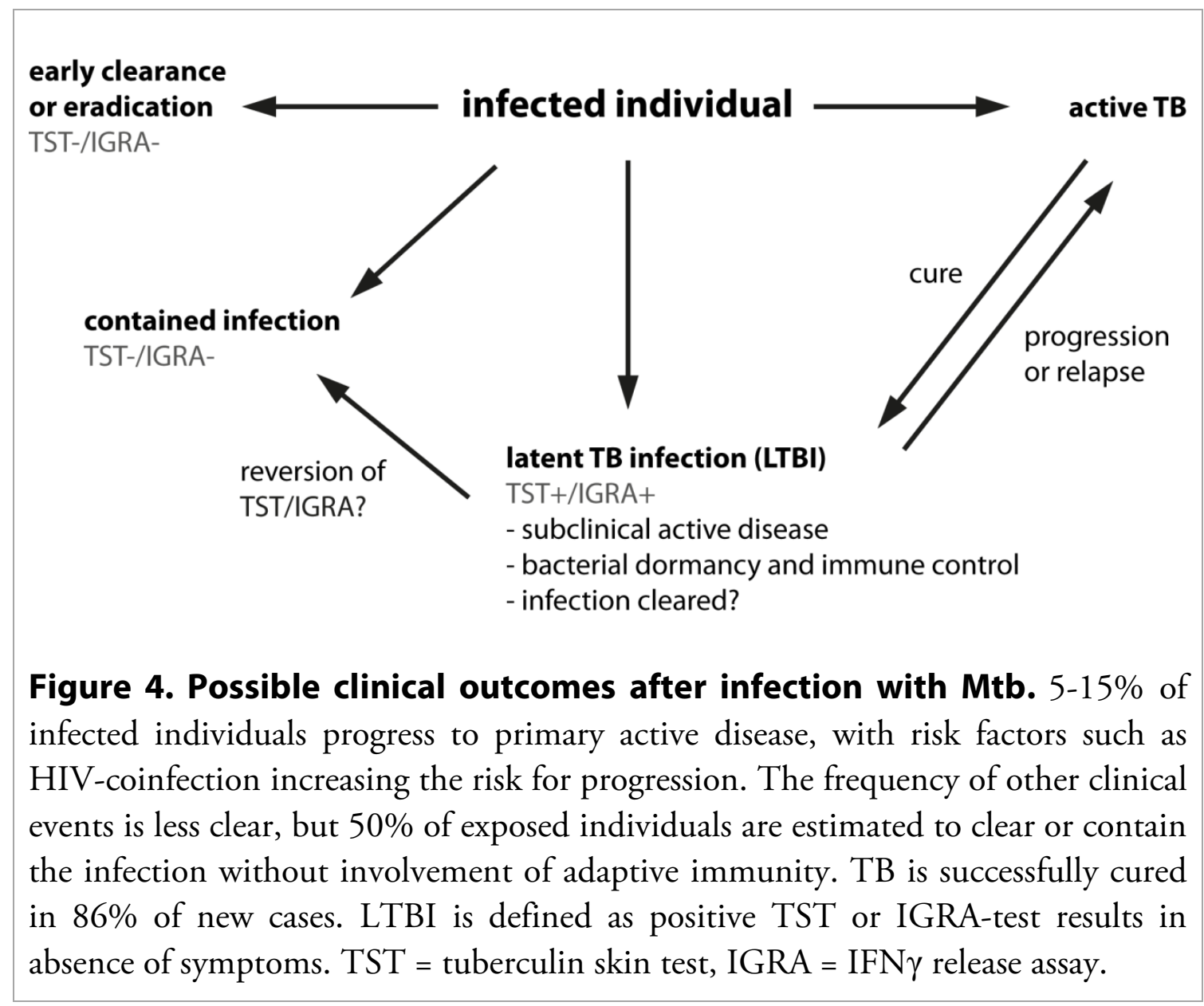

Active TB disease most often presents as a pulmonary disease, although dissemination typically occurring via the lymphatic system to other organs is common in HIV-positives and children aged $0-5$ years $[87,88]$. Extrapulmonary TB presents for example as TB meningitis or miliary TB. The clinical signs and symptoms of pulmonary TB are a chronic cough, sputum production (with or without blood), loss of appetite and weight, night sweats and fever [89]. 


\section{Granuloma formation}

Granulomas constitute the pathological hallmark of $\mathrm{TB}$ and consist of many different cell types. The emergence of 'innate granulomas' as precursors of classical granulomas has been proposed [90]. These consist of innate immune cells such as macrophages and neutrophils recruited to the initial niches of infection and might suffice to contain and eradicate Mtb without the requirement of adaptive immune responses.

Formation of classical granuloma occurs when infection cannot be eradicated as infected alveolar macrophages serve as a place for Mtb replication. Infected DCs migrate to local lymph nodes to present Mtb antigens to $\mathrm{T}$ cells, and recruitment of monocytes and neutrophils from the blood stream due to inflammatory responses leads to the accumulation of phagocytic cells at the site of infection, followed by primed $\mathrm{T}$ cells and $\mathrm{B}$ cells. This cellular granuloma is surrounded by fibroblasts, which create a peripheral fibrotic capsule [91]. Macrophages differentiate into epithelioid cells, fuse to form multi-nucleated giant cells and accumulate lipid bodies, characteristic for foam cells (see Figure 5).

The initiation of Mtb-specific adaptive immune responses is actively delayed by Mtb and takes about 3-8 weeks to occur in humans $[92,93]$. Antigen-specific CD4+ T cells stimulate infected macrophages at the site of infection by the release of IFN $\gamma$, which induces bactericidal mechanisms such as for example autophagy [94] and antimicrobial peptides [95]. Activated CD8 + T cell exert cytotoxic effects on infected macrophages via different pathways, which all ultimately lead to target cell apoptosis. Firstly, exocytosis of cytotoxic granules containing perforin, granulysin and granzymes leads to apoptosis via lysis of the target cell, and granulysin has been shown to directly kill Mtb [96]. Secondly, apoptosis can be directly induced via the cell surface proteins FAS or FAS ligand, and thirdly via tumor necrosis factor (TNF) and the TNF receptor on macrophages [97, 98]. Apoptotic cells can be engulfed by uninfected macrophages leading to rapid delivery of Mtb to lysosomes in a process called 'efferocytosis', which facilitates killing of Mtb [99]. Lymphoid follicle-like structures were found in the periphery of granulomas and consist of mainly B cells in different states of differentiation and antigen-presenting cells containing Mtb, but also $\mathrm{T}$ cells [100]. They are believed to orchestrate local adaptive immune responses.

A lot of our current knowledge about granulomas comes from early pathological observations and recently from the non-human primate (NHP) model. Granulomas can be broadly defined as solid (non-necrotic), caseous (necrotic) or end-stage cavitary. As necrotic granulomas expand, they can merge with parts of the bronchial tree gaining access to the airways, which ultimately leads to emptying of caseum and transmission of Mtb by 

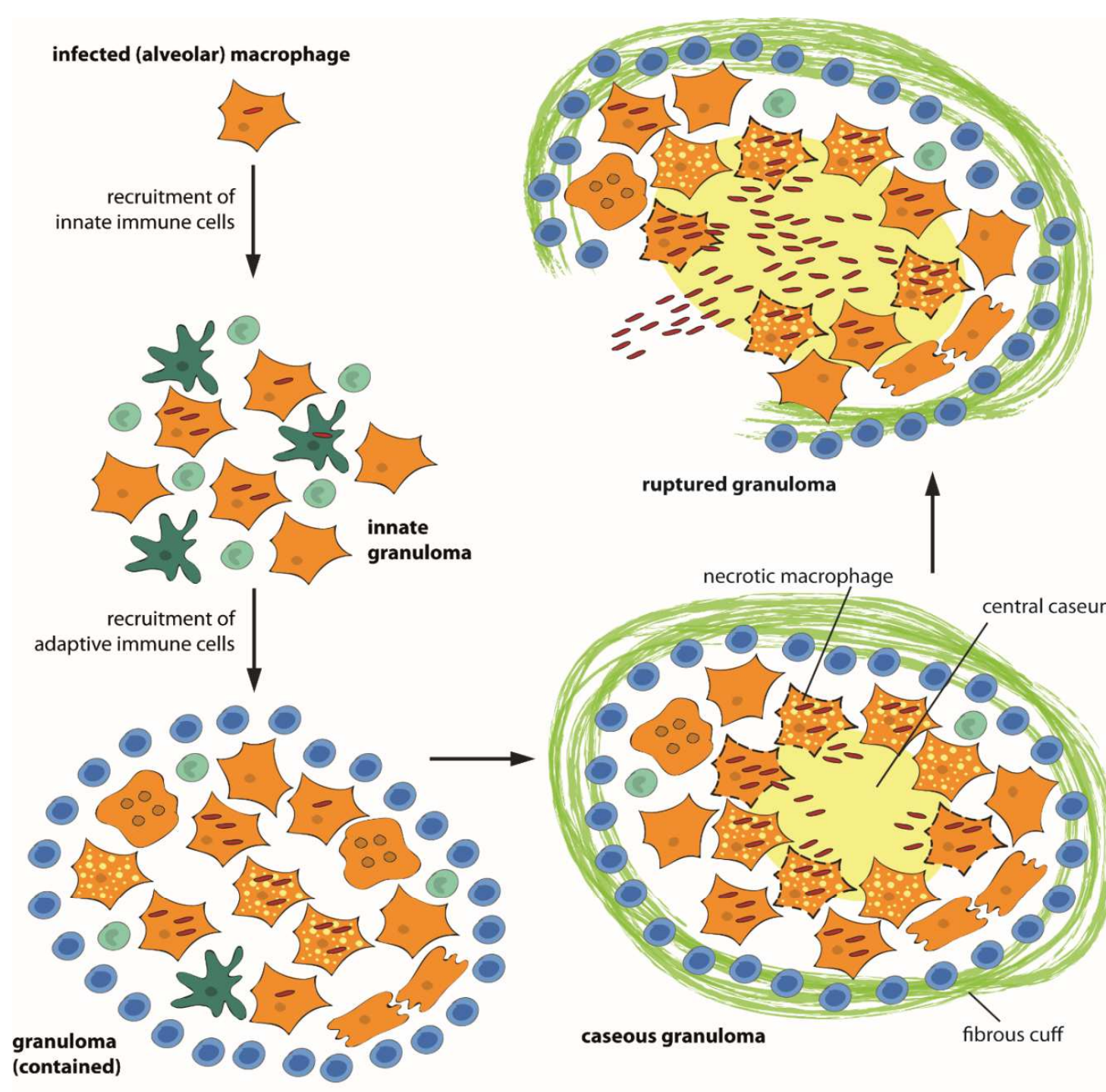

central caseum

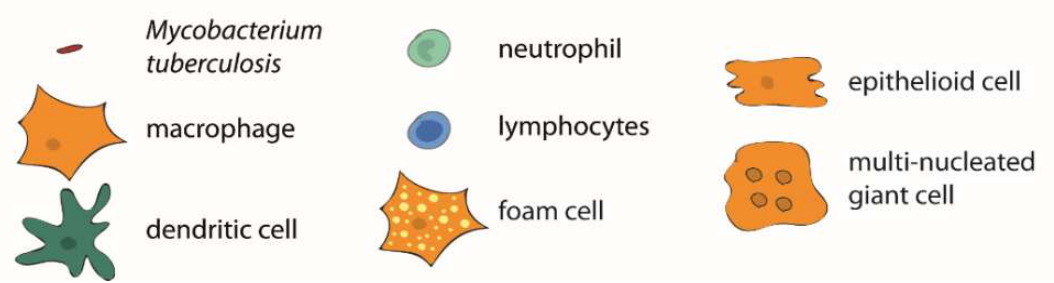

Figure 5. Granuloma formation. Upon inhalation of contagious droplets, alveolar macrophages are the first cell to encounter and phagocytose Mtb. Inflammatory cytokines and chemokines secreted by infected macrophages mediate the recruitment of monocytes and other innate immune cells from the blood, forming the 'innate granuloma'. Upon antigen-presention and priming of adaptive immunity, lymphocytes ( $\mathrm{T}$ cells, B cells, NK cells) are recruited, forming a cellular granuloma. Mtb can hypothetically be killed in the initially infected macrophage, the innate as well as the cellular granuloma. Granulomas are typically contained within a fibrotic rim (collagen). Proceeding inflammation and bacterial factors induce the differentiation of macrophages into epithelioid and foam cells, and multi-nucleated giant cells. Lysis of foamy macrophages and coinciding release of host lipids into the necrotic center lead to the accumulation of central caseum in the caseous granuloma. Rupture of the granuloma leads to spillage of bacteria into airways, ultimately permitting transmission. 
coughing. This is often accompanied by erosion of arteries, resulting in blood-stained sputum. Advancement into the caseous state was believed to correlate with disease progression into active TB. This is controversial, as it has been suggested that the development of caseum could coincide with bacterial killing [101] and non-human primates with latent TB were found to present caseous granulomas [102]. Granuloma formation is now believed to be a highly dynamic process with granuloma lesions in different states presenting in the same host [103]. Granuloma caseation occurs already at early stages of infection [104] and the lipid-rich material originates from dead foamy macrophages. Mtb mediates dysregulation of lipid metabolism in macrophages leading to accumulation of intracellular lipid bodies, and Mtb is able to switch its metabolism and use host lipids inside foamy macrophages as a nutrient source [105-107]. The necrotic core of granulomas was shown to feature hypoxia, constituting a site for Mtb persistence [108, 109]. If host immunity manages to control the bacterial growth, necrosis halts and while healing, the caseum may be replaced by fibrosis and calcification.

For decades, IFN $\gamma$-mediated immunity was believed to be the major driver for protective immunity and constituted the main objective of vaccine research, as well as granulomas were believed to be host-protective by encapsulating the infection and restraining it to the lung. All of this has been questioned, as $\mathrm{Mtb}$ seems to benefit from a strong pro-inflammatory $\mathrm{T}$ cell response and exploits granuloma formation for dissemination and transmission [98, 110112].

\section{Diagnosis of TB}

Diagnosis of LTBI and active TB is often difficult due to the heterogeneity of TB disease in terms of immune response, progression and clinical manifestation,

Diagnosis of LTBI is indicated in individuals at high risk of reactivation, such as children, close contacts of index cases, HIV-positives or patients receiving immunosuppressive therapy. LTBI can be diagnosed by the tuberculin skin test (TST) or the more specific (but also more expensive) IFN $\gamma$ release assay (IGRA). Both detect Mtb-specific adaptive immune responses, and in the case of the widely-used TST, purified protein derivative (PPD) is injected into the skin. In individuals with Mtb-specific immunity a delayed-type hypersensitivity reaction occurs within 48-72 hours after injection as an induration of the skin [113]. Since PPD is a crude protein mixture prepared from Mtb culture filtrate, falsepositive TST results can be obtained in BCG-vaccinated individuals. This is not the case for the more specific IGRA, which measures IFN $\gamma$ release after incubation of peripheral blood with antigens specific for Mtb, such as ESAT6 and CFP10. Diagnosis of LTBI can be 
hampered by immune-compromising conditions, such as HIV [80]. After a positive TST or IGRA, active TB disease needs to be excluded to confirm LTBI. For the diagnosis of active TB disease, sputum microscopy, chest radiography and culture with - if available subsequent drug susceptibility testing are recommended in addition to the common clinical manifestations of TB. Direct microscopy of acid-fast bacilli in sputum smears is the fastest, simplest and cheapest method to demonstrate $\mathrm{Mtb}$, but often unreliable and suboptimal in sensitivity. It depends on the ability of the patient to produce sputum, which can be difficult, especially in children. Also, a certain amount of bacilli in the sample is required to preclude false negative results, impeding the TB diagnosis of HIV-positives due to lower counts of bacteria in their sputum. Furthermore, acid-fast staining does not distinguish between Mtb and other mycobacteria. Culture in liquid medium is more reliable but often not available in remote areas and low-income countries and only performed additionally to direct microscopy since the slow growth of the bacilli causes a delay in the diagnosis. Other confirmatory tests include nucleic acid amplification tests, sometimes with simultaneous detection of drug resistance mutations in the Mtb DNA. An example is the Xpert MTB/RIF assay, which allows for DNA extraction from sputum, amplification and detection in a single cartridge [114]. A cheaper test for drug resistance is the microscopic-observation drug susceptibility (MODS) assay, which simultaneously detects Mtb growth in liquid medium and tests for isoniazid (INH) and rifampin (RIF) resistance [115]. For the diagnosis of TB in often sputum-scarce, smear-negative HIV-patients, the recently introduced lateral flow lipoarabinomannan assay, detecting mycobacterial LAM in urine, facilitates diagnosis and offers higher sensitivity than sputum smear microscopy [116].

Significant progress has been made during the last decades, but new diagnostic tools are urgently needed in order to quickly identify $\mathrm{TB}$ cases on site in primary health clinics, to determine the drug susceptibility of the strain and to prevent transmission. Efforts for the development of new diagnostic tools are also focused on the development of sputumindependent tests, since ca. $15 \%$ of TB cases manifest as extrapulmonary $\mathrm{TB}$, a number that is much higher in HIV-positives [70].

\section{Treatment of TB}

Treatment of drug-sensitive TB is lengthy, and even more so in cases of drug-resistance. Most anti-TB drugs were developed decades ago, and 3.3\% of new and $20 \%$ of relapse cases are due to drug-resistant strains [16].

Drug-sensitive TB is usually treated with a combination of four drugs: isoniazid (INH), rifampicin (RIF), pyrazinamide (PZA) and ethambutol (EMB) for 2 months as an intensive 
phase', followed by 4 months of 'continuation phase' with only INH and RIF. This 'short course' regimen is highly effective when completed, but due to its length and side effects prone to patient noncompliance, which can lead to treatment failure and the emergence of drug resistance [70]. To avoid that, directly observed therapy (DOT) was implemented as part of the global TB strategy launched in the 1990's. During DOT, patients take medication observed by a health care professional in order to improve adherence, and the global treatment success rate is now at least $86 \%$ [16]. Therapy success of pulmonary TB is usually monitored by sputum smear sampling every few weeks and at the end of treatment. However, treatment may be extended if sputum conversion has not occurred after eight weeks of treatment or if other risk factors for relapse are present [89]. Treatment of MDRTB is more complicated with the use of a combination of usually five first- and second-line drugs (chosen according to the drug resistance pattern of the infecting strain) for 20 to 30 months. Infrastructure for Mtb culture and reliable drug susceptibility testing are not always available in TB-endemic regions, and empirical application of treatment regimens, intermittent adherence due to heavy side effects of second-line drugs or unavailability of certain drugs could in the past have fueled the emergence of MDR and XDR-TB $[17,117]$. Furthermore, treatment is more complicated in HIV-positive patients receiving highly active antiretroviral treatment (HAART), which can lead to immune reconstitution inflammatory syndrome (IRIS) with worsening TB symptoms due to exuberant pro-inflammatory responses after commencement of HAART [118].

For the shortening of the 'short course' therapy and for successful treatment of MDR and XDR-TB, new drugs are urgently needed. Current research not only focuses on new antimicrobials and treatment regimens, but also on host-directed therapies and new antimicrobial approaches, such as for example virulence blockers [44]. Aiming at reducing inflammation and tissue damage in the lung, inhibitors of matrix metalloproteinases have been suggested as host-directed therapy in combination with antimicrobials [119], and a recent study presented blockers of ESX-1 secretion, abolishing ESAT6-induced cytotoxicity [120].

\section{TB vaccination}

In order to achieve the WHO goal of eradicating TB by 2050, an effective vaccine is needed. The only available TB vaccine is the attenuated M. bovis Bacille Calmette Guérin (BCG), which is in use since almost 100 years and is the most widely used vaccine ever with 4 billion recipients so far [121]. The protective efficacy against pulmonary TB in adults is however low, and protection is characterized by variability between populations [122]. BCG is still 
administered to newborns in TB-endemic regions where it provides significant protection against severe forms of TB in children, such as TB meningitis and miliary TB [123].

During the last decades, $\mathrm{T}$ cell-mediated immunity has been believed to confer protection from active TB, supported by the increased risk of active TB in HIV-positives with lowered CD4 $\mathrm{T}$ cell counts as well as by extreme susceptibility of humans and mice deficient in IFN $\gamma$ signaling [124-126]. The dogma of purely $\mathrm{T}$ cell-mediated protection has been questioned, as successful $\mathrm{T}$ cell priming (in terms of IFN $\gamma$ production and multifunctionality of $\mathrm{T}$ cells) could not be correlated with protection $[98,127]$. As an example, the MVA85A vaccine has been developed as a booster upon BCG vaccination, aiming at enhancing adaptive responses by presenting the $\mathrm{Mtb}$ antigen $85 \mathrm{~A}$. Despite promising results from animal challenge models and although MVA85A elicited more IFN $\gamma$-producing and polyfunctional $\mathrm{T}$ cells in humans, boosting upon BCG vaccination failed to protect better than BCG alone in a clinical trial [128-130]. So despite longstanding research, it is not clear which other factors confer natural or vaccine-induced protection. Knowledge of these factors, and of surrogate endpoint markers of protection, could considerably speed up vaccine discovery due to shorter trials.

Countless efforts have been made to enhance the limited protection conferred by BCG, mainly by introducing Mtb antigens, such as for example avirulent variants of ESAT6 [131, 132], or by enhancing antigen presentation by the addition of listeriolysin to BCG [133]. Besides attenuated or heat-inactivated whole cell vaccines, vaccine development extends also to subunit vaccines and viral vectors evolving around immunodominant $M t b$ antigens, with around a dozen formulations currently being investigated in clinical trials [134]. These antigen-based approaches are however being questioned by the finding that $\mathrm{TB}$ antigens are hyperconserved, implying that Mtb could actually benefit from $\mathrm{T}$ cell-mediated immunity [110].

Taken together, TB vaccine discovery has proven difficult due to insufficient knowledge of correlates of protections, and current efforts aim at understanding the heterologous effects of BCG [135]. 


\section{Interplay of macrophages and Mycobacterium tuberculosis}

\section{Innate immunity}

Macrophages, neutrophils, dendritic cells (DC) and mast cells constitute the innate immune defense against invading pathogens in tissue. In order to quickly eradicate pathogenic bacteria and viruses, these cells are equipped with a range of different systems, aiming at recognition, uptake and killing. Most often, this happens completely unnoticed, before the establishment of infection and inflammation.

Macrophages constitute the primary host cell for Mtb, since alveolar macrophages in the lung are the first to encounter inhaled bacilli, and macrophages are a place for Mtb survival, replication and persistence. Macrophages possess different receptors for the recognition of $\mathrm{Mtb}$, and induce different defense mechanisms. Mtb has been shown to interfere with all of these processes, probably owing to co-evolution of humans and Mtb for thousands of years. Appropriate macrophage activation has been suggested to suffice for eradication of Mtb, but in case macrophages (and other innate immune cells) fail to contain the Mtb infection, additional systems of the human immune system can be called into action, which gradually leads to Mtb eradication on one hand or latent or active TB disease on the other.

In the following chapter, the macrophage defense mechanisms will be described, as well as how Mtb as an active manipulator of the immune system circumvents and hijacks these, all to secure its survival and multiplication.

\section{Polarization - heterogeneity of macrophages}

Macrophages are present in all tissues, either as tissue-resident macrophages or differentiated from monocytes which circulate in peripheral blood and migrate into tissue in response to inflammation. Macrophages react to environmental cues with physiological alterations and exhibit a range of phenotypes in response to priming and their localization. Classically activated macrophages (M1) are pro-inflammatory and exhibit enhanced microbicidal activity, whereas alternatively activated macrophages (M2) are anti-inflammatory and have more homeostatic, immune-regulatory and tissue protective functions. This classification originates from macrophages being stimulated by $\mathrm{T}$ cells during adaptive immune responses, with M1 macrophages arising from stimulation with Th1 cytokines (IFN $\gamma$ and TNF) and M2 macrophages from stimulation with Th2 cytokines such is IL-4 or IL-13, and functional characterization is often based on expression of inducible nitric oxide synthase (iNOS) in M1 and arginase 1 (M2). Between the M1 and M2 phenotype is a range of states that macrophages can exhibit. Macrophage polarization is reversible and the ultimate aim is to act 
in concert in order to dispose of pathogens while minimizing tissue damage upon inflammation [136].

The phenotype and origin of alveolar macrophages initially encountering Mtb is less clear. During homeostasis, tissue macrophages likely originate from the yolk sac and have the ability of self-renewal and longevity [137, 138]. Studies on human alveolar macrophages from healthy individuals revealed that they carry markers for both M1 and M2 macrophages [139]. During infection and inflammation, peripheral blood monocytes originally derived from hematopoietic stem cells migrate into the airways, where they differentiate into macrophages. In TB disease, both M1 and M2 macrophages were observed in granulomas from humans and non-human primates, where macrophages at the inner regions of the granulomas express iNOS whereas anti-inflammatory arginase-expressing macrophages preferentially reside at the outer regions, probably dampening inflammation and peripheral tissue damage [140]. Granuloma outcome was suggested to benefit from early M1polarization of macrophages in granulomas [141]. In vitro, the Mtb virulence factor ESAT6 has been shown to interfere with the M1 phenotype by inhibiting toll-like receptor 2 (TLR2) signaling and subsequent NFKB activation [142], and Mtb infection skewed macrophage polarization towards an M2-phenotype [143], which could facilitate Mtb survival and persistence.

Altogether, this highlights the plasticity and variety of macrophage populations, phenotypes and functions at the lung interface and during TB pathogenesis.

\section{Recognition and uptake of Mtb by macrophages}

Macrophages have a range of surface and intracellular receptors serving to recognize and internalize pathogens. In the case of $\mathrm{Mtb}$, pattern recognition receptors (PRRs) recognize a range of mycobacterial danger-associated molecular patterns (DAMPs), many of which not surprisingly originate from the complex mycobacterial cell wall, while other receptors bind IgG- or complement-opsonized bacteria. Ligation of different receptors leads to induction of several pathways, ultimately resulting in phagocytosis and macrophage activation.

C-type lectin receptors such as the mannose receptor (MR) and dendritic cell-specific intercellular adhesion molecule-3 grabbing non-integrin (DC-SIGN) recognize polysaccharide structures of pathogens. The MR is highly expressed on tissue-resident alveolar macrophages and serves as a scavenger receptor [144]. Upon ligation by mannosecontaining mycobacterial cell wall components such as ManLAM, a mannosylated glycolipid on virulent strains of mycobacteria [145], binding of Mtb initiates phagocytosis, but subsequent entry via the mannose receptor diminishes phagolysosomal fusion, which is beneficial for intracellular survival of the bacterium $[146,147]$. DC-SIGN is best known as 
a receptor on DCs, but is also expressed on macrophages. Like the mannose receptor, DCSIGN preferentially binds mannosylated LAM from virulent strains through selective binding to the mannose cap [148], indicating that phagocytes are trained to recognize virulent mycobacteria, or alternatively, that virulent strains are better equipped to enter host cells than avirulent mycobacteria. Besides ManLAM, DC-SIGN recognizes $\alpha$-glucan, a component of the mycobacterial capsule [149]. The complement receptor CR3 recognizes complement-opsonized or unopsonized bacteria, in the latter case through interaction with Mtb polysaccharides [150], and the consequences of CR3 ligation for Mtb are unknown [151]. Ligation of another opsonic receptor, the Fc $\gamma$ receptor with IgG usually causes a superoxide burst generated by the NADPH oxidase complex assembled in the phagocytic cup. This early microbicidal mechanism was however not observed upon binding of Mtb [152], probably due to neutralization of superoxide by mycobacterial enzymes such as superoxide dismutase and the katG catalase-peroxidase [153, 154], but nevertheless phagolysosomal fusion succeeding Fc $\gamma$ receptor ligation is enhanced.

Opsonization of Mtb not only occurs via the complement cascade or by specific antibodies produced during humoral response, but also by the soluble C-type lectins surfactant protein A (SP-A) and SP-D. These are components of the lung surfactant produced by pulmonary epithelial cells and serve as bacterial opsonins. SP-A and SP-D enhance and impede phagocytosis, respectively [155, 156], and SP-D augments phagolysosomal fusion [157]. Constituting the first barrier Mtb encounters during infection, lung surfactant was shown to alter Mtb gene expression [158] and Mtb cell wall lipids change the function of lung surfactant $[159,160]$. SP-A and SP-D deficiency did not change the outcome of infection in mice [161], but the effect of lung surfactant on interactions between Mtb and macrophages is not fully understood.

Toll-like receptors (TLRs) are a family of highly conserved transmembrane receptors recognizing both extra- and intracellular ligands and typically induce pro-inflammatory responses. TLR-1, 2, 4, 6 and 9 are involved in Mtb recognition, and TLR-2 and TLR-4 ligation leads to induction of TNF and apoptosis [162]. TLR-2 is also essential for the upregulation of the vitamin $\mathrm{D}$ receptor and antimicrobial defensins cathelicidin and $\beta$ defensin 4 with the potential of killing Mtb [163]. Furthermore, TLR-2 signaling is inhibited by the secreted Mtb virulence factor ESAT6 [142]. Other studies show indispensability of TLRs for the induction of autophagy, granuloma formation, IL-1 $\beta$ and IFN $\gamma$ production.

As a member of another class of PRRs, the cytosolic NOD-like receptors, NOD2 recognizes the $\mathrm{Mtb}$ cell wall component peptidoglycan, and contributes to the control of Mtb infection [164]. NOD2 ligation induces NFkB activation and plays a role in autophagy. 
Genetic variants of NOD2 and TLRs and their adaptor proteins were found to increase susceptibility to TB in humans [165]. NLRP3 is another NOD-like receptor and can be induced by many different stimuli, among them ESAT6 [166]. Induction leads to caspase-1 activation and cleavage of pro-IL-1 $\beta$ and subsequent IL-1 $\beta$ release, which controls Mtb growth in vivo [167]. Gene polymorphisms in NLRP3 and its adaptor protein CARD8 led to increased IL-1 $\beta$ production and thereby enhanced control of mycobacterial growth in macrophages [168].

Involving another cytosolic receptor, the cytosolic surveillance pathway recently received considerable attention in connection to Mtb infection. Cyclic GMP-AMP synthase (cGAS) senses cytosolic Mtb DNA in an ESAT6-dependent, not fully unraveled manner, and cGASinduction leads to production of type I interferons (IFN) and autophagy [169-171]. As shown in mice, IL-1 $\beta$ balances type I IFN for Mtb growth control by avoidance of excessive inflammation [167].

Taken together, the route of entry of Mtb into the macrophage can influence the outcome of the subsequent processes inside the host cell, and thereby affects the outcome of infection.

\section{Phagolysosomal maturation and autophagy}

Upon uptake of Mtb into a phagosome, the phagosomal machinery attempts to subject the organelle to a range of fusion and fission events, with the ultimate aim to recruit degrading enzymes and oxidative mediators to the lumen. This process has been extensively studied during the last decades, and was long believed to be decisive for the fate of $\mathrm{Mtb}$ and the outcome of infection.

The phagocytosis process requires actin polymerization (controlled by Rho GTPases) for the formation of the phagocytic cup [172]. As phagosomal maturation proceeds, the bacteriumcontaining phagosome fuses with vesicles from the trans-golgi network, endosomes, lysosomes and autophagosomes. During the fusion and fission events, the Mtb vacuole acquires and loses state-specific markers, and the whole process involves a range of GTPases from the Rab family providing energy for fusion events and motor proteins physically directing organelles into close vicinity. Early phagosomes fuse with endosomes, but retain an almost neutral $\mathrm{pH}$. The late phagosome acquires lysosome-associated membrane proteins (LAMP1, LAMP2 and LAMP3) and fuses with vesicles from the trans-Golgi network carrying mannose-6-phosphate receptors and lysosomal enzymes. Enzymes delivered to late endosomes include proteases (such as cathepsins B and D), peptidases and lipases. Recruitment of vATPase, a proton pump, into the phagosomal membrane and fusion with lysosomes allows for acidification, and defines a late phagosome, or phagolysosome. 
Acidification is crucial for phagolysosomal function as most hydrolases require acidic $\mathrm{pH}$, and a luminal $\mathrm{pH}$ of 4-4.5 enables high hydrolytic activity [173] (Figure 6).

Mtb is able to actively interfere with the process of phagolysosomal maturation, and the Mtb-containing phagosome is characterized by an elevated $\mathrm{pH}(\mathrm{pH}$ 6.2) due to the absence of vATPase [174] and a lack of late endosomal and lysosomal markers, such as Rab7 and LAMPs (Figure 6). The different mechanisms employed by Mtb to block phagosomal maturation involve for example the hydrolysis of membrane-bound PI3P by the secreted acid phosphatase of $M$. tuberculosis (SapM), thereby avoiding docking of proteins involved in the progression of fusion events $[175,176]$. This is reinforced by mycobacterial LAM preventing PI3P accumulation on phagosomal membranes [177]. Another phosphatase, PtpA, interacts with the vesicular protein sorting 33B (VPS33B) that is involved in membrane fusion during endocytic processes, and its dephosphorylation by PtpA arrests phagosome maturation [178]. Besides that, PtpA binds to a subunit of the vATPase, thereby disrupting the assembly of the proton pump and inhibiting acidification of the Mtb-containing organelle [179]. Furthermore, the mycobacterial eukaryote-like serine/threonine protein kinase $\mathrm{G}(\mathrm{PknG})$ is essential for the inhibition of phagolysosomal maturation [180], probably by modifying host enzymes in the cytosol, but it remains unclear how SapM and PknG gain access to the cytosol [154]. Retention of Coronin 1 (TACO) on the Mtb-containing phagosome also contributes to phagosomal maturation arrest by interference with calcium-dependentsignaling [181], and in Mycobacterium marinum, loss of ESAT6 secretion not only attenuates the bacteria, but also inhibits phagolysosomal fusion [182]. An involvement of ESAT6 or ESX-1 in Mtb-induced inhibition of phagosomal acidification was investigated but not conclusive [183], but inhibition of phagolysosomal acidification is a prerequisite for the ESX-1-mediated escape of Mtb into the cytosol [184].

Altogether, Mtb employs several molecular mechanisms working together to inhibit acidification and fusion with hydrolase-carrying lysosomes, resulting in a premature and dysfunctional Mtb-containing phagosome, ultimately facilitating Mtb survival. The arrest of phagolysosomal fusion can be overcome, for example by stimulation of macrophages with LPS and IFN $\gamma$, as demonstrated in BCG and M. avium-infected cells $[185,186]$, and vitamin D-signaling is essential for delivery of $\mathrm{Mtb}$ to mature phagolysosomes and phagoautolysosomes [95].

Autophagy is another degradative process evolving around membrane-bound vesicles serving to sequester cytoplasmic organelles and intracellular pathogens into an autophagosome with subsequent autophagolysosomal fusion. Autophagosomes have a double membrane and originate from the ER, and autophagy is carried out by the coordinated action of more than 30 autophagy-related proteins (Atgs) [173, 187]. 

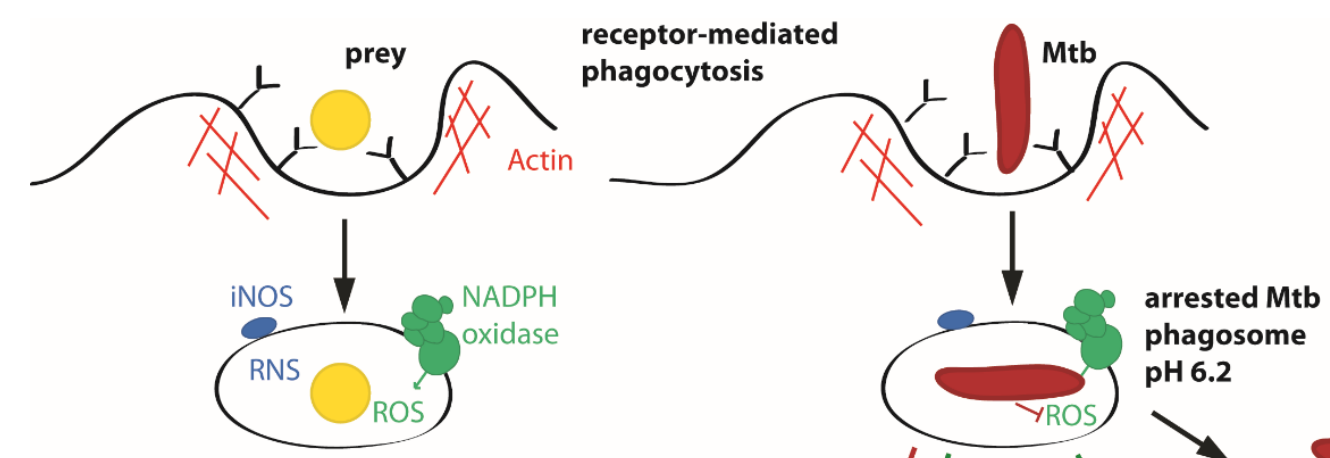

early phagosome $\mathrm{pH} 6.5$

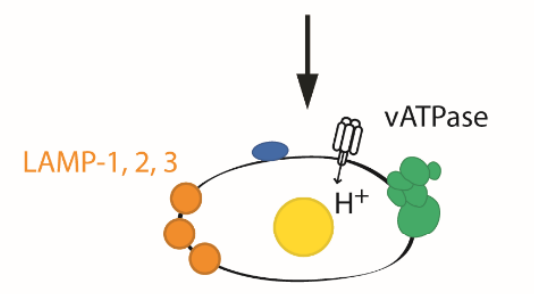

late phagosome pH 5.5

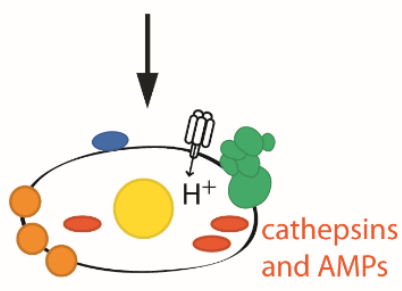

phagolysosome $\mathrm{pH} 4.5$
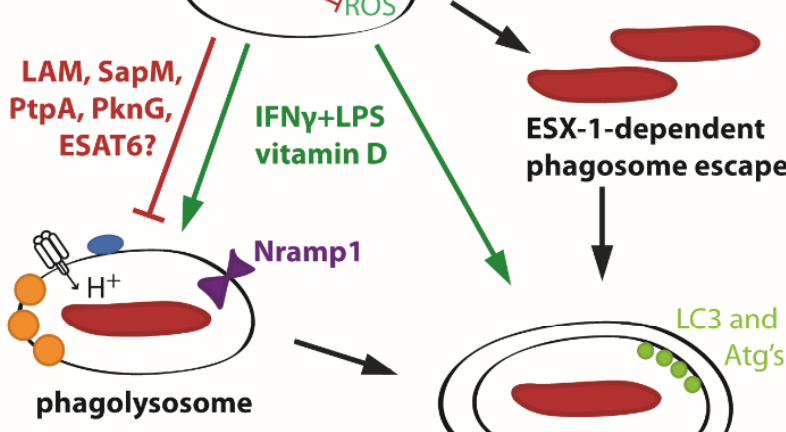

$\downarrow$ phagosome escape
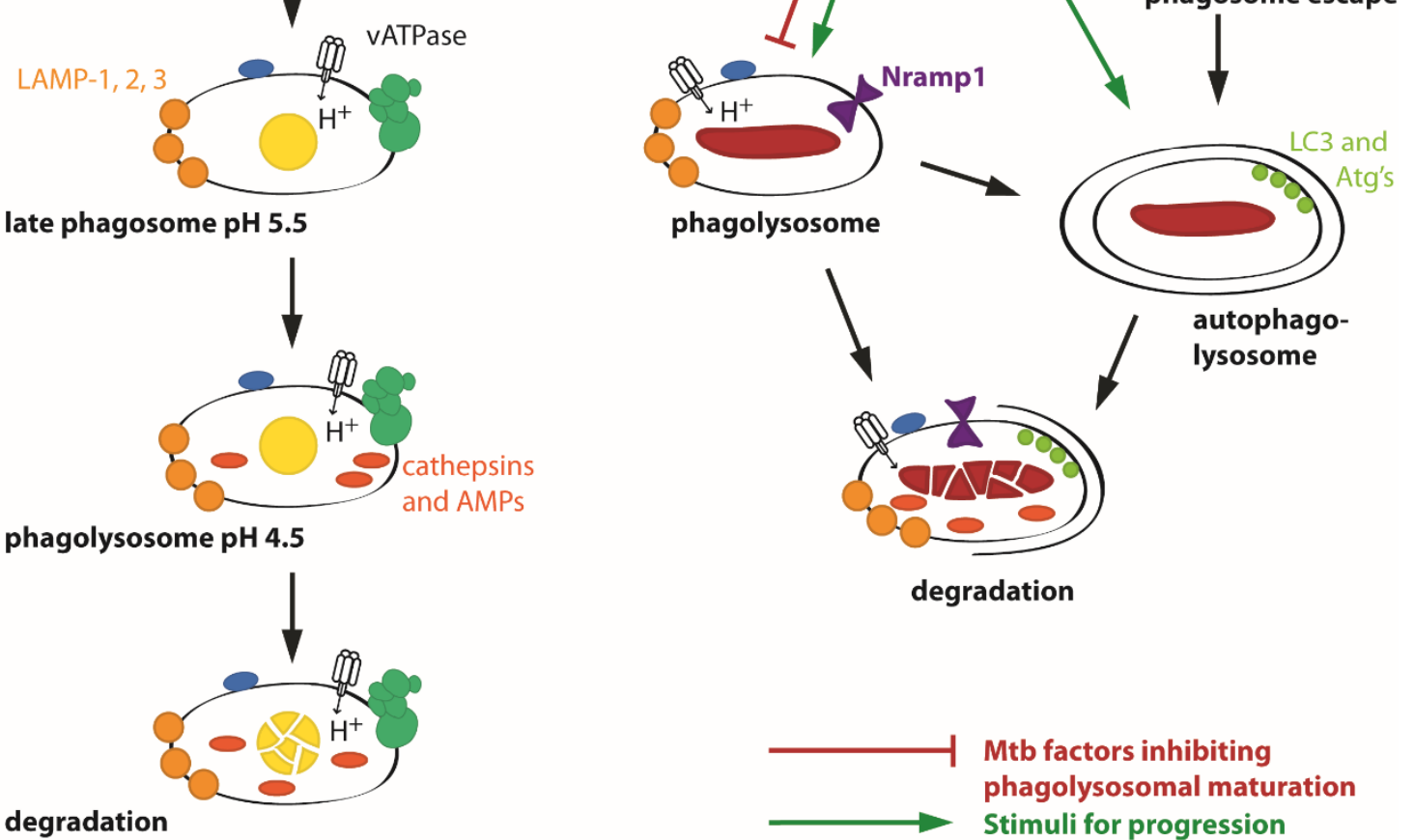

Figure 6. Phagolysosomal maturation and autophagy. Phagocytosis of a phagocytic prey usually leads to its degradation (left part of schematic). This is achieved via a cascade of fusion and fission events leading to phagolysosomal maturation, characterized by a decrease in $\mathrm{pH}$ exerted by the vATPase which activates lysosomal hydrolases as well as by the recruitment of iNOS, NADPH oxidase and antimicrobial peptides (AMP). Mtb interferes with this maturation process via several different effectors, leading to an arrested phagosome with elevated $\mathrm{pH}$ (right part of schematic). Activation of host cells can help cells to override the Mtb-induced arrest, and can also lead to the induction of autophagy. Both Mtb in a phagolysosome as well as cytosolic Mtb can be subjected to autophagy.

Activation of murine macrophages with for example IFN $\gamma$ aids to override the phagolysosomal maturation arrest and induces autophagy [94], and also the upregulation of immunity-related GTPases (IRG) upon IFN $\gamma$ treatment promotes lysosomal and autophagosomal delivery [188]. Macrophage activation with IFN $\gamma$ further induces Nramp1, a metal ion transporter scavenging metal ions from the phagosome [189]. Besides that, 
macrophage activation via TLR signaling and vitamin D induced autophagy-mediated killing of Mtb [189]. Also the role of ESAT6 in autophagy has been studied, and induction of the DNA sensing pathway requires functional ESX-1, probably for the transfer of Mtb DNA into the cytosol, and ultimately induces autophagy in murine macrophages [169], while Mtb secreting the virulence factor ESAT6 are able to inhibit autophagosome-lysosome fusion in DCs [190].

Autophagy is generally believed to be host beneficial and leads to a decrease of Mtb burden in mice $[94,191]$, but pharmacological induction of autophagy has also been shown to facilitate bacterial growth inside macrophage infected with a low burden of Mtb [192].

\section{Cell death and efferocytosis}

In order to spread to new cells and hosts, Mtb overrides macrophage defenses leading to necrotic cell death, which is characterized by excessive inflammation, bacterial replication and - on the cellular level - by rupture of the plasma membrane and destabilization of lysosomes and mitochondria [193]. Attempting to avoid spread of bacilli, neutrophils and macrophages induce apoptotic cell death. As opposed to necrosis, apoptosis is a 'silent' and tightly regulated form of cell death, where cytoplasmic contents are contained within membrane-bound structures. Phosphatidyl serine on these apoptotic bodies leads to recognition and removal in a process called efferocytosis, exerted by tissue macrophages recruited monocyte-derived macrophages and neutrophils [194]. Thereby, efferocytosis constitutes a second line of defense, limiting tissue damage and inflammation due to apoptotic cells undergoing secondary necrosis.

Infection of macrophages with avirulent Mtb H37Ra or M. bovis BCG leads to apoptosis and production of PGE2, an eicosanoid which protects the infected cell against necrosis and induces cell membrane repair [195-197]. Apoptosis is also linked to more efficient antigen presentation [198], a process typically impaired by virulent strains [194], and experimental induction of macrophage apoptosis severely attenuated the viability of intracellular bacteria [199]. This could not be attributed to intrinsic microbicidal activity of apoptotic macrophages, but to efferocytosis by bystander macrophages, resulting in successful lysosomal delivery and degradation of the apoptotic Mtb-containing macrophage [99]. Similarly, engulfment of Mtb-triggered apoptotic neutrophils induced a stronger inflammatory response in macrophages and Mtb growth control [200].

Virulent Mtb actively block induction of apoptosis in macrophages and induce necrosis, for example by inner mitochondrial membrane rupture [201] and by inhibiting membrane repair [197]. Furthermore, necrosis was shown to depend on ESAT6 and on intracellular bacterial numbers, indicating that Mtb seeks to disseminate only when a certain amount of 
bacilli is present $[202,203]$. Several bacterial effectors are involved in inhibition of apoptosis, such as nuoG, a subunit of the NADPH dehydrogenase that suppresses ROS-induced apoptosis. NuoG is essential for Mtb growth in vivo, and its deletion reversed apoptosis inhibition [204, 205].

Taken together, macrophage cell death during Mtb infection was described as a spectrum of cell death modalities with both necrotic and apoptotic features.

\section{ESX-1-secreted virulence factors and the human immune system}

When ESAT6 was identified in 1995 it was due to its strong T cell antigenicity and found to be absent from the vaccine strain M. bovis BCG [206]. Complementation of BCG with ESX-1 achieved a significant increase in virulence [207], whereas deletion of RD1 from Mtb yielded a strain reminiscent of BCG [208], featuring lower bacterial burden and decreased pathology in infected mice $[208,209]$. Beside its significance for immune memory and in vivo virulence, the impact of ESAT6 on innate immunity is less well established and receptors for neither ESAT6 nor CFP10 have been identified. Beyond that, the localization of the ESX-1 substrates during host cell infection is unclear, something that we aimed to address in Paper 3. Many experimental in vitro studies compare the consequences of infection with ESAT6- or ESX-1-deficient Mtb strains to wildtype Mtb, and bacilli with a deletion in the RD1-region are unable to lyse alveolar epithelial cells [210] and to spread to uninfected macrophages [209]. This is in line with the reported membrane-lysing activity of ESAT6, and already in the 1980s there was evidence for phagosomal escape of Mtb [211]. This was highly debated, and a range of studies showed the opposite, namely containment of bacilli in more or less mature phagosomes [212-214]. The discrepancies between studies might be of methodological nature and concern the choice of cells as well as EM sample preparation and microscopy techniques. Peters and his group later demonstrated the escape of Mtb from phagosomes in DCs and macrophages using cryosectioning, immunogoldlabeling and transmission electron microscopy, and translocation could be coupled to functional ESAT6 secretion in pathogenic strains $[215,216]$. Still controversial, it was argued that phagosomal membrane disintegration during Mtb infection constitutes a feature of cell death rather than a true virulence mechanism with the aim of escaping phagolysosomal effectors and accessing the nutrient-rich cytosol for replication. Anyhow, there is evidence that phagosomal rupture precedes host cell death [217], and phagosomal escape has been demonstrated in vivo in mice [184].

Besides cytosolic translocation, many other effects of ESAT6 have been demonstrated in host cells related to cell death, inflammation and modulation of immune pathways, with both 
beneficial and detrimental outcomes for the host. Many of these results were obtained by comparison of ESAT6-deficient mutants to wildtype Mtb strains and, in the light of phagosomal escape, are attributed to the cytosolic presence of Mtb and access of intracellular receptors to Mtb DAMPs, rather than constituting a direct effect of ESAT6. In our group, host cell necrosis upon a high-burden infection with Mtb was investigated and ESAT6 was found to induce host cell necrosis and IL-1 $\beta$ secretion without the involvement of caspase-1 [202], while others showed NLRP3-induction by ESAT6-proficient Mtb [218]. This could be replicated with recombinant ESAT6, suggesting a direct interaction of ESAT6 and components of the NLRP3 inflammasome [166]. Furthermore, ESAT6 is essential for the induction of apoptotic cell death in macrophages [219] and apoptosis has been reported to be both beneficial for the host and for bacterial spread [220]. The intracellular growth of Mtb was also controlled by ESAT6-dependent sensing of Mtb DNA by the cytosolic receptor cGAS, which leads to the induction of type I interferon and autophagy [169, 170]. The origin of cytosolic Mtb DNA is not clear, bud could stem from membrane vesicle buds released from Mtb [183].

Seeking to investigate direct effects of ESAT6 and to identify targets of interaction several studies using recombinant ESAT6 or ESAT6-CFP10 have been carried out. Thereby, ESAT6 was shown to interact with beta-2-microglobulin in the ER, leading to inhibited loading of antigen-derived peptides on the MHC-I complex [221]. This is in line with other reports demonstrating a role for ESAT6 in antigen presentation on MHC-II [222]. Another study demonstrated the involvement of recombinant ESAT6 in metabolic flux perturbations in macrophages through interaction with glycolytic pathway enzymes [223]. Furthermore, ESAT6 interacts with TLR-2, thereby attenuating TLR-mediated NFKB signaling [142], and similarly, each ESAT6, CFP10 and the 1:1 complex inhibit reactive oxygen species production in mouse macrophages, decreasing LPS-induced NFKB signaling [224]. CFP10 (but not ESAT6) on the other hand has been shown to interact with and activate human neutrophils [225].

In summary, ESAT6 impacts innate immune responses in several ways, with both benefits and disadvantages for the bacterium and the host. Due to the inability of ESAT6-deficient Mtb to spread to new cells and under the perspective of virulence blockers as a new drug development strategy [44], ESAT6 is an attractive target and host cell cytolysis an interesting readout. An anticytolytic screen recently led to the identification of new lead compounds that indirectly abolish ESAT6 secretion [120]. 


\section{Mtb phenotypes and their interaction with the host}

As seen above, Mtb has evolved mechanisms to withstand or modulate virtually all macrophage defense mechanisms. Besides that, $\mathrm{Mtb}$ is capable to adapt to and reside in a dormant state inside the macrophage and perhaps other cells in vitro and in vivo, as well as survive antibiotic treatment, which will be discussed in the following chapters. Firstly, the terminology for different bacterial states will be introduced, followed by a summary of the current knowledge of localization of $\mathrm{Mtb}$ and conditions encountered in vivo. Some distinct mycobacterial phenotypes will be considered as well as mechanisms and models for dormancy and persistence. Finally, attempting to highlight the role of Mtb phenotypes during TB treatment and LTBI, some recent clinical findings will be discussed.

\section{Terminology of dormancy and persistence}

Several terms are used to describe different phenotypes of Mtb, such as latent, dormant, drug-resistant, drug-tolerant and persistent bacteria. These terms are not clearly defined, and in some cases used interchangeably. In order to facilitate reading and understanding, the use of these terms shall be defined briefly: latent TB infection (LTBI) or latency refers to the clinical definition of an adaptive Mtb-specific immune response (TST or IGRA-positive) in humans in the absence of symptoms.

Dormancy has been suggested to be a term specifically for non-replicating INH-tolerant Mtb (as in the Wayne model), but since the physiological/clinical relevance of this phenotype is not entirely clear and there is a lack of terms for adapted bacteria resisting host pressures, it will here be used in a broader sense, including all adapted states of Mtb able to survive in the host under innate and adaptive immune pressures.

Drug-resistant Mtb feature genetic mutations rendering them drug resistant, while persisters and drug-tolerant bacteria survive antibiotic pressure due to phenotypic drug tolerance, without any genetic changes. Still, drug tolerance is inheritable, probably due to epigenetic modulations or phenotypic features being passed along during bacterial cell division.

\section{Mtb in different environments}

As already discussed, infection with Mtb can present as two very diverse clinical outcomes: either active TB disease, pulmonary or even disseminated, presenting with systemic symptoms such as fever and weight loss, local tissue destruction and transmission of Mtb. The other possible outcome is asymptomatic LTBI. Eradication of infection by innate 
immune responses has also been discussed and is likely, but difficult to prove. In recent years, it has been recognized that clinical presentation is not binary but heterogeneous, and so are the different environments that Mtb can reside in. Classically, Mtb is believed to reside inside granulomas during latent TB infection. LTBI can last for decades or life-long, and besides lung granulomas, there are many niches for $\mathrm{Mtb}$, with many of them being more or less investigated and characterized. Modeling of these locations and the prevailing conditions has been attempted for drug discovery.

\section{Mtb in different human tissues}

Epidemiological evidence for the life-long presence of Mtb in lesions during LTBI was obtained from studies from Denmark where Mtb strains were collected from patients since the 1960s and their DNA patterns were compared to those from strains causing disease during the 1990s. Strains shared identical or very similar DNA sequences, even though they were collected more than 30 years apart, indicating transmission followed by several decades of latency before reactivation of the same strain [226, 227].

Autopsy studies have been carried out as early as in the 1920s, when Mtb could be cultured from lesion-free tissue from lungs and lymph nodes taken from asymptomatic individuals. The authors further found bacteria more often outside of focal lesions than inside, and suggested that post-primary disease after a phase of LTBI was caused by bacteria outside of initial lesions [228, 229]. Another study was even less successful in demonstrating viable Mtb inside encapsulated granulomatous lesions by inoculation on agar or in the highly susceptible guinea pig model [230]. These findings are in line with fact that post-primary disease and cavitation often occurs in the apical regions of the lung lobes, whereas the lower zones of the lung are the initial place of infection [231]. Persistence of Mtb in superficial healthy lesionfree lung tissue was also demonstrated by in situ PCR targeting Mtb DNA. In autopsies from individuals who died from causes other than TB, Mtb DNA was detected, mainly in macrophages, but also in non-professional phagocytes such as type II pneumocytes, endothelial cells and fibroblasts [83]. These cells types were henceforward hypothesized to constitute a place for Mtb persistence during LTBI and the results could be replicated in mice [232]. Upon investigation of the Mtb phenotype, bacilli in lung tissue from LBTIindividuals were found to be refractive to Ziehl-Neelsen staining. Since acid-fast staining depends on the mycobacterial cell wall composition, cell-wall alterations were suggested to occur during Mtb dormancy [233].

In necropsy studies on histologically normal tissue obtained from individuals who died from other causes than TB, Mtb DNA was further detected at extrapulmonary locations, such as for example in the spleen, kidney and liver in different cell types. The study was conducted 
in a high-endemic setting, and Mtb DNA was found in the lungs of $70 \%$ of individuals, most of which also harbored Mtb DNA in at least one extrapulmonary site [234]. A similar study on individuals without known TB revealed Mtb DNA residing in adipose tissue surrounding several organs (heart, kidney, skin and lymph nodes). Necropsies were taken in high and low-endemic settings, and even in the latter, six out of 20 individuals carried Mtb (or at least Mtb DNA) in different adipose tissues. In vitro, Mtb could enter an adipocyte cell line and remain dormant without a net change in bacterial numbers for ten days [235].

The discovery of Mtb DNA in non-professional phagocytes and at extrapulmonary locations has subsequently fueled investigations on all kinds of cell types hosting dormant Mtb. At the site of infection, type II epithelial cells outnumber alveolar macrophages by far, and they express TLRs and produce surfactant proteins, making them a part of the alveolar innate immune response. Entry of $\mathrm{Mtb}$ can occur via macropinocytosis and several Mtb proteins were shown in vitro to interact with epithelial cells [236]. One of them, a surface-exposed adhesin called heparin-binding hemagglutinin (HBHA), enables dissemination of Mtb from the lung in mice [237] and dissemination through the epithelium could be a prerequisite for extrapulmonary dormancy. Lymphatic endothelial cells from TB patients harbored Mtb, and in vitro, ESAT6-dependent replication in the cytosol of human lymphatic endothelial cells could be restricted by IFN $\gamma$. This suggests that not only lymph nodes but also the lymphatic system could play a role during Mtb infection [238].

Viable Mtb were also found in a subpopulation of mesenchymal stem cells isolated from bone marrow from individuals with pulmonary TB after TB-treatment [239], and in turn mesenchymal stem cells were found to be recruited to Mtb granulomas and to exert immunosuppressive effects [240]. Residence and antibiotic tolerance of Mtb in bone marrow stem cells was demonstrated in the mouse model [239, 241].

Taken together, these findings fueled a debate of the place of residence of Mtb, since Mtb was traditionally believed to reside inside hypoxic granulomas during latency. TB was also discussed to be a lymphatic disease, with a pulmonary site for entry and presentation [242]. Furthermore, these findings suggest an alternative way for the pathogenesis of extrapulmonary TB (comprising ca. 15\% of all TB cases), and instead of hematogenous or lymphatic spread upon pulmonary reactivation, TB could reactivate directly at the site of extrapulmonary residence [243]. 


\section{Conditions and adaptation inside the macrophage}

Mtb is able to resist macrophage defense mechanisms, and hence macrophages are believed to harbor dormant bacteria. Mtb is able to adapt to the macrophage, and several general mechanisms such as the inhibition of phagolysosomal maturation have already been discussed, while others are more specifically linked to dormancy.

Transcriptomics performed on Mtb from infected murine macrophages revealed that the intracellular environment is oxidative, nitrosative and nutrient-limited [244], and Mtb reacts specifically to acidic $\mathrm{pH}$ both in vivo and in vitro. Several genes are expressed differentially at $\mathrm{pH} 6.5$ (early endosome) as compared to $\mathrm{pH} 5.5$ (phagolysosome), and the lower $\mathrm{pH}$ represses genes required for replication while inducing genes involved in a general stress response [245]. Resulting in acidified phagolysosomes, the arrest of phagolysosomal fusion can be overcome by stimulation of macrophages with IFN $\gamma$ upon induction and recruitment of $\mathrm{T}$ cells $[185,186]$. Further evidence for acidic conditions in the host comes from the fact that the first-line drug PZA only kills at acidic $\mathrm{pH}$, and from acid-sensitive Mtb mutants being attenuated in vivo [246]. Being capable of tolerating acidic stress that is lethal for many other microbial pathogens, Mtb possesses a membrane protein maintaining neutral intracellular $\mathrm{pH}$ in an acidic environment [247], and a $\mathrm{pH}$-responsive locus, aprABC, present exclusively in the Mtb complex strains. apr $A B C$ expression is regulated by the phoP two component regulatory system that - in an acidic environment - slows Mtb growth, stops growth when certain carbon sources are missing, and induces genes for lipid metabolism [248, 249]. Therefore, the acidic environment per se does not affect Mtb viability, but rather prepares the bacterium to adapt to intracellular challenges, and phagolysosomal effector functions such as hydrolytic enzymes are in many cases dependent on acidic $\mathrm{pH}$. Other macrophage defenses also synergize with lysosomal $\mathrm{pH}$, such as for example nitric oxide (NO). IFN $\gamma$-activated murine macrophages are unable to kill Mtb when iNOS is knockedout [250], and these mice are highly susceptible to Mtb [251]. NO-mediated mycobacterial killing is potentiated by acidification of Mtb-containing phagosomes [250], which is a selfprotective mechanism of phagocytes to avoid cytosolic harm by reactive nitrogen species (RNS). iNOS, encoded by the nos 2 gene and located at the cytoplasmic side of the phagosomal membrane, generates $\mathrm{NO}$ and L-citrulline from L-arginine and oxygen. Upon diffusion into the phagolysosomal lumen, nitrite converts at low $\mathrm{pH}$ to nitrous acid that forms NO and nitrogen dioxide, both highly reactive nitrogen species. Finally, NO and superoxide form the toxic peroxynitrite [246]. iNOS-generated RNS target membrane lipids, DNA, thiol and tyrosine residues [173], and iNOS-expression distinguishes M1 from M2 macrophages [136]. In the context of Mtb infection, expression of iNOS in human macrophages is induced via NOD2 and subsequent NFKB signaling [252]. 
Knowledge on NO and iNOS mainly originates from mouse models, as murine macrophages readily produce NO, while NO levels from human macrophages are much lower [253]. Epigenetic silencing of nos 2 in human macrophages has been suggested to account for species differences [254]. Evidence for a host-protective role of NO in human TB exists, as iNOS is expressed in granulomas from humans and NHPs [140, 255, 256] and in alveolar macrophages from TB patients [257]. Likewise, arginase is expressed in macrophages, which converts L-arginine to urea and L-ornithine, the latter giving rise to Lproline involved in collagen synthesis and wound healing [140]. Therefore, iNOS and arginase compete for L-arginine, and oral supplementation of L-arginine during TB treatment accelerated sputum-conversion and improved clinical outcome [258], while another study did not find any such effect [259]. Polymorphisms in nos 2 predispose for increased susceptibility to TB [260], and the new drug pretomanid (PA-824) - active under anaerobic conditions and currently under phase 3-evaluation - is believed to acts as an NO donor [261].

Generation of toxic peroxynitrite from NO also requires superoxide, which - along with other reactive oxygen species (ROS) - is generated from the multimeric NADPH oxidase complex (NOX2) upon phagocytosis. Similarly to iNOS, NOX2 is recruited to the Mtbcontaining phagosome upon IFN $\gamma$ or TNF stimulation [173] and mutation in a NOX2 subunit causes hypersusceptibility to TB [262]. The most prominent defense mechanism of $\mathrm{Mtb}$ against ROS is the mycobacterial catalase-peroxidase katG that decomposes hydrogen peroxide into water and oxygen. Neutralizing ROS using a similar mechanism, Mtb has two superoxide dismutases located in the bacterial cell wall, and several other enzymes contributing to ROS and RNS neutralization [263]. Both katG and superoxide dismutase were found in the mycobacterial capsule [38, 264]. Besides these direct detoxifying effects, generation of ROS is downregulated by the mycobacterial protein 'enhanced intracellular survival' (eis) which further modulates ROS-dependent cell death and autophagy [265]. Repair of oxidatively damaged proteins by ROS or RNS is carried out by mycobacterial methionine sulphoxide reductases (Msr) [266], and essentiality of proteasomal components indicates that turnover of damaged proteins in the proteasome is another mycobacterial detoxification mechanism [246, 267].

Besides these defense mechanisms against ROS and RNS, Mtb reacts to nitrosative stress by inducing a specific transcriptional response via the dosS/dos T-dos R regulatory complex. It regulates about 50 genes, the dormancy regulon ( $\mathrm{dos} R$ ), that govern the shift from aerobic to anaerobic metabolism allowing the bacteria to survive hypoxia-induced dormancy with subsequent reversal to growth under normoxia [246, 268]. Besides hypoxia, dosR also responds to $\mathrm{NO}$ and low $\mathrm{pH}[269-271]$ and is induced inside macrophages [244, 245, 272, 
273]. Induction of dosR is further essential for the metabolic shift that Mtb undergoes when entering non-replicating persistence in the Wayne model [274]. Besides external stimuli, dosR-dependent genes were upregulated by simply decelerating the mycobacterial growth in vitro [275], highlighting the role of dosR during mycobacterial adaptation.

In addition to reactive molecules, macrophages starve Mtb-containing phagosomes or target them with heavy metals. The essential micronutrient manganese and iron are depleted, for example by efflux of iron by Nramp1 [276]. To overcome iron limitation, Mtb chelates iron via capture systems, so-called mycobactins [277] and utilizes heme [278] and binds ironloaded transferrin via specific receptors [173]. Contrary to that, the macrophages 'poisons' the phagosome with zinc and copper ions [279, 280], which Mtb counteracts by expressing metal efflux pumps [276].

Further macrophage defense mechanisms evolve around cationic antimicrobial peptides. One of them, LL-37, is expressed upon TLR-dependent induction by bioactive vitamin D (1,25dihydroxyvitamin D) and kills $\mathrm{Mtb}$ in vitro and after expression inside monocytes or macrophages [163, 281, 282]. Besides the induction of LL-37, vitamin D also enhances IFN $\gamma$-induced autophagy and phagosomal maturation [95]. Providing a clinical link to the experimental observations, vitamin D-deficiency and vitamin D-receptor polymorphisms were found to predispose for higher TB susceptibility in humans [283], and in individuals with a certain polymorphism, vitamin D3 supplementation during TB-treatment accelerated sputum conversion [284].

On the host cell level, vitamin D has antiadipogenic effects in Mtb-infected macrophages and abrogates the Mtb-induced changes in host cell lipid metabolism [285]. To ensure access to carbon sources, Mtb drives foam cell formation which is mediated through TLRrecognition of the mycobacterial cell wall component trehalose dimycolate (TDM) [286]. Foamy macrophages carry lipid storage organelles, so-called lipid bodies, originating from a dysregulated influx and efflux of low-density lipoprotein (LDL) leading to retention of cholesterol in the cytosol, esterification and sequestration into a phospholipid monolayer together with triacylglycerides (TAG) $[106,287]$. In an in vitro model with foamy macrophages generated from murine macrophages, $M$. avium-containing phagosomes fused with lipid-laden vacuoles [288], similar to observations in adipocytes [235]. This constitutes a way for mycobacteria to exploit host lipids and is substantiated by the accumulation of lipid droplets inside Mtb with similar composition as the host cell lipid bodies. This was hypothesized to occur by hydrolysis of host TAG by a mycobacterial lipase [289], followed by import of the fatty acids into the bacterial cytoplasm and local de novo synthesis of TAG [290]. Although TAG constitutes a carbon source for mycobacteria, intracellular counts of M. avium did not change. Similarly, no Mtb net growth was observed inside monocyte- 
derived foamy macrophages during extended infection while bacterial numbers increased in non-foamy macrophages in the same samples. Mtb induced dormancy-related genes such as dosR [105], leading to the idea of Mtb residing in a dormant state inside these cells. While the limited mechanistic knowledge on foamy macrophages originates from in vitro models, infected foamy macrophages are abundant in human granulomas at the interface of cellular and caseous region and constitute the source of caseous debris accumulating in the granuloma center $[107,286]$. The exact mechanisms of Mtb dysregulating the macrophage metabolism and of Mtb-containing vacuoles fusing with macrophage lipid droplets is not known, but foam cell formation has been linked to inflammation in other diseases [291] and was enhanced upon mycobacterial infection as compared to uninfected cells [288].

Another immunometabolic change in host cells was discovered recently, and evolves around the shift from oxidative phosphorylation to the less energy-efficient glycolysis upon Mtb infection. This modification was a prerequisite for IL-1 $\beta$ release, which in turn contributed to the control of Mtb growth in macrophages [292], and glycolytic energy acquisition in immune cells was confirmed in granulomatous lesions in infected mice [293]. Increased glucose consumption by immune cells is made use of in positron emission tomographycomputed tomography (PET-CT) imaging of granulomatous lesions labeled by the glucose analog ${ }^{18}$ F-fluorodeoxyglucose $\left({ }^{18} \mathrm{FDG}\right)$ [294]. Linking the phenomena of foamy macrophages and the glycolytic shift, recombinant ESAT6 was described to enhance glycolysis in THP-1 macrophages and to induce the accumulation of TAG [223, 295], though this observation requires further characterization.

Coinciding with alterations in the host cell lipid metabolism, Mtb shifts its own metabolism from glycolytic to lipolytic. The Mtb genome contains all the enzymes belonging to the glyoxylate cycle, a pathway exploiting lipids as carbon sources and is enriched in enzymes for $\beta$-oxidation required for lipid catabolism. The inability of an Mtb strain deficient in a cholesterol transport system to persist in vivo highlights the importance of the lipid metabolism [296], and mutagenesis studies revealed further proteins essential for survival. One of them, the enzyme isocitrate lyase (ICL), present in two isoforms in Mtb and central to the glyoxylate cycle, received a lot of attention due to its crucial role for growth on fatty acids. Furthermore, the Mtb mutant with deletions in both isoforms of ICL was eradicated from mouse lungs within two weeks [297]. Instead of being proof for the essentiality of the glyoxylate cycle for Mtb survival, this heavy attenuation was later attributed to an 'intoxication' caused by the concurrent methylisocitrate lyase activity of ICL, as deletion of the enzyme led to the accumulation of intermediates that ultimately interfered with $\mathrm{Mtb} \mathrm{pH}$ homeostasis and caused death of the bacilli [298]. Another pathway for the exploitation of lipids as carbon sources besides the glyoxylate cycle is gluconeogenesis that Mtb performs to 
obtain building blocks for nucleotide and cell wall biosynthesis. The enzyme controlling the rate-limiting step in gluconeogenesis was found to exist twice in the Mtb genome, and deletion of both again caused eradication of bacilli in vivo [299]. This genomic redundancy hints at the importance of lipid exploitation during Mtb dormancy. In general, results on the metabolism of $\mathrm{Mtb}$ are difficult to interpret, since the physiology of Mtb differs significantly between in vitro culture and in vivo settings, and little is known about Mtb metabolism in human TB. The metabolic and respiratory shift of Mtb so easily induced by hypoxia, low $\mathrm{pH}$ or $\mathrm{NO}$ has often been hypothesized to constitute a virulence mechanism for intracellular survival and persistence, and transcriptional studies often focus on comparing Mtb cultivated in broth to those inside of cells. On the contrary, the observed shift could just be the 'default' setting for mycobacterial metabolism and physiology, since Mtb does not encounter simple sugars during its life cycle (besides during transient access to the host cell cytosol after phagosomal rupture and during extracellular growth), and what has been described as 'nutrient-limited' is maybe not so limited after all when preferring lipids.

\section{The environment in the granuloma}

As illustrated with the examples above, Mtb has developed strategies to combat most macrophage killing mechanisms, and the interplay between the bacterium and the host cell resembles a balance that can be tied to either the one or the other side by a multitude of factors. If bacteria take over and macrophages (or other potential host cell) fail to kill or to contain Mtb in a dormant state, the infection subsequently succeeds to a higher level, the multicellular granuloma.

The conditions inside human granulomas are believed to be crucial for Mtb dormancy and persistence, but are difficult to characterize due to their inaccessibility. Hypoxia is a main feature of solid, necrotic and liquefied granulomas in guinea pigs, rabbits and NHPs [300] and severe hypoxia was recently also demonstrated in human lesions by PET-CT scanning [109]. Hypoxia was believed to be one of the main factors driving Mtb into dormancy and persistence, and absence of necrotic and hypoxic granulomas in the commonly used C57Bl/6 and $\mathrm{BALB} / \mathrm{c}$ mouse models could explain the high bacterial burden observed in mouse organs $[108,300]$.

Addressing another parameter that affects Mtb physiology, the $\mathrm{pH}$ of caseous lesions has been discussed [301]. Due to the release of phagolysosomal content, acidic conditions are conceivable, while a slightly basic $\mathrm{pH}$ was measured in lesions from the 'Kramnik mouse' model $(\mathrm{C} 3 \mathrm{HeB} / \mathrm{FeJ})$, which features hypoxia, necrosis and liquefaction unlike other mouse models [301-303]. 
The caseum inside granulomas mainly consists of cholesterol, cholesterol esters and TAG, and the composition resembles the lipids inside foamy macrophages, and caseum is probably derived from necrotic foam cells. In vitro, foamy macrophage formation was also induced by hypoxia, but it remains to be investigated if uninfected macrophages inside granulomas also accumulate lipid bodies. The bacterial lipid TDM is a strong inducer of granulomas in mice, as demonstrated by the formation of granulomas around TDM-coated beads probably triggered by excessive inflammation [107]. Therefore and due to a range of other observations, granuloma formation and necrosis were hypothesized to be a process driven by the bacterium, as opposed to earlier beliefs that granulomas are purely host-protective [111].

In granulomas, Mtb resides both inside immune cells but also extracellularly upon necrotic host cell death. Cell wall alterations are believed to be a consequence of Mtb residing in lung tissue [233] or inside macrophages [304] and were substantiated by transcriptomic findings of altered expression of cell wall synthesis genes in host cells [244, 305]. These alterations lead to a decrease in acid-fastness, and coincide with the accumulation of TAG-containing lipid droplets in the cytoplasm of Mtb, probably derived from host cell lipids [288, 306]. As demonstrated with a non-acid fast Mtb mutant, loss of acid fastness could be due to the synthesis of shorter mycolic acids, which further abolished cording of Mtb and produced an overall attenuated phenotype [307]. Acid-fast staining of bacilli in caseous granulomas reveals only a low number of bacilli in the caseum and the abundant mycobacterial DNA originates from dead bacilli, since the less stable RNA was only detected at the outer region of the caseum where foamy macrophages are localized [308, 309].

The mechanisms behind granuloma liquefaction, cavitation and ultimately rupture into the airways are not entirely clear, but are driven by inflammation, tissue remodeling and damage, such as for example by matrix metalloproteinases upregulated during Mtb infection [310]. On the one hand, inflammatory responses are crucial for the control of Mtb growth. Pharmacological inhibition of TNF or IL-1 $\beta$ signaling can lead to reactivation of LTBI [311, 312] and genetic polymorphisms promoting anti-inflammatory immune responses cause hypersusceptibility to TB [313]. On the other hand, dampening of excessive inflammation and inhibiting MMPs can contribute to a beneficial outcome of the infection, as dexamethasone added to TB treatment downregulated MMP-9 and improved survival of TB patients [314] and ibuprofen without any additional antibiotic treatment decreased the Mtb load and increased survival in the 'Kramnik mouse' [315]. On several occasions, the inflammatory optimum required for the control of $\mathrm{TB}$ infection has been described as a balance between pro-and anti-inflammatory mediators [316, 317]. A recent study combining mass spectrometric analysis of microdissected granulomas with information on their histopathological structure revealed that human granulomas are rather pro-inflammatory in 
the necrotic center, but anti-inflammatory at the cellular rim, suggesting balancing of proand anti-inflammatory mediators at the lesional level [318].

\section{Mtb in sputum}

Transmission of Mtb occurs via airborne droplets expelled during coughing, and diagnosis of $\mathrm{TB}$ is based on the demonstration of acid-fast bacilli in sputum. Few studies have focused on the phenotype of sputum bacteria, although these bacilli are on the way to a new host, potentially establishing infection.

Against common belief, transcriptional analysis of sputum Mtb revealed a 'fat and lazy'phenotype, as termed by the study authors. Gene expression pattern was strikingly different from Mtb cultivated aerobically, and pathways for aerobic respiration and ribosomal function were downregulated but cholesterol utilization was upregulated. In line with findings from different infection and stress models, dos $R$ was the most prominently activated regulon in sputum bacteria $[319,320]$. The study authors further attempted to model the transcriptomic results using bacteria growing according to the Wayne model, but besides dos $R$ induction, in vitro phenotypes did only poorly recapitulate sputum patterns [319]. One of the upregulated genes in the dosR regulon, tgs 1 , encodes a triacylglycerol synthase involved in the accumulation of TAG-containing lipid droplets inside the Mtb cytosol [321]. Staining of sputum samples for lipids revealed lipid droplet accumulation in sputum bacteria [319, 322] reminiscent of stressed or dormant Mtb phenotypes [290, 321] and of bacilli in foamy macrophages [288]. Furthermore, time to positivity of sputum samples correlated with the proportion of lipid droplet-positive bacteria [319], indicating that this subpopulation requires more time to resume growth upon inoculation into broth. Combination of acid-fast and lipid staining has been suggested to enhance the clinical evaluation of TB treatment, since treatment increases the proportion of lipid dropletcontaining cells and reduced the acid-fast population [323]. This enrichment of 'fat and lazy' bacilli is in agreement with the concept of mainly growing bacilli being targeted by TB antibiotics. A higher proportion of lipid body-positive bacteria after three or four weeks of treatment was observed in the sputum of patients with unfavorable outcomes 6 months after end of treatment, as compared to patients with a stable cure [324]. Among the same lines, sputum contains non-culturable and drug-tolerant Mtb phenotypes [325, 326] (both discussed later). 


\section{Phenotypes of Mtb}

When cultivated in rich broth supplemented with detergent, Mtb readily grows without aggregating and is acid-fast, especially so if cultures are aerated by agitation. Changing any of these parameters, such as restricting oxygen supply, limitation of nutrients or omitting detergent can have drastic changes on culture morphology and the bacterial phenotype, as outlined in the previous chapter.

\section{Morphologic Mtb phenotypes}

Several mechanisms for bacterial adaptation to harsh environments are known. Bacillus subtilis is the major example of a sporulating bacterium, forming endospores resistant to many external threats when residing in a nutrient-limited environment. Spore-formation has also been observed in mycobacteria, as small, spherical and non-acid fast particles initially described almost a century ago in M. bovis BCG [229], and morphologically similar cell-wall deficient forms of Mtb ('L-forms') appearing during nutrient starvation have been shown [327]. In 2009, both M. bovis BCG and M. marinum were shown to form heat-tolerant endospores during extended cultivation of 14 days and 6 months, respectively, characterized by positive malachite staining and the presence of dipicolinic acid, a hallmark of endospores [328]. This led to an elaborate scientific debate and attempts to reproduce mycobacterial spores by other labs which failed [329, 330].

Morphologically different from endospores, ovoid cells of Mtb H37Rv were observed when bacteria were cultivated for extended time periods and the growth medium underwent gradual acidification. These ovoid cells were acid-fast but non-culturable on solid agar, and this impaired culturablity of Mtb has been suggested to be a physiological characteristic of dormant phenotypes. Mtb ovoid cells resumed growth when supernatant from actively growing cultures or recombinant resuscitation-promoting factors (Rpf) were added [331].

Mtb encodes for five Rpf-like proteins (RpfA-E), these are dispensable for in vitro growth while attenuating $\mathrm{Mtb}$ in the mouse [332], and addition of picomolar Rpf concentrations effectively resuscitates 'viable but non-culturable' (VBNC) bacteria typically formed during extended hypoxic cultivation [333]. After propagation, this Rpf-dependency is lost, and therefore suggests a phenotypic rather than a genetic change [325]. Rpfs have cell wallhydrolytic activity which is believed to trigger a signaling cascade leading to metabolic activation [334], but the exact mode of action of resuscitation is unknown. Addition of Rpfs to sputum from TB patients increased the obtained bacterial count several-fold, suggesting a significant non-culturable population in sputum [325]. Rpf-dependent mycobacteria were further present in lungs and in peritoneal macrophages from infected mice [335, 336], and 
Rpf proteins could be labeled in tissues from TB patients in the vicinity of acid-fast bacilli [337]. Similar to Rpf-dependent bacilli, a subset of non-growing but metabolically active (NGMA) Mtb was identified in stationary-phase cultures and in infected mice. These exhibited active mRNA transcription, but failed to resume growth [338].

Another acknowledged phenotype of $\mathrm{Mtb}$ is the cording phenotype, typically observed when Mtb are grown in an unpertubed manner or as pellicular biofilm. Cording has been observed in both pathogenic and non-pathogenic mycobacteria [339] and depends on the presence of the cord-factor TDM, a cell wall glycolipid with potent immunogenic properties. TDM contributes to the inhibition of phagolysosomal fusion [340], drives granuloma formation [107, 341] and activates tissue-damaging matrix metalloproteinases [342], suggesting a role as a virulence factor. Furthermore, cording mycobacteria were observed in vivo in the zebra fish model, and were phagocytosed to a lower degree [343]. In vitro, cording or biofilm formation of $\mathrm{Mtb}$ has sometimes been attributed to the presence or absence of detergent in the growth medium, and biofilms cultivated without Tween-80 are tolerant to $\mathrm{TB}$ antibiotics which could be reversed by dispersion into planktonic cultures with Tween-80 or DNase [344, 345]. This phenotypic drug tolerance could be attributed to extrinsic factors, such as the lipid-enriched extracellular matrix surrounding the biofilm, and intrinsic factors, such as physiological changes of Mtb in nutrient- and oxygen-limited microenvironments. The use of a biofilm model for drug screening has led to the identification of a new compound active against nutrient-starved Mtb [346].

To date, it is not known if cording Mtb populations exist in human TB, although it has been suggested that cording bacteria line lung cavities during cavitary disease [347]. Likewise, the physiological significance of sporulation is unknown, and it remains to be determined, if Rpf-dependent Mtb populations are responsible for dormancy or persistence.

\section{Encapsulated Mtb}

The interactions between the Mtb capsule and the host have been neglected in TB research, possibly owing to its absence when Mtb are cultivated in detergent-containing broth. Constituting the first 'contact zone' between $\mathrm{Mtb}$ and alveolar macrophages during transmission of $\mathrm{Mtb}$, it is not surprising that all capsular components (carbohydrates, proteins and lipids) affect the interaction.

The presence of a capsule enhanced the attachment of $M$. bovis BCG to macrophages [38], while in another study, the capsule was suggested to be antiphagocytic, leading to decreased phagocytosis of Mtb by macrophages [348]. In the latter study, bacteria were however cultivated in the presence of Tween-80, which later was shown to remove the capsule [38]. Attachment of Mtb to macrophages was attributed to the most abundant capsular 
polysaccharide in Mtb, $\alpha$-glucan, which binds to the complement receptor 3 (CR3) under non-opsonic conditions [150]. Furthermore, $\alpha$-glucan modulates immune responses as a ligand of DC-SIGN [149] and alters the differentiation of monocyte-derived DCs and blocks CD1-expression, thereby inhibiting presentation of antigenic lipids of Mtb to CD1restricted T cells [349]. Furthermore, Mtb mutants deficient in the synthesis of capsular glucan were less virulent and therefore unable to persist in vivo in mice [350, 351]. In another mouse study, the capsular component arabinomannan (AM) could be detected in mouse tissue and its amount correlated with colony-forming units (CFU). Furthermore, a humoral response against both AM and $\alpha$-glucan was mounted, indicating that capsular AM and $\alpha$-glucan are synthesized, secreted and antigenic in the host $[352,353]$. This indicates a role for capsular components in vivo, which is supported by electron microscopy findings of Mtb capsules in tissues from infected mice [34, 40, 41].

Besides polysaccharides, also capsular proteins and lipids play a role in the interaction with the host. Several enzymes were shown to be secreted from Mtb and to reside in the capsule. Among them, superoxide dismutase and the catalase-peroxidase kat $G$ which neutralize reactive oxygen species, and were absent from the capsule of non-pathogenic mycobacteria $[38,264]$. Retaining these enzymes close by at its surface might be a smart mechanism for Mtb to be prepared for the encounter of phagocytic cells. Also the Mtb-specific lipid phthiocerol dimycocerosate (PDIM) was found in the Mtb capsule [354], and constitutes a virulence factor essential for growth in infected mice. PDIM-deficient Mtb are susceptible to host killing early during infection but not later after onset of adaptive immunity, indicating a protective effect against innate immunity [355].

Several recent studies consider the effects of the Mtb capsule. Striking differences in the transcriptional response of primary murine macrophages to an MDR strain cultivated in the presence and absence of detergent were found [356]. Mtb devoid of a capsule induced a strong pro-inflammatory response, and downregulated for example the expression of the IFN $\gamma$ receptor, which could promote survival and persistence of Mtb [356, 357]. Another study looking into the transcriptional response of bovine alveolar macrophages after $M$. bovis infection obtained conclusions different from other studies with similar settings, partly attributed to the use of detergent-free cultivated bacilli, but unfortunately a direct comparison of the transcriptomics upon infection of $\mathrm{Mtb}$ cultivated with or without detergent was not performed here [358]. Looking into the immunological response after BCG-vaccination and Mtb-challenge of mice, encapsulated BCG triggered a more potent immune response as compared to non-encapsulated (detergent-cultivated) BCG, featuring polyfunctional $\mathrm{T}$ cells, higher IFN $\gamma$ production and lower CFU burden [359]. In line with 
earlier studies in mice mentioned above [352, 353], an antibody response against capsular polysaccharides was observed.

In the serum of TB patients, antibodies against arabinomannan have been found [360], but it was not clear whether those antibodies were mounted against the arabinomannancontaining portion of lipoarabinomannan, which is a glycolipid antigen situated in the cell wall and not part of the capsule [361]. Furthermore, killing and degradation of Mtb and presentation of its antigen would explain inconclusive humoral responses in vivo.

ESAT6, CFP10 and other ESX-1 substrates have been suggested to reside in the mycobacterial capsule $[35,38]$, and so far conflicting evidence exists whether encapsulated $\mathrm{Mtb}$ elicit stronger pro-inflammatory responses in macrophages than non-encapsulated bacilli $[38,356]$.

\section{Mechanisms and models for Mtb dormancy and persistence}

The term 'persisters' was coined in the 1940's, when an army medical doctor investigated why penicillin-treated wounds often were only partially sterilized and prone to subsequent re-infection. He identified a very small subpopulation in a Staphylococcus aureus culture which survived prolonged exposure to bactericidal concentrations of penicillin. Upon recultivation of this subpopulation and another round of antibiotic exposure, an equal proportion of bacilli survived, indicating that survival was not due to genetically inherited antibiotic resistance [362]. Persistence has been shown in all bacteria tested for it, and there are two types of persistence: Type 1 persistence requires a triggering signal such as starvation, biofilm formation, quorum sensing, exposure to the host immune system or to antibiotics, and this can be genetically encoded, for example by toxin-antitoxin systems [362]. Type 1 persistence is further characterized by slowed or arrested growth (the classical definition of dormancy), and in a stationary phase-culture of Escherichia coli, growth-arrested but not dividing bacteria survived a subsequent ampicillin shock [363]. As opposed to that, type 2 persisters are generated continuously during growth, do not need a trigger to form but appear stochastically, and the growth rate prior to antibiotic pulsing does not correlate with drug tolerance [364].

For Mtb, both modes of persistence (type 1 and type 2) have been demonstrated, and the differences are not always as clear-cut as in the E. coli model organism. Mtb growth arrest has been believed to be the major mechanism for phenotypic drug tolerance, as observed in the Wayne model. It features nutrient-starved stationary-phase Mtb cultivated under hypoxia leading to growth arrest and phenotypic tolerance to INH [365]. These bacteria exhibit 
downregulation of growth-related genes and upregulation of the dosR regulon, and therefore states of bacteria with dosR induction were believed to feature slowed or arrested growth [246]. Although growth arrest undeniably contributes to drug tolerance, there are a few paradoxes around it, and several other mechanisms for drug tolerance exist. More recent models suggest stochastic mechanisms, where persisters arise independently of the environment [366]. Besides stochastic changes in gene expression, factors contributing to drug tolerance can be found in the bacteria themselves, in where they are located during pathogenesis and in tolerance mechanisms induced upon encounter of (host) stress. Due to impracticalities of studying bacterial replication and phenotypes in humans, most knowledge on dormancy and persistence is derived from different models, which also shall be introduced here.

\section{Intrinsic factors}

One of several intrinsic factor for drug tolerance is the impermeable and unique cell wall of Mtb which was acknowledged as being a more efficient permeability barrier than cell walls of any other class of bacteria [75]. Responsible for this 'passive' tolerance are the unusually long mycolic acids covalently attached to the peptidoglycan layer leading to a thicker and less fluid cell wall structure. Passive diffusion is low, but is facilitated by water porins, and active transport is carried out by influx transporters and efflux pumps, with the latter playing a significant role in natural and induced drug tolerance. Mtb possesses ATB-binding cassettes (ABC) transporters, but also transport systems relying on proton-motive force, and efflux of all first-line and many second-line drugs has been demonstrated [75]. Expression of efflux pumps can also be induced by antibiotics, and isoniazid tolerance in vitro was attributed to the induction of isoniazid efflux systems as it could be reversed by efflux pump inhibitors [367]. These inhibitors could be exploited clinically to treat MDR-TB [368]. Nutrientstarved Mtb on the other hand exhibit decreased intrabacterial drug concentrations, and treatment with efflux pump inhibitors did not increase drug penetration, highlighting that there are also other tolerance mechanisms at play [75, 246].

Besides physical features of $\mathrm{Mtb}$, fluctuations in gene expression and asymmetric cell division as well as coinciding functional heterogeneity constitute another mechanism for persistence. Initial reports showed that the expression of katG, the mycobacterial catalase-peroxidase converting the prodrug INH to its active form, fluctuates in M. smegmatis cultures. Hence, downregulation of kat $G$ allows single bacteria to survive and even replicate under antibiotic pressure. Against earlier beliefs, katG fluctuations do not correlate with the growth rate of individual bacteria, but correlate between sibling cells, indicating that epigenetic effects might underlie katG pulsing [366]. Also in Mtb, adoption of slowed or arrested growth was not a prerequisite for persistence during INH treatment [338]. Phenotypic diversity, as 
measured by fluctuations in ribosomal activity, was common in Mtb cultures and even more pronounced during macrophage or mouse infection [338]. It is unclear if increased heterogeneity emerges as a direct effect upon encounter of stressful conditions, or simply as a side effect of the adaptation to stress. Besides fluctuations in gene expression, the mycobacterial cell cycle constitutes another heterogeneous process. As opposed to many other bacteria, cell division occurs in an asymmetric manner giving rise to differently-sized daughter cells $[22,24]$. There is however conflicting evidence if these daughter cells have similar or different antibiotic tolerance $[22,24]$. In general, heterogeneity within the bacterial population and stochasticity in gene expression are believed to enhance chances for survival of at least a few bacteria.

\section{TB pathogenesis}

Besides Mtb-intrinsic factors for drug tolerance, several parameters inherent to TB pathogenesis are now held responsible for drug tolerance, and granuloma composition as well as different lesion types (cellular, caseous, cavitary) contribute to suboptimal exposure to antibiotics. Analysis of the spatial drug distribution in necrotic granulomas from humans undergoing antibiotic treatment and comparison of the distribution pattern to adjacent histological sections revealed that TB drugs penetrate differently into the caseum and cellular layers, largely depending on their lipophilicity [73]. This could lead to local monotherapy, or to suboptimal drug concentrations in certain regions of lesions, facilitating Mtb persistence and the emergence of genetic drug resistance. Furthermore, the lesions within one individual receiving $\mathrm{TB}$ treatment are heterogeneous, with some lesions responding to treatment while others do not decrease in size or activity [369]. These differences have been attributed to differential immune responses at the lesional level, although this is hypothetical.

\section{Host-induced phenotypes}

Many implications of in vivo dormancy and persistence were derived from models, but many ideas still lack support from studies on human TB. These models are based on exposure of Mtb to stresses that it encounters inside the host cells or the granuloma: hypoxia, nitric oxide, acidic $\mathrm{pH}$, nutrient limitation, etc. Since dormancy and persistence are strongly linked to the phenomenon of LTBI and to TB pathogenesis, animal model studies aim at replicating human disease as closely as possible, not least to obtain reliable models for drug testing.

In vitro models focus on exposure of $\mathrm{Mtb}$ to different stresses. The best-characterized among them is the Wayne model of non-replicating persistence, published in 1996 [365]. Mtb is stirred in sealed tubes in broth with a defined ratio of broth and headspace volume. As the bacteria grow, oxygen is continuously consumed and gradually depleted, leading to 
microaerobic conditions. Under 1\% dissolved oxygen, Mtb enters the state of microaerobic nonreplicating persistence 1 (NRP1), characterized by termination of replication and transcription and thickening of the outer cell wall. After approximately 9 days, oxygen has dropped to under $0.06 \%$, Mtb enters NRP2 and is susceptible to metronidazole but tolerant to anaerobiosis and INH, which led to the assumption that INH only kills replicating bacteria. Upon resuspension in fresh medium and aeration Mtb resumes growth and is drugsusceptible [365]. The dosR regulon is induced during anaerobic dormancy, and crucial for tolerance to anaerobiosis [370]. Infection of macrophages with NRP2-phase Mtb revealed that dormant bacteria are initially unable to replicate intracellularly and are unable to inhibit phagolysosomal acidification [371, 372].

Nutrient limitation has been another way to induce dormancy. Exponentially grown Mtb cultures are transferred to PBS and incubated, again leading to growth arrest and tolerance to INH but also metronidazole. In nutrient-starved $\mathrm{Mtb}$, transcription of genes involved in energy metabolism, lipid biosynthesis, transcription and cell division ceased while stringent response genes were induced [373]. Other in vitro models combine two or more stress factors, and upon exposure to low oxygen, high carbon dioxide, low $\mathrm{pH}$ and nutrient starvation, the Mtb phenotype exhibits replication arrest, loss of acid fastness and concurrent accumulation of intrabacterial lipid droplets, as well as tolerance to INH and RIF [374]. Besides subjecting $\mathrm{Mtb}$ to a range of stresses, other approaches have rendered Mtb nonreplicative. A streptomycin-resistant clinical Mtb isolate was found to be unable to grow when streptomycin is withdrawn and could therefore be exploited for drug tolerance testing upon growth arrest, again exhibiting tolerance to INH [375].

Macrophages are acknowledged as the first host cell that Mtb encounters upon infection and are believed to induce Mtb dormancy, or vice versa, Mtb is believed to withstand macrophages defenses and adapt to the host cell for dormancy, residing in a state characterized by absence of or slowed replication. Due to these adaptation, macrophage models are also an attractive tool to study the intracellular antibiotic tolerance of $\mathrm{Mtb}$, and the impact of host factors on persistence.

Macrophage models of dormancy evolve around activation of macrophages with different stimuli. THP-1 macrophages treated with vitamin D and retinoic acid contain nonreplicating Mtb for several weeks and form multi-nucleated giant cells. In this case, control of infection was attributed to autophagy as well as iNOS induction and ROS production [376]. Primary human macrophages differentiated and activated with cytokines also controlled Mtb replication [377]. Notably, these studies did not report any data on antibiotic susceptibility of intracellular Mtb [376, 377]. Tolerance to INH could be recapitulated in a THP-1 macrophage-based model of Mtb infection when cells were 
cultivated at a reduced oxygen tension of 1\%. Macrophages accumulated lipid bodies and Mtb synthesized lipid droplets from host-derived fatty acids, and similarly to the multiplestress in vitro model developed by the same group and described above, intracellular Mtb experienced loss of acid fastness [306]. Controlling Mtb replication for a few days only, it is not clear if upregulation of $d o s R$ and other dormancy-related genes and tolerance to INH was mediated by macrophage mechanisms, by the hypoxic cultivation conditions or by a combination of both [306]. Other studies on foamy macrophages confirmed the growth arrest, induction of dormancy-related genes as well as Mtb 'feeding' on host lipids [105, 288]. Unfortunately, antibiotic tolerance inside these foamy macrophages was not investigated. One drawback of macrophage models is that replication arrest inside macrophages is difficult to determine, since absence of a net change in colony forming units (CFU) counts could also be interpreted as coinciding mycobacterial replication and killing at similar rates [105, 288, 306, 377]. Furthermore, cell death is often not taken into account.

Besides attempting to model absence of replication, other macrophage studies focused on the role of intracellular localization for the emergence of tolerance, and after passage through macrophages, M. marinum and Mtb were found to be (partly) tolerant to INH and RIF [378]. Taking intracellular replication rates as determined with the replication clock plasmid into account, replicating $M$. marinum were even found to be more tolerant against INH, RIF and moxifloxacin than non-replicating bacilli. Addition of the efflux pump inhibitor verapamil reduced INH tolerance in M. marinum, but not in Mtb [378]. Also in vivo in the zebra fish model, INH tolerance was attributed to macrophage localization of mycobacteria [378]. These results of macrophage-induced drug tolerance questioned the prevalent view that absent or slowed bacterial replication inside host cells is a prerequisite for drug tolerance. Efflux pump-induced INH tolerance in replicating Mtb was also observed in vitro [367, 379, 380], and tolerance can be induced by cultivation of Mtb in stepwise increasing INH concentrations and reversed by inoculation into antibiotic-free broth. Needless to say, this Mtb phenotype did not carry mutations in any of the genes known to confer INH resistance [379]. In these in vitro studies, Mtb acquires tolerance by exposure to increasing INH concentrations, while tolerance inside macrophages emerges without antibiotic pressure [378]. This phenomenon of host cell-induced tolerance was recently confirmed, as mouse macrophages harbored a higher percentage of tolerant Mtb when cells were IFN $\gamma$ and LPSactivated, and Mtb burden in immunized mice was similar in untreated and INH-treated animals. iNOS-mediated host defenses contributed most to the induction of tolerance in murine cells [381].

Altogether, the knowledge of phenotypic drug tolerance inside host cells has changed and broadened during the last decades, and not only arrest of Mtb replication upon encounter of 
macrophage stresses but also host-induced factors conferring tolerance to replicating bacilli are possible mechanisms for drug tolerance.

Extending macrophage-based models, a range of granuloma models have been developed to study the early steps of granuloma formation and maintenance. These are often based on human PBMCs and a support matrix such as collagen [382]. One such model featured Mtb dormancy with loss of acid fastness and accumulation of lipid droplets, which could be reactivated upon TNF blocking [383]. A more complex three-dimensional system based on human lung fibroblasts and epithelial cells forms innate granulomas by recruitment of monocytes to infected macrophages in an ESAT6-dependent manner [384]. Comparing granulomas from PBMCs from individuals with and without LTBI, granuloma formation was altered and Mtb growth controlled in PBMCs when individuals had LTBI [385].

Another model to study early granulomas without the influence of adaptive immunity is the embryonic zebra fish model. Infection with its natural pathogen $M$. marinum revealed the contribution of innate granuloma formation to dissemination of mycobacteria [386], and the central role of TNF in granuloma formation [387].

Constituting the most commonly used TB model, inbred mice are highly susceptible and have small granulomas characterized by absence of necrosis and hypoxia and high bacterial loads which are controlled from the onset of cell-mediated immunity [108, 300]. Mtb dormancy was modeled in the 'Cornell model' by sterilizing INH- and PZA-treatment of intravenously infected mice with a high burden of Mtb. After withdrawal of antibiotics, TB spontaneously reactivates in a part of the mice, and immunosuppression leads to reactivation in all mice [388]. Due to the inability to form CFU after antibiotic treatment, Mtb were believed to prevail in a dormant non-replicating state. In a low-dose aerosol infection model, $\mathrm{Mtb}$ was found to replicate very slowly during the latent phase, as determined by comparing CFUs and chromosomal equivalents (CEQ), the amount of DNA detected originating from both live and dead bacteria [389]. This was questioned by the infection with Mtb carrying the replication clock plasmid, allowing the determination of mycobacterial replication and killing when a net change in CFU is not observed. Mtb replicated significantly throughout the experiment, so also during the latent phase controlled by adaptive immune responses, and during the early phase of infection a substantial part of the bacilli were killed by innate immunity [390].

$\mathrm{TB}$ in rabbits and guinea pigs more closely resembles human disease as they develop hypoxic and fibrotic granulomas and cavities [300]. Rabbits exhibits latency and reactivate upon immunosuppression, while guinea pigs are highly susceptible and succumb quickly to infection [382]. 
Non-human primates (NHP) closely recapitulate human TB disease with a spectrum of disease states, human-like lesions, immunological responses and clinical outcomes. NHPs feature some key components of human immune responses that are absent in the other models, such as granulysin and CD1-restricted T cells [391]. When outbred cynomolgus macaques are infected with a low dose of Mtb, typically half of them progresses to primary $\mathrm{TB}$, while the other develop a clinically latent infection. Constituting the model closest to human LTBI, few later reactivate to active TB while reactivation can be induced by simian immunodeficiency virus (SIV) infection and TNF neutralization [102, 392, 393]. Pathology in active TB features granulomas similar to human disease, with cellular, necrotic, caseous and fibrotic lesions. Also asymptomatic macaques were found to harbor a range of different granuloma states and even fibrotic and mineralized lesions, but interestingly no nonnecrotizing cellular granulomas. Some monkeys cannot be assigned to either active or latent $\mathrm{TB}$, since they are asymptomatic but occasionally have positive Mtb cultures from bronchoalveolar lavage (BAL) or gastric aspirates which is not observed in the 'truly latent' animals. These macaques with subclinical disease are termed 'percolators' [102]. Repeated PET-CT imaging of animals allowed closer characterization of asymptomatic LTBI and disease progression, and led to the conclusion that lesions in animals with both active and latent TB are dynamic and individual units with individual outcomes, as both progressing and healing lesions manifest simultaneously within the same animal. Sterilization of lesion is common in both active and latent animals, and lesional characteristics overlap between both states. Not only in NHPs but also in humans the factors decisive for progression into active disease as opposed to subclincal asymptomatic TB (LTBI) are unknown. Bacterial phenotypes present in different lesions have not been studied in the NHP model, but similar numbers of CEQs were found in active lesions as compared to lesions that were sterile, indicating that bacteria had replicated to a similar extent but with opposing outcomes [103]. 


\section{Clinical implications of dormancy and persistence}

Constituting one of the major infectious diseases worldwide, effective TB treatment is essential to lower the fatality of cases and spread of the bacterium. With one third of the world population being latent carriers of $\mathrm{Mtb}$, there is a huge reservoir for reactivating disease. TB antibiotics are bacteriostatic or bactericidal and were developed to inhibit the growth or to kill Mtb in vitro, and they target processes essential for bacterial growth such as cell wall synthesis and RNA transcription. Combination of these drugs kills Mtb within days or even hours in vitro, but the same drugs take months to kill Mtb in patients. Eradication of Mtb during treatment typically follows a biphasic killing curve, similarly to the killing kinetics in a bacterial culture containing persisters (Figure 7A). Although time to sputum conversion in drug-susceptible TB is a few weeks, TB is treated for 6 to 9 months with a combination of initially four and later two drugs. A shorter TB treatment regimen could affect patient compliance positively and thereby avoid emergence of drug resistance and relapse. Shortening standard treatment from 6 to 4 months in patients that were sputum negative after 2 months of treatment significantly increased the risk of relapse [394].

The reasons for the requirement of lengthy treatment regimens and combination of several drugs with at times heavy side effects are many. TB lesions within one host are generally heterogeneous with different biochemical characteristics, impeding the access for drugs. In advanced granulomas, antibiotics need to diffuse from the vasculature through dense fibrotic and cellular layers to reach necrotic and caseous regions, and abundance in tissue is typically lower than in plasma [73]. This is exemplified by moxifloxacin that showed promising activity in mice and killed both replicating and anaerobic non-replicating Mtb in vitro. In contrast, the results from phase III clinical trials were disappointing, as no shortening of standard treatment regimen by addition of moxifloxacin could be achieved [77, 395]. Analysis of drug concentrations in TB lesions revealed that moxifloxacin successfully diffuses into cellular regions but fails to penetrate caseous acellular parts of granulomas, and thereby simply does not succeed in reaching a major bacterial subpopulation [73]. The major TB drug RIF diffuses efficiently into caseous regions, while PZA is distributed equally well in cellular and caseous regions [73]. These findings warrant evaluation of drug distribution and kinetics of accumulation in TB lesions for future drug development [396].

Besides spatial variations in drug abundance, mycobacteria are intrinsically tolerant to many antibiotics and are able to not only evade innate immune mechanisms but to thrive inside immune cells by interfering with macrophage defense mechanisms and by phenotypic adaptation to stresses encountered inside host cells and in granulomas. These phenotypic changes in Mtb have often been linked to antibiotic tolerance and persistence, as well as to 
the dormant state of Mtb during LTBI. With one third of the world population being latent carriers of $\mathrm{Mtb}$, there is a huge reservoir for reactivating disease, and both the phenotypes of dormant bacilli during latency as well as drug tolerant Mtb persistent to antibiotic treatment need to be taken into account when designing new treatments and vaccines.

Currently, it is not clear if dormant and persistent Mtb are phenotypically similar, and knowledge about these states has mainly been obtained from in vitro and animal models. Upon exposure to hypoxia and other stresses that Mtb is likely to encounter in vivo, Mtb ceases to replicate and is drug tolerant, and this non-replicating state has long been believed to be the underlying mechanism during LTBI and persistence. Several paradoxes emerged around this hypothesis, such as successful treatment of LTBI with INH monotherapy [80]. Generally, the WHO recommends preventive treatment of LTBI only in risk groups [16], and INH is given for 6 to 9 months [80]. Although clearly inactive against non-replicating $\mathrm{Mtb}$ in vitro, INH considerably decreases the risk for active disease in individuals with LTBI [80]. PZA on the other hand kills slow- and non-replicating bacteria and is essential for the success of standard TB treatment [397], indicating that non-replicating Mtb might also be part of the bacterial population [398].

Attempts to model latency in mice resulted in diverging results regarding the replicating status of bacilli $[389,390]$, and analysis of latent and active disease in the NHP model demonstrated that the number of CEQs in individual lesions in active and latent animals are similar, while CFUs are significantly different, indicating similar bacterial burden in both disease states but efficient killing only in latent animals [103]. This of course is not compatible with the view of dormant bacilli and quiescent infection during latency, but could constitute a phenomenon inherent to the macaque model.

Overall bacterial replication during latency does not exclude the possibility of the existence of a non-replicating population as well. Although the presence of non-replicating bacteria has not been directly demonstrated in humans, sputum samples from TB patients contain bacilli that fail to grow upon inoculation into liquid medium and even less so on solid agar. These bacteria are drug-tolerant and can be resuscitated with Rpfs, and non-growing but metabolically active (NGMA) Mtb exist in lesions from infected mice [325, 335, 338]. Growth arrest per se is not a prerequisite for drug tolerance [399], and replicating bacteria are refractory to drugs due to stochastic expression of gene products essential for drug efficacy [366] or by enhanced activity of efflux pumps [75]. In line with that, a recent study provided evidence for 'active persisters' in TB patients. Employing ${ }^{18}$ FDG-PET-CT scanning to monitor lesion activity during antibiotic treatment, many granulomas were found to abate and resolve, but still one third of patients showed intensified and new lesions [369]. Even if lesions intensified due to killed bacteria triggering local immune responses, the emergence of 
new lesions is hard to explain if not by ongoing infection. In the same study, sputum and BAL samples were analyzed and - although culture negative - often contained Mtb DNA and mRNA. The stable DNA molecules but not the rather instable mRNA could originate from dead and lysed bacilli, suggesting a non-culturable but viable Mtb population or at least bacilli with active transcription remaining in lesions after successful completion of $\mathrm{TB}$ treatment [369]. Under the assumption that emergence and increase of lesions during treatment reflects growing bacteria, it could indicate that different lesions contain different phenotypes, with for example non-culturable bacilli in cavitary lesions but growing Mtb in contained granulomas. This could add another level of complexity to TB immunopathogenesis, namely different Mtb phenotypes within different lesion types.
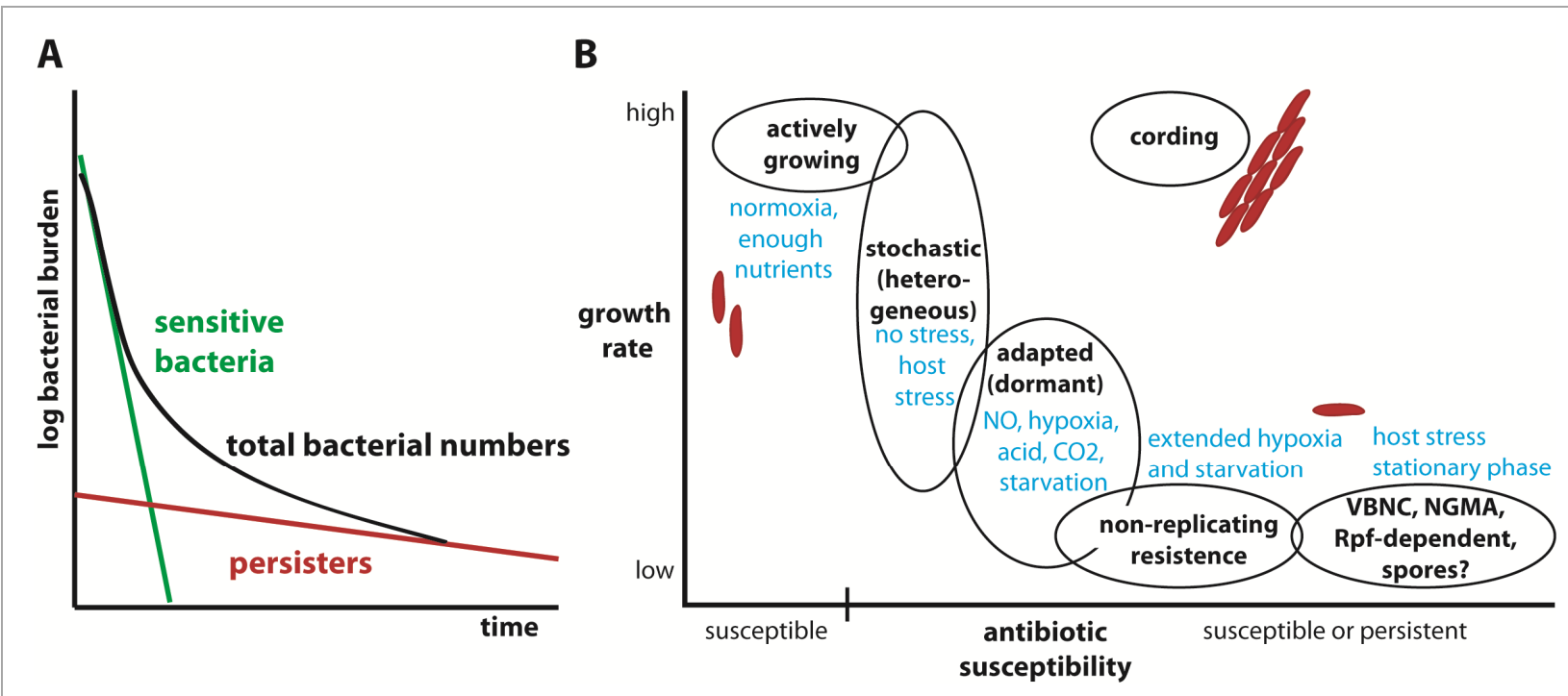

Figure 7. Mtb phenotypes. Antibiotic treatment of Mtb typically generates a bi-phasic killing curve, characterized by a strong early bactericidal effect killing drug-sensitive bacteria, followed by decreased killing due to the presence of persister phenotypes. Bi-phasic killing can for example be observed in vitro, in the sputum of TB patients and in experimentally infected mice (A). So far, many different phenotypes of Mtb have been defined and discussed in this thesis, and the graph in (B) attempts to summarize them, as well as the different conditions inducing their formation (written in blue). Antibiotic tolerance has been attributed to lower Mtb growth rates, but there are exceptions. Hypothetically, there is consistent overlap between different phenotypes, as many of them share similar features. For cording bacteria, the inducing factor is not known, but this phenotype has been observed in aerated cultures as well as in TB cavities. VBNC = viable but nonculturable, NGMA = non-growing but metabolically active, Rpf-dependent = resuscitationpromoting factor-dependent bacteria.

The physiological state of Mtb during LTBI is not any better defined than that of persisters. Bacilli have been found in lungs from individuals who died from other causes than TB, and tissues looked superficially normal [83]. Besides residing in healthy lung tissue, Mtb was found in several organs and in adipose tissue from individuals with LTBI [234, 235], indicating that dissemination might occur even without preceding active disease, explaining 
reactivation after latency without pulmonary involvement. Mtb in lung tissue is refractory to acid-fast staining due to cell wall alterations [233, 307], and models of LTBI suggest slowed replication, metabolic adaptation and accumulation of storage lipids. Similar features have been observed in bacteria in sputum from TB patients [319], but again it is not clear if and how expectorated bacilli from cavitary lesions resemble dormant bacilli during latency. Overall, the state of $\mathrm{Mtb}$ in sputum is rather poorly characterized considering that these bacteria are potentially infecting new hosts.

Many attempts have been made to model Mtb dormancy and persistence, and a mixture of several different states seems plausible and could in itself constitute a mechanism for survival inside a host. There is evidence for co-existence of different bacterial populations during latent infection as well as during and after TB treatment as depicted in Figure 7B. Different phenotypes could have overlapping features and could prevail in lesions with different characteristics. This of course complicates drug development, and warrants the development of new assays to test efficacy of antimicrobials. Screenings for antibiotics active against nonreplicating bacteria are ongoing or have recently been published [400], and it will be exciting to learn about their in vivo activity. Also, better understanding of the phenotype that the bacteria have during transmission could lead to prophylactic treatment to avoid transmission. 


\section{Aims}

The general aim of this thesis was to characterize how Mtb phenotypes interact with human macrophages and alter the outcome of the infection.

Paper 1: The aim was to elucidate the mechanism for intracellular Mtb growth restriction. Specifically, early events during infection were investigated, namely the acquisition of phagolysosomal markers by the Mtb-containing phagosome as well as phagolysosomal acidification.

Paper 2: Based on the findings from Paper I, the aim in this study was to characterize the infection model during extended time periods. Specifically, the phenotypic state of intracellular Mtb during low and high burden infection was investigated, as well as their intracellular replication rates and antibiotic susceptibility. The macrophage response to different bacterial burdens was assessed by analyzing released cytokines.

Paper 3: The aim was to investigate the interaction of macrophages with encapsulated Mtb carrying abundant ESAT6 on their surface. More specifically, the Mtb-associated ESAT6 during phagocytosis was assessed, as well as the cytotoxicity of encapsulated Mtb. 


\section{Results and Discussion}

Macrophages are the primary host cell for Mtb, and early interactions between bacteria and macrophages can play a major role for the outcome of infection. An earlier finding in our group led us to investigate Mtb-macrophage interaction at early and later time points during infection, and strikingly, restriction of bacterial growth correlated with the burden of infection. Low-burden infection was efficiently controlled by the host cells, whereas a higher multiplicity of infection (MOI) allowed intracellular bacterial replication leading to macrophage cell death. This central finding was investigated from the host point of view (Paper 1), aiming at identifying host factors involved in the bacterial growth control during low MOI infection and from a more bacterial point of view, asking which state the bacteria are in during situations with fundamentally different outcomes (Paper 2). Results from these papers then sparked investigations around secreted mycobacterial virulence factors, ultimately leading to Paper 3. Figure 8 summarizes the findings from this thesis.

\section{Phagosomal maturation}

The inhibition of phagosomal maturation is crucial for Mtb survival in host cells, and successful maturation arrest allows Mtb to replicate inside host cells in an unharmed manner, ultimately spreading to other cells and new hosts aided by secreted virulence factors. The conditions in the mycobacterial phagosome are well-studied, and phagosomal maturation arrest can be overcome by activation and stimulation of macrophages, for example by IFN $\gamma$ secreted from $T$ cells during adaptive responses $[185,186]$. Phagosomal maturation itself is a complex process of multiple fusion and fission events and ultimately leads to the acidification of the phagosome, recruitment of hydrolases and the generation of NOS [173], all of which collaborate to kill the bacterium or at least restrict mycobacterial replication. Due to the central role of phagosomal maturation for the outcome of infection, attempts have been made to identify potential drug targets by screening of Mtb mutants for incapability of arresting phagolysosomal fusion in functional screening assays [401]. Several mycobacterial effectors targeting and inhibiting or modulating different stages of the phagolysosomal maturation process have been identified, and this multitude highlights the relevance of maturation arrest for the pathogen. When conditions are detrimental for the bacterium, it is able to adapt to host responses and reside in a dormant state. Absence of bacterial net growth in viable macrophages during low MOI-infection suggested bacterial adaptation and absence or slowing of growth. In parallel, a tenfold higher MOI allowed Mtb replication with coinciding host cell death (Paper 2, Figure 1A and 1B).

Looking into the early events of macrophage infection, we found that recruitment of the late endosomal marker CD63 (LAMP-3) to Mtb-containing organelles occurred to the same 
extent in both cells infected with a low and a high burden of the virulent Mtb strain $\mathrm{H} 37 \mathrm{Rv}$ and the avirulent H37Ra (Paper 1, Figure 2A and 2B). CD63 translocation was lower than in macrophages infected with $\gamma$-irradiated $H 37 \mathrm{Rv}$, in line with reports that dead bacilli are unable to restrict phagosomal maturation [176], indicating that for the inhibition of CD63 recruitment soluble cell wall components are not sufficient but actively secreted effectors from live bacilli required.

The ultimate consequence of phagosomal maturation is the recruitment of the vATPase proton pump into the phagosomal membrane, leading to acidification of the organelle and enabling the activation of lysosomal hydrolases. Constituting a more functional readout for phagosome status, quantification of acidification allows conclusions about conditions prevailing in Mtb-containing compartments. After high burden infection, acidification of the Mtb-containing phagosome was effectively restricted, but macrophages infected with a lower bacterial burden achieved significantly higher acidification (Paper 1, Figure 3A and 3B). Although the avirulent $\mathrm{H} 37 \mathrm{Ra}$ were unable to replicate in our macrophages, acidification was inhibited to a similar extent as for $\mathrm{Mtb} \mathrm{H} 37 \mathrm{Rv}$ and in an MOI-dependent manner, indicating that both the virulent and avirulent strain carry the virulence factors leading to inhibition of acidification in human macrophages, while subsequently only the virulent strain is able to replicate. Differences in acidification between MOIs were observed as early as 4 hours after infection, whereas bacterial growth was similar during the first 24 hours (Paper 1, Figure 3B and Figure 1A). This could originate from ongoing bacterial replication at the time of infection that is not slowed upon delivery to acidic phagolysosomes and by lysosomal effectors within the first day yet, but later during the course of infection, reflecting that Mtb needs time to adapt to host pressures. Mtb is well equipped to withstand acidic conditions and hence slows its replication [247-249] as reflected in Paper 1, Figure 1A.

Arguing that phagolysosomal acidification is essential for growth restriction, we attempted to pharmacologically inhibit the vATPase with bafilomyin [402]. This abrogated growth restriction during low $\mathrm{MOI}$ infection, and $\mathrm{Mtb}$ numbers in Baf-treated macrophages were significantly higher than in untreated cells (Paper 1, Figure 4A). Cathepsin D is one of the lysosomal hydrolases active in acidified compartments, and inhibiting cathepsin $\mathrm{D}$ with pepstatin A had a similar effect as inhibition of acidification, leading to increased bacterial numbers (Paper 1, Figure 4B). Decreased control of intracellular BCG growth in macrophages treated with bafilomycin and pepstatin was confirmed by others [403]. Contrary to that, inhibition of the NADPH oxidase did not lead to increased bacterial numbers (Paper 1, Figure 4C), indicating that ROS-mediated bactericidal mechanisms are not effective. NADPH oxidase is recruited to the Mtb-containing phagosome upon stimulation with pro-inflammatory cytokines [173, 404], and neutralization of ROS by 
mycobacterial enzymes such as superoxide dismutase and catalase-peroxidase has been reported $[153,154]$, both of which could explain why we did not see an effect of NADPH inhibition in unstimulated macrophages.

Taken together, this study demonstrates the crucial role for phagolysosomal acidification and effector functions for the restriction of Mtb growth. Furthermore, lysosomal markers such as CD63 have only limited value as surrogate markers for phagolysosomal maturation, and our results suggest that functional readouts such as acidification and inhibitions of acidification and effector functions are better suited to study the state of Mtb-containing phagosomes. Furthermore, early events during macrophage infection seem to be decisive for the overall outcome of infection, since delivery of Mtb to functional phagolysosomes resulted in control of bacterial replication for up to two weeks (Paper 2, Figure 1). Therefore, enhancement of macrophage functions could lead more efficient phagolysosomal maturation and to increased control of Mtb replication or Mtb eradication.

\section{Mtb replication}

Experimental infection of human macrophages with Mtb typically permits intracellular replication, ultimately resulting in host cell necrosis or apoptosis. Measurement of intracellular bacterial numbers is commonly carried out by CFU plating, which is timeconsuming and often inaccurate due to technical difficulties. We therefore use a luciferasebased method to determine bacterial numbers both in the cell supernatant as well as in the cell lysate, and added fluorescence-based cell viability measurements [405]. Cell infection studies often abstain from cell viability measurements, which can lead to artifacts in the interpretation of results, as for as example a decrease in intracellular numbers of Mtb can be due to killing of Mtb or alternatively due to cell detachment upon host cell death. Another challenge in infection models is that quantification of bacterial numbers at a certain time point only yields a snap shot, and absence of a net increase of bacterial numbers between two time points does not necessarily represent absence of replication, but could imply mycobacterial replication and killing at equal rates. To differentiate between these situations, we used the replication clock plasmid, a low copy number mycobacterial plasmid that is lost from Mtb during replication at a constant rate [390]. In the mouse model, unchanged CFU numbers were believed to represent a chronic infection state with halted replication, but the replication clock plasmid proved ongoing replication and killing at similar rates, with enhanced replication rates when an immunosuppressant was added [390]. We adapted the replication clock plasmid for macrophage infection experiments, and investigated the replicative status of Mtb H37Rv during low- and high-burden infection, using an MOI of 1 and 10, respectively. Using the higher MOI, Mtb replicated inside hMDMs during the first week of infection causing 50\% loss of cell viability, with an estimated generation time of 76 
h (Paper 2, Figure 1 and 2). Intracellular bacterial replication and host cell death correlate strongly in our model, and induced the release of pro-inflammatory cytokines as well as antiinflammatory IL-10, which is typically co-induced with pro-inflammatory cytokines by TLR-dependent and independent stimuli in innate immune cells [406]. During infection with the lower bacterial burden no intracellular net growth of Mtb H37Rv could be observed for 10 days (Paper 2, Figure 1A and Supplementary Figure S1A). During the first 7 days of low MOI-infection, intracellular Mtb replicated little, were even less killed and divided on average once, whereas during the second week of infection, Mtb resumed growth and was killed to a higher extent (Paper 2, Figure 1 and 2). The cell viability of macrophages infected with the lower MOI did not significantly differ from uninfected macrophages at any time point (Paper 2, Figure 1B). Restriction of intracellular mycobacterial growth and integrity of host cells was reflected in the cytokines released, as all pro-inflammatory cytokines tested were undetectable or much lower compared to the amount released from MOI 10-infected cells. In contrast, significant amounts of the anti-inflammatory cytokine IL-10 were detected 3 days after infection, and as high as in MOI 10-infected macrophages by day 7 (Paper 2, Figure 1C). Taken together, the 'silent' (low MOI) infection was characterized by significantly slowed bacterial replication, maintained cell viability and low inflammatory responses.

\section{Intracellular Mtb phenotype}

We next investigated the phenotypic state of these bacilli during 'silent' infection, and one measure for phenotypic changes are alterations in the bacterial cell wall as well as metabolic changes. These manifest as altered acid fastness and accumulation of intrabacterial lipid droplets. Loss of acid fastness has been attributed to Mtb in superficially normal lung tissue from latently infected individuals [233] and was recapitulated in in vitro models subjecting Mtb to stress where loss of acid fastness coincided with a metabolic shift towards fatty acid metabolism [306, 374]. During dormancy, Mtb exploits host lipids, ultimately leading to the accumulation of bacterial storage lipids in the form of TAG, [105, 288, 306]. Combined acid fast and lipid droplet-staining revealed that $\mathrm{Mtb}$ adopts a significantly more active phenotype when replicating intracellularly during MOI 10-infection, whereas the proportion of acid fast and lipid droplet-positive bacilli remains unchanged during the low MOI infection, coinciding with slow bacterial replication (Paper 2, Figure 3). While others have demonstrated a shift of bacterial metabolism after phagocytosis inside of macrophages [288, 306], our model features a rather different initial Mtb phenotype, since we infect with bacilli already rather 'fatty' to begin with (Paper 2, Figure 3B). This is probably due to static and thereby oxygen-limited cultivation conditions, and agitation of our cultures by shaking profoundly altered the bacterial phenotype, with an increase in acid fastness and a decrease in lipid droplets (data not shown). The phenotype of Mtb in sputum has so far been poorly 
characterized, but besides a population of non-culturable but viable bacilli [325], intrabacterial lipid droplets have been demonstrated [319], and transcriptomic analysis of sputum bacilli revealed induction of dormancy-related genes [319, 407].

\section{Antibiotic susceptibility}

Having established macrophage infection models differing in intracellular bacterial replication rates and phenotypes as well as outcome, we next addressed the antibiotic susceptibility of intracellular bacilli. A few years back, there was little evidence for host cell induced tolerance, and antibiotic tolerance had mainly been attributed to absence of replication in dormant bacilli, explaining tolerance to antibiotics targeting growth mechanisms [365]. In the meantime, several studies have addressed these issues, and INH tolerance has been attributed to stochastic fluctuations of the INH-activating enzyme katG in a replication rate-independent manner [366] and host immunity amplified the heterogeneity of the bacterial population [338]. Furthermore, passage of M. marinum through macrophages induced drug tolerance, also here independent of the bacterial replication rate [378]. Recently, bacterial tolerance was demonstrated in activated macrophages, and was mainly attributed to nitrosative stress [381]. Whereas these studies used murine macrophages (or human macrophages cultivated at hypoxic conditions [306]), our results from human macrophages incubated in normoxia did not show intracellular tolerance, a finding that we expanded by prolonging antibiotic treatment times and by lowering drug concentrations to the levels inducing tolerance in macrophages in other studies [306, 378] (Paper 2, Figure 4). Although expressing iNOS, cultured human macrophages generally produce only small amounts of $\mathrm{NO}$ as compared to murine cells [253, 408], and evidence exists for a tighter regulation or epigenetic silencing of NO production [254, 409]. Several studies suggested a role for NO in human TB [140, 255, 256], but it is conceivable that NO production in human macrophages requires further activation signals. If induction of drug tolerance also in humans largely depends on RNS stress as demonstrated in mice [381], the choice of cells could explain why we did not observe antibiotic tolerance in vitro.

Recent studies evaluated bacterial transcriptomics of sputum Mtb during antibiotic therapy, and noted the transient induction of INH stress-related genes during the first days of treatment [320, 407]. In line with that, TB treatment enriched the lipid droplet-positive population in the sputum of patients [323]. When we tested if antibiotic treatment enriched the acid-fast or lipid droplet-positive bacterial phenotype inside macrophages, we did not observe any changes (data not shown). Also this could be linked to the inability of human macrophages to induce tolerance. 
Antibiotic treatment did not rescue macrophages from Mtb-induced cell death (Paper 2, Supplementary Figure S5), and while macrophages during MOI 10-infection succumb to a necrotic cell death mode [202], the nature of cell death in antibiotic-treated cells was not investigated. In vivo, efferocytosis mediates clearance of apoptotic cells and could contribute to clearance of bacteria and resolution of inflammation, at least in those lesions that resolve during treatment. The phenomenon of 'dose-dependency' in terms of correlation of bacterial burden and host cell death or clinical outcome was also demonstrated in other models, such as in mice and NHPs [102, 203].

Overall, our results (Paper 2) support the importance of phagolysosomal functionality, and indicate that early events during infection could be crucial for the infection outcome. Clinical studies support this notion, since for example vitamin D supplementation improves TB outcome, a phenomenon that has been linked to enhanced macrophage functions [282, 284], but could also be due to more systemic effects. In contrast to that, enhanced immunity induces drug tolerance during antibiotic treatment, and inhibitors preventing phenotypic adaptation of Mtb to host stresses could improve the efficiency of antibiotic treatment.

\section{ESAT6}

Slowed replication during low MOI-infection can be seen as an active process steered by $\mathrm{Mtb}$ in order to adapt and survive, whereas it could also constitute a process controlled by macrophages. Secretion of the Mtb virulence factor ESAT6 has been linked to induction of host cell death and escape from the phagosome [202, 215], and investigating if ESAT6 secretion can be inhibited by macrophage functions or is abrogated as a bacterial mechanism for adaptation seemed interesting, especially in our infection model featuring different outcomes in terms of bacterial replication and host cell death. ESAT6 antibody staining has not been shown inside infected macrophages, although the general notion supports secretion of ESAT6 inside host cells. We constructed plasmids allowing for expression of tagged ESAT6 and CFP10 (Paper 3, Supplementary Material and Methods), the proteins forming a stable 1:1-complex essential for secretion through the ESX-1 secretion system. The tags tested were hemagglutinin and c-mycosin, both ten amino acids in length. Shortness of the antigenic tags seemed crucial to allow for secretion of the fusion proteins. The tagged proteins were successfully expressed and most of them secreted from different Mtb strains, but antibody staining directed against the tags in infected macrophages did not lead to detectable levels of fusion proteins (data not shown). There are several possible explanations for the failure to detect the tagged proteins during macrophage infection, such as inhibition of secretion inside macrophages, too low levels of secreted proteins to allow for detection, or washout of membranes and potentially membrane-integrated ESAT6 during staining procedures. 
In most experimental studies, Mtb are cultured in broth containing detergent such as Tween-80 or tyloxapol to avoid aggregation of bacilli during growth. Omitting detergent from bacterial cultures has led to the discovery of the outermost layer of the mycobacterial cell wall, the capsule. ESX-1 secreted proteins have been suggested to reside in the capsule [35, 38], and cultivation without detergent revealed an electron-translucent zone surrounding Mtb and allowed us to immunolabel ESAT6 retained on the bacterial surface, whereas only small amounts of detergent led to loss of staining (Paper 3, Figure 1). Surface association of ESAT6 has already been suggested earlier, when ESAT6 was detected in the cell wall extract of Mtb. It is however unclear if bacilli were cultured with or without detergent, and if cell wall association could be due to the presence of the Mtb capsule [47].

Infection of human macrophages with Mtb 'coated' with ESAT6 led to rapid cell death, and this cytotoxicity could be attributed to the presence of ESAT6 as it was not observed during infection with ESAT6-deficient Mtb. Furthermore, ESAT6 staining was lost during macrophage infection in a manner dependent on contact between bacilli and macrophages (Paper 3, Figure 2). ESAT6 has been shown to integrate into artificial membranes which could explain the rapid loss of antibody staining [65]. Failure to stain ESAT6 inside infected macrophages was not due to insufficient permeabilization or due to conformational changes at the lower $\mathrm{pH}$ potentially encountered inside phagolysosomes (Paper 3, Supplementary Figure $1 \mathrm{~B}$ and 2D). Therefore, we speculate that ESAT6 readily integrates into the plasma membrane upon cell contact, and leads to early phagosome rupture and subsequent host cell death (Figure 12). The requirement of low $\mathrm{pH}$ for ESAT6-induced membrane lysis is controversial, with biochemical analyses suggesting that a low $\mathrm{pH}$ of 5.0 or lower is a prerequisite for lysis of artificial membranes by recombinant ESAT [61, 65], whereas native ESAT6 purified from Mtb could exert lysis at neutral $\mathrm{pH}$ but acidic conditions were required for the dissociation of the ESAT6-CFP10 complex [59]. Yet another study demonstrated membrane lysis by both recombinant ESAT6 and a ESAT6-CFP10 dimer at neutral $\mathrm{pH}$ [410]. These discrepancies could be due to posttranslational modifications in native ESAT6 not present in recombinant protein [52] and the different membrane models used.

Some evidence however is questioning the central role of secreted ESAT6 for Mtb virulence, as for example blocked ESAT6 and CFP10 secretion due to a point mutation in EspA, an ESX-1 substrate co-secreted with the ESAT6-CFP10 dimer, did not reduce virulence in macrophages and in vivo, constituting the unique case of disconnection of ESAT6 secretion and virulence [411]. Failure to detect secreted ESAT6 could be due to lower levels of secretion and bacilli being cultured in detergent-free medium, leading to surface retention of ESX-1 substrates. Similarly, genetic complementation of $M$. marinum mutants unable to 
secrete ESAT6 only partially restored virulence, and was mediated by surface-associated ESAT6 [412]. This supports our findings of rapid cell death after ingestion of bacilli with surface-associated ESAT6, and loss of ESAT6 staining observed upon dilution of bacterial cultures in neutral or acidic buffers could represent diffusion of excess surface-associated ESAT6 into the medium.

Although we did not analyze phagosomal rupture, rapid host cell death within $24 \mathrm{~h}$ of infection is indicative of early escape or phagosomal membrane disintegration, which others have shown to occur within hours of infection, even with Mtb cultivated in detergent [184, 215]. Inhibition of phagolysosomal acidification was suggested to be a prerequisite for rupture [184]. Controversially, upregulation of the expression of ESX-1 components in acidic $\mathrm{pH}$ was reported, which could constitute an ultimate escape mechanism from acidified phagolysosomes [413], while other studies report downregulation during macrophage infection [244, 272]. The controversy around $\mathrm{pH}$ conditions for ESX-1 expression, membrane lysis and escape could be due to experimental conditions involving the use of artificial membranes and recombinant proteins, as well as differences between host cell and mycobacterial species.

The phenotype of Mtb bacilli in sputum from TB patients is not very well characterized, and it is unknown if and why these bacteria carry a capsule and superficial virulence factors. There is the possibility that superficial ESAT6 does not represent a physiological state of $\mathrm{Mtb}$ in vivo, and is simply due to specific cultivation conditions. We were however unable to detect ESAT6 in infected macrophages by immunolabeling, although ESAT6 clearly was present on bacilli before contact with macrophages. Our study as well as findings from others warrant a re-evaluation of cultivation conditions for experimental studies, since the sole presence of a mycobacterial capsule elicited differential responses in macrophages and in a murine vaccination model, and cultivation without detergent profoundly altered the transcriptome of $\mathrm{Mtb}[356,359]$.

In summary, this thesis describes mechanisms of both macrophages and Mtb aiding at tipping the balance of interaction to the respective side. Whereas host cells benefit from efficient phagolysosomal defenses, Mtb benefits from adaptation to host cells and slow growth for survival as well as from replication and host cell death when conditions are favorable. Furthermore, Mtb carrying a capsule are equipped to rapidly kill host cell, whereas the physiological significance of this phenotype is not yet uncovered. 

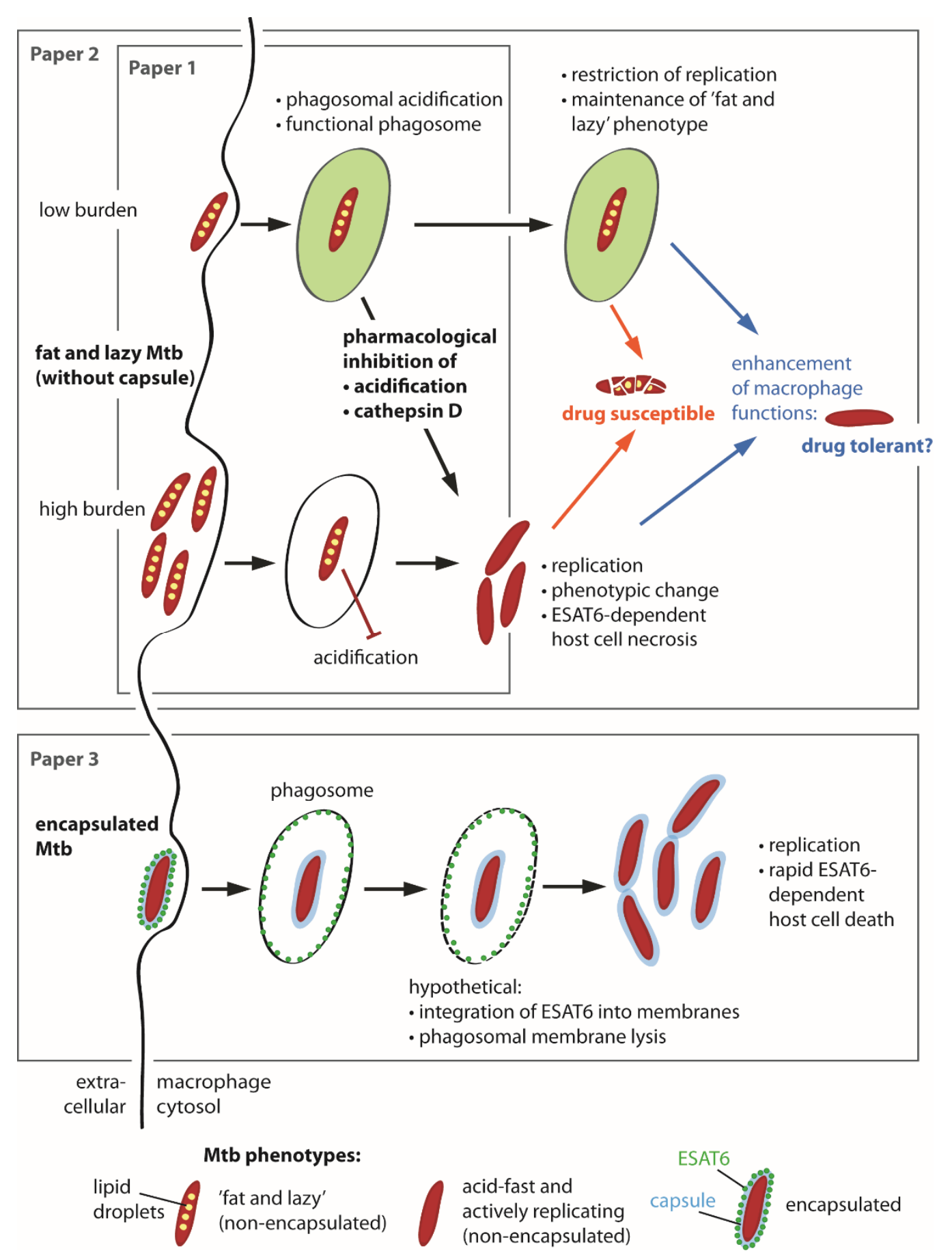

Figure 8 Mtb phenotypes and their interaction with macrophages. Infection with 'fat and lazy' Mtb leads to different outcomes, depending on the initial bacterial burden (Paper 2). Highburden infection leads to necrotic cell death, as shown by Welin et al. [202]. Bacterial replication is restricted by phagolysosomal effectors (Paper 1). Although we did not observe drug tolerance of intracellular Mtb, activation of cells hypothetically induces drug tolerance, as demonstrated by Liu et al. for murine macrophages [381]. Encapsulated Mtb with ESAT6 on their surface lead to rapid ESAT6-dependent host cell death, hypothetically via integration of ESAT6 into host membranes and membrane lysis (Paper 3). 


\section{Concluding remarks and outlook}

Tuberculosis has plagued humankind throughout history, and although the causative agent, Mtb, has been known for more than 130 years, no effective vaccine is available, and treatment of TB is still lengthy and complicated. Vaccine and drug discovery is impeded by the splendid adaptive capabilities of Mtb which favor intracellular survival and insufficient host responses. Furthermore, Mtb can remain in a latent state for decades, pointing at mechanisms that sense the right time point for resumed activity, ultimately leading to transmission.

This thesis aimed at studying host cell mechanisms conferring control of Mtb replication, as well as the effect of bacterial phenotypes on host cells. Different Mtb phenotypes have been acknowledged to play a role during LTBI as well as being the cause for drug tolerance and the resulting extensive treatment regimens. Being able to withstand antibiotic treatment and to even replicate under antibiotic pressure, Mtb persisters pose the major challenge in $\mathrm{TB}$ drug discovery.

We here developed a macrophage infection model characterized by restriction of bacterial replication. Contrary to other in vitro models, intracellular slow-growing Mtb were not more drug tolerant compared to their replicating phenotypic counterpart. Recent evidence suggests that $\mathrm{NO}$ is the major host effector driving induction of drug tolerance inside macrophages [381], but NO production is also host-protective. This ambivalence regarding the effects of NO is not surprising, as Mtb obviously has learned to cope with host pressures. Therefore, studying possible effects of $\mathrm{NO}$ regarding drug tolerance in human macrophages could be of great interest. Better knowledge of the mechanisms inducing drug tolerance in Mtb inside host cells could lead to the development of drugs that inhibit mycobacterial adaptation and act in synergy with current antibiotics to shorten treatment.

Turning to host functions, our infection model suggests that human macrophages are able to restrict Mtb growth when infected with a low bacterial burden. Future studies could address whether macrophage functions can be strengthened in order to even cope with higher bacterial burdens, leading to the maintenance of a 'fat and lazy' Mtb phenotype with restricted replication rather than to bacterial replication and host cell death. This could lead to the development of host-directed therapies, which has been extensively discussed as an alternative or adjunct to antibiotic treatment.

Identification of an encapsulated Mtb phenotype with increased cytotoxicity warrants reevaluation of experimental Mtb cultivation conditions. In our infection model featuring encapsulated bacteria, the proposed membrane-integration and membrane-lysing activity of 
the Mtb virulence factors ESAT6 should be investigated, as well as how membrane-rupture can be avoided. A closer characterization of the direct effects of ESAT6 will lead to increased understanding of basic virulence mechanisms and could stimulate the targeted development of virulence blockers. 


\section{References}

1. Daniel, T.M., The history of tuberculosis. Respiratory Medicine, 2006. 100(11): p. 1862-70.

2. Herzog, H., History of tuberculosis. Respiration; international review of thoracic diseases, 1998. 65(1): p. 5-15.

3. Nerlich, A.G., et al., Molecular evidence for tuberculosis in an ancient Egyptian mummy. The Lancet, 1997. 350(9088): p. 1404.

4. Donoghue, H.D., et al., Tuberculosis in Dr Granville's mummy: a molecular re-examination of the earliest known Egyptian mummy to be scientifically examined and given a medical diagnosis. Proc Biol Sci, 2010. 277(1678): p. 51-6.

5. Crubézy, E., et al., Identification of Mycobacterium DNA in an Egyptian Pott's disease of 5400 years old. Comptes Rendus de l'Académie des Sciences - Series III - Sciences de la Vie, 1998. 321(11): p. 941951.

6. Zimmerman, M.R., Pulmonary and osseous tuberculosis in an Egyptian mummy. Bulletin of the New York Academy of Medicine, 1979. 55(6): p. 604-608.

7. Brosch, R., et al., A new evolutionary scenario for the Mycobacterium tuberculosis complex. Proceedings of the National Academy of Sciences of the United States of America, 2002. 99(6): p. 3684-9.

8. Gutierrez, M.C., et al., Ancient origin and gene mosaicism of the progenitor of Mycobacterium tuberculosis. PLoS Pathog, 2005. 1(1): p. e5.

9. Chisholm, R.H., et al., Controlled fire use in early humans might have triggered the evolutionary emergence of tuberculosis. Proceedings of the National Academy of Sciences of the United States of America, 2016.

10. Comas, I., et al., Out-of-Africa migration and Neolithic coexpansion of Mycobacterium tuberculosis with modern humans. Nature genetics, 2013. 45(10): p. 1176-1182.

11. Gagneux, S., Host-pathogen coevolution in human tuberculosis. Philosophical Transactions of the Royal Society B: Biological Sciences, 2012. 367(1590): p. 850-859.

12. Hippocrates, The Genuine Works of Hippocrates 1868: Charles Darwin Adams, New York. Retrieved from http://www.perseus.tufts.edu/hopper/text?doc=Perseus:abo:tlg,0627,006:1:1 on 2016-08-11.

13. McCarthy, O.R., The key to the sanatoria. Journal of the Royal Society of Medicine, 2001. 94(8): p. 413-7.

14. Keshavjee, S. and P.E. Farmer, Tuberculosis, drug resistance, and the history of modern medicine. The New England journal of medicine, 2012. 367(10): p. 931-6.

15. Crofton, J. and D.A. Mitchison, Streptomycin resistance in pulmonary tuberculosis. British medical journal, 1948. 2(4588): p. 1009-15.

16. WHO, Global Tuberculosis Report, in WHO Reports2015, WHO: Geneva, Switzerland.

17. Lawn, S.D. and A.I. Zumla, Tuberculosis. Lancet, 2011. 378(9785): p. 57-72.

18. Clark, M., P. Riben, and E. Nowgesic, The association of housing density, isolation and tuberculosis in Canadian First Nations communities. International Journal of Epidemiology, 2002. 31(5): p. 940 945.

19. Moller, M., E. de Wit, and E.G. Hoal, Past, present and future directions in human genetic susceptibility to tuberculosis. FEMS immunology and medical microbiology, 2010. 58(1): p. 3-26.

20. World_Health_Organization. World : Estimated TB incidence rates, 2014 2015; Available from: http:/gamapserver.who.int/mapLibrary/Files/Maps/Global TBincidence 2014.png.

21. Ducati, R.G., et al., The resumption of consumption -- a review on tuberculosis. Memorias do Instituto Oswaldo Cruz, 2006. 101(7): p. 697-714.

22. Aldridge, B.B., et al., Asymmetry and aging of mycobacterial cells lead to variable growth and antibiotic susceptibility. Science (New York, N.Y.), 2012. 335(6064): p. 100-104.

23. Joyce, G., et al., Cell division site placement and asymmetric growth in mycobacteria. PLoS One, 2012. $7(9)$. 
24. Santi, I., et al., Single-cell dynamics of the chromosome replication and cell division cycles in mycobacteria. Nature communications, 2013. 4: p. 2470.

25. Kieser, K.J. and E.J. Rubin, How sisters grow apart: mycobacterial growth and division. Nature reviews. Microbiology, 2014. 12(8): p. 550-62.

26. Hett, E.C. and E.J. Rubin, Bacterial growth and cell division: a mycobacterial perspective. Microbiology and molecular biology reviews : MMBR, 2008. 72(1): p. 126-56, table of contents.

27. Karakousis, P.C., W.R. Bishai, and S.E. Dorman, Mycobacterium tuberculosis cell envelope lipids and the host immune response. Cellular Microbiology, 2004. 6(2): p. 105-16.

28. Abdallah, A.M., et al., Type VII secretion--mycobacteria show the way. Nature reviews. Microbiology, 2007. 5(11): p. 883-91.

29. Rastogi, N., C. Frehel, and H.L. David, Triple-layered structure of mycobacterial cell wall: Evidence for the existence of a polysaccharide-rich outer layer in 18 mycobacterial species. Current microbiology, 1986. 13(5): p. 237-242.

30. Frehel, C., et al., The electron-transparent zone in phagocytized Mycobacterium avium and other mycobacteria: formation, persistence and role in bacterial survival. Annales de l'Institut Pasteur. Microbiologie, 1986. 137B(3): p. 239-57.

31. Jankute, M., et al., Assembly of the Mycobacterial Cell Wall. Annual Review of Microbiology, 2015. 69: p. 405-23.

32. Daffé, M. and M.-A. Lanée, Analysis of the Capsule of Mycobacterium tuberculosis, in Mycobacterium tuberculosis Protocols, T. Parish and N.G. Stoker, Editors. 2001, Humana Press: Totowa, NJ. p. 217227.

33. Ortalo-Magné, A., et al., Identification of the surface-exposed lipids on the cell envelopes of Mycobacterium tuberculosis and other mycobacterial species. Journal of Bacteriology, 1996. 178(2): p. 456-461.

34. Ortalo-Magne, A., et al., Molecular composition of the outermost capsular material of the tubercle bacillus. Microbiology, 1995. 141 ( Pt 7): p. 1609-20.

35. Daffe, M. and G. Etienne, The capsule of Mycobacterium tuberculosis and its implications for pathogenicity. Tubercle and lung disease : the official journal of the International Union against Tuberculosis and Lung Disease, 1999. 79(3): p. 153-69.

36. Fréhel, C., et al., Do test tube-grown pathogenic mycobacteria possess a protective capsule? FEMS Microbiology Letters, 1988. 56(2): p. 225-229.

37. Daffe, M., The cell envelope of tubercle bacilli. Tuberculosis, 2015. 95 Suppl 1: p. S155-8.

38. Sani, M., et al., Direct visualization by cryo-EM of the mycobacterial capsular layer: a labile structure containing ESX-1-secreted proteins. PLoS pathogens, 2010. 6(3): p. e1000794.

39. Lemassu, A., et al., Extracellular and surface-exposed polysaccharides of non-tuberculous mycobacteria. Microbiology, 1996. 142 ( Pt 6): p. 1513-20.

40. Chapman, G.B., J.H. Hanks, and J.H. Wallace, An electron microscope study of the disposition and fine structure of Mycobacterium lepraemurium in mouse spleen. Journal of Bacteriology, 1959.

41. Draper, P. and R.J. Rees, The nature of the electron-transparent zone that surrounds Mycobacterium lepraemurium inside host cells. J Gen Microbiol, 1973. 77(1): p. 79-87.

42. Niederweis, M., Mycobacterial porins--new channel proteins in unique outer membranes. Molecular Microbiology, 2003. 49(5): p. 1167-77.

43. Champion, P.A. and J.S. Cox, Protein secretion systems in Mycobacteria. Cellular Microbiology, 2007. 9(6): p. 1376-84.

44. Bitter, W. and C. Kuijl, Targeting bacterial virulence: the coming out of type VII secretion inhibitors. Cell Host \& Microbe, 2014. 16(4): p. 430-2.

45. Simeone, R., et al., ESX/type VII secretion systems of mycobacteria: Insights into evolution, pathogenicity and protection. Tuberculosis (Edinburgh, Scotland), 2015. 95 Suppl 1: p. 4.

46. Mahairas, G.G., et al., Molecular analysis of genetic differences between Mycobacterium bovis BCG and virulent M. bovis. Journal of Bacteriology, 1996. 178(5): p. 1274-1282. 
47. Pym, A.S., et al., Loss of RD1 contributed to the attenuation of the live tuberculosis vaccines Mycobacterium bovis BCG and Mycobacterium microti. Molecular Microbiology, 2002.

48. Harboe, M., et al., Evidence for occurrence of the ESAT-6 protein in Mycobacterium tuberculosis and virulent Mycobacterium bovis and for its absence in Mycobacterium bovis BCG. Infection and immunity, 1996. 64(1): p. 16-22.

49. Stoop, E.J., W. Bitter, and A.M. van der Sar, Tubercle bacilli rely on a type VII army for pathogenicity. Trends in microbiology, 2012. 20(10): p. 477-84.

50. Burts, M.L., et al., EsxA and EsxB are secreted by an ESAT-6-like system that is required for the pathogenesis of Staphylococcus aureus infections. Proceedings of the National Academy of Sciences of the United States of America, 2005. 102(4): p. 1169-74.

51. Garufi, G., E. Butler, and D. Missiakas, ESAT-6-like protein secretion in Bacillus anthracis. Journal of Bacteriology, 2008. 190(21): p. 7004-11.

52. Okkels, L.M., et al., CFP10 discriminates between nonacetylated and acetylated ESAT-6 of Mycobacterium tuberculosis by differential interaction. Proteomics, 2004. 4(10): p. 2954-60.

53. Champion, P.A., et al., C-terminal signal sequence promotes virulence factor secretion in Mycobacterium tuberculosis. Science, 2006. 313(5793): p. 1632-6.

54. Renshaw, P.S., et al., Structure and function of the complex formed by the tuberculosis virulence factors CFP-10 and ESAT-6. The EMBO journal, 2005. 24(14): p. 2491-8.

55. Renshaw, P.S., et al., Conclusive evidence that the major T-cell antigens of the Mycobacterium tuberculosis complex ESAT-6 and CFP-10 form a tight, 1:1 complex and characterization of the structural properties of ESAT-6, CFP-10, and the ESAT- ${ }^{*} C F P-10$ complex. Implications for pathogenesis and virulence. The Journal of biological chemistry, 2002. 277(24): p. 21598-603.

56. Stanley, S.A., et al., Acute infection and macrophage subversion by Mycobacterium tuberculosis require a specialized secretion system. Proceedings of the National Academy of Sciences of the United States of America, 2003. 100(22): p. 13001-6.

57. Brodin, P., et al., Functional analysis of early secreted antigenic target-6, the dominant T-cell antigen of Mycobacterium tuberculosis, reveals key residues involved in secretion, complex formation, virulence, and immunogenicity. The Journal of biological chemistry, 2005. 280(40): p. 33953-9.

58. Daleke, M.H., et al., General secretion signal for the mycobacterial type VII secretion pathway. Proceedings of the National Academy of Sciences of the United States of America, 2012. 109(28): p. 11342-7.

59. de Jonge, M.I., et al., ESAT-6 from Mycobacterium tuberculosis dissociates from its putative chaperone CFP-10 under acidic conditions and exhibits membrane-lysing activity. Journal of Bacteriology, 2007. 189(16): p. 6028-34.

60. Lightbody, K.L., et al., Molecular Features Governing the Stability and Specificity of Functional Complex Formation by Mycobacterium tuberculosis CFP-10/ESAT-6 Family Proteins. Journal of Biological Chemistry, 2008. 283(25).

61. De Leon, J., et al., Mycobacterium tuberculosis ESAT-6 exhibits a unique membrane-interacting activity that is not found in its ortholog from non-pathogenic Mycobacterium smegmatis. The Journal of biological chemistry, 2012. 287(53): p. 44184-91.

62. Hsu, T., et al., The primary mechanism of attenuation of bacillus Calmette-Guerin is a loss of secreted lytic function required for invasion of lung interstitial tissue. Proceedings of the National Academy of Sciences of the United States of America, 2003. 100(21): p. 12420-12425.

63. Smith, J., et al., Evidence for pore formation in host cell membranes by ESX-1-secreted ESAT-6 and its role in Mycobacterium marinum escape from the vacuole. Infection and immunity, 2008. 76(12): p. 5478-5487.

64. Peng, X., et al., Characterization of differential pore-forming activities of ESAT-6 proteins from Mycobacterium tuberculosis and Mycobacterium smegmatis. FEBS Letters, 2016. 590(4): p. 509-19.

65. Ma, Y., V. Keil, and J. Sun, Characterization of Mycobacterium tuberculosis EsxA membrane insertion: roles of $N$ - and C-terminal flexible arms and central helix-turn-helix motif. The Journal of biological chemistry, 2015. 290(11): p. 7314-22. 
66. Frigui, W., et al., Control of M. tuberculosis ESAT-6 secretion and specific T cell recognition by PhoP. PLoS pathogens, 2008. 4(2): p. e33.

67. Zhang, Y., et al., The catalase-peroxidase gene and isoniazid resistance of Mycobacterium tuberculosis. Nature, 1992. 358(6387): p. 591-3.

68. Zhang, Y., The magic bullets and tuberculosis drug targets. Annual review of pharmacology and toxicology, 2005. 45: p. 529-64.

69. Zumla, A., P. Nahid, and S.T. Cole, Advances in the development of new tuberculosis drugs and treatment regimens. Nature Reviews Drug Discovery, 2013. 12(5): p. 388-404.

70. Dheda, K., C.E. Barry, 3rd, and G. Maartens, Tuberculosis. Lancet, 2016. 387(10024): p. 1211-26.

71. Boritsch, E.C., et al., Key experimental evidence of chromosomal DNA transfer among selected tuberculosis-causing mycobacteria. Proceedings of the National Academy of Sciences of the United States of America, 2016. 113(35): p. 9876-9881.

72. Eldholm, V. and F. Balloux, Antimicrobial Resistance in Mycobacterium tuberculosis: The Odd One Out. Trends in microbiology, 2016. 24(8): p. 637-648.

73. Prideaux, B., et al., The association between sterilizing activity and drug distribution into tuberculosis lesions. Nature medicine, 2015.

74. Pienaar, E., et al., A computational tool integrating host immunity with antibiotic dynamics to study tuberculosis treatment. Journal of theoretical biology, 2014. 367.

75. Sarathy, J., V. Dartois, and E. Lee, The Role of Transport Mechanisms in Mycobacterium Tuberculosis Drug Resistance and Tolerance. Pharmaceuticals, 2012. 5(11): p. 1210-1235.

76. Miyazaki, E., et al., Moxifloxacin (BAY12-8039), a new 8-methoxyquinolone, is active in a mouse model of tuberculosis. Antimicrobial agents and chemotherapy, 1999. 43(1): p. 85-9.

77. Gillespie, S.H., et al., Four-month moxifloxacin-based regimens for drug-sensitive tuberculosis. The New England journal of medicine, 2014. 371(17): p. 1577-87.

78. Warrier, T., et al., N-methylation of a bactericidal compound as a resistance mechanism in Mycobacterium tuberculosis. Proceedings of the National Academy of Sciences, 2016. 113(31).

79. Grosset, J., Mycobacterium tuberculosis in the extracellular compartment: an underestimated adversary. Antimicrobial agents and chemotherapy, 2003. 47(3): p. 833-6.

80. Getahun, H., et al., Latent Mycobacterium tuberculosis infection. The New England journal of medicine, 2015. 372(22): p. 2127-35.

81. Kwan, C.K. and J.D. Ernst, HIV and tuberculosis: a deadly human syndemic. Clinical microbiology reviews, 2011. 24(2): p. 351-76.

82. Verver, S., et al., Rate of Reinfection Tuberculosis after Successful Treatment Is Higher than Rate of New Tuberculosis. American Journal of Respiratory and Critical Care Medicine, 2005. 171(12): p. 14301435.

83. Hernandez-Pando, R., et al., Persistence of DNA from Mycobacterium tuberculosis in superficially normal lung tissue during latent infection. Lancet, 2000. 356(9248): p. 2133-8.

84. Fox, G.J., et al., Contact investigation for tuberculosis: a systematic review and meta-analysis. The European respiratory journal, 2013. 41(1): p. 140-56.

85. Morrison, J., M. Pai, and P.C. Hopewell, Tuberculosis and latent tuberculosis infection in close contacts of people with pulmonary tuberculosis in low-income and middle-income countries: a systematic review and meta-analysis. The Lancet infectious diseases, 2008. 8(6): p. 359-68.

86. Hawn, T.R., et al., Tuberculosis Vaccines and Prevention of Infection. Microbiology and Molecular Biology Reviews, 2014. 78(4): p. 650-671.

87. Donald, P.R., Childhood tuberculosis: the hidden epidemic. The international journal of tuberculosis and lung disease : the official journal of the International Union against Tuberculosis and Lung Disease, 2004. 8(5): p. 627-629.

88. Donald, P.R., B.J. Marais, and C.E. Barry, Age and the epidemiology and pathogenesis of tuberculosis. Lancet (London, England), 2010. 375(9729): p. 1852-1854.

89. Zumla, A., et al., Tuberculosis. The New England journal of medicine, 2013. 368(8): p. 745-55. 
90. Shaler, C.R., et al., Within the Enemy's Camp: contribution of the granuloma to the dissemination, persistence and transmission of Mycobacterium tuberculosis. Frontiers in immunology, 2013. 4: p. 30.

91. O'Garra, A., et al., The immune response in tuberculosis. Annual review of immunology, 2013. 31: p. 475-527.

92. Jasenosky, L.D., et al., $T$ cells and adaptive immunity to Mycobacterium tuberculosis in humans. Immunological Reviews, 2015. 264(1): p. 74-87.

93. Urdahl, K.B., S. Shafiani, and J.D. Ernst, Initiation and regulation of T-cell responses in tuberculosis. Mucosal immunology, 2011. 4(3): p. 288-293.

94. Gutierrez, M.G., et al., Autophagy is a defense mechanism inhibiting BCG and Mycobacterium tuberculosis survival in infected macrophages. Cell, 2004. 119(6): p. 753-766.

95. Fabri, M., et al., Vitamin $D$ is required for IFN-gamma-mediated antimicrobial activity of human macrophages. Science translational medicine, 2011. 3(104): p. $104 \mathrm{ra} 102$.

96. Stenger, S., et al., An antimicrobial activity of cytolytic T cells mediated by granulysin. Science, 1998. 282(5386): p. 121-5.

97. Woodworth, J.S. and S.M. Behar, Mycobacterium tuberculosis-specific CD8+T cells and their role in immunity. Critical Reviews in Immunology, 2006. 26(4): p. 317-52.

98. Nunes-Alves, C., et al., In search of a new paradigm for protective immunity to TB. Nature reviews. Microbiology, 2014. 12(4): p. 289-99.

99. Martin, C.J., et al., Efferocytosis is an innate antibacterial mechanism. Cell Host \& Microbe, 2012. 12(3): p. 289-300.

100. Ulrichs, T., et al., Human tuberculous granulomas induce peripheral lymphoid follicle-like structures to orchestrate local host defence in the lung. The Journal of pathology, 2004. 204(2): p. 217-28.

101. Dorhoi, A., S.T. Reece, and S.H. Kaufmann, For better or for worse: the immune response against Mycobacterium tuberculosis balances pathology and protection. Immunological Reviews, 2011. 240(1): p. 235-51.

102. Lin, P.L., et al., Quantitative comparison of active and latent tuberculosis in the cynomolgus macaque model. Infection and immunity, 2009. 77(10): p. 4631-42.

103. Lin, P.L., et al., Sterilization of granulomas is common in active and latent tuberculosis despite withinhost variability in bacterial killing. Nature medicine, 2014. 20(1): p. 75-9.

104. Lin, P.L., et al., Early events in Mycobacterium tuberculosis infection in cynomolgus macaques. Infect Immun, 2006. 74(7): p. 3790-803.

105. Peyron, P., et al., Foamy macrophages from tuberculous patients' granulomas constitute a nutrient-rich reservoir for M. tuberculosis persistence. PLoS Pathog, 2008. 4(11): p. e1000204.

106. Russell, D.G., et al., Foamy macrophages and the progression of the human tuberculosis granuloma. Nature immunology, 2009. 10(9): p. 943-948.

107. Kim, M.-J.J., et al., Caseation of human tuberculosis granulomas correlates with elevated host lipid metabolism. EMBO molecular medicine, 2010. 2(7): p. 258-274.

108. Tsai, M.C., et al., Characterization of the tuberculous granuloma in murine and human lungs: cellular composition and relative tissue oxygen tension. Cellular Microbiology, 2006. 8(2): p. 218-232.

109. Belton, M., et al., Hypoxia and tissue destruction in pulmonary TB. Thorax, 2016.

110. Comas, I., et al., Human T cell epitopes of Mycobacterium tuberculosis are evolutionarily hyperconserved. Nature genetics, 2010. 42(6): p. 498-503.

111. Ramakrishnan, L., Revisiting the role of the granuloma in tuberculosis. Nature Reviews Immunology, 2012. 12(5): p. 352-366.

112. Coscolla, M., et al., M. tuberculosis T Cell Epitope Analysis Reveals Paucity of Antigenic Variation and Identifies Rare Variable TB Antigens. Cell Host Microbe, 2015. 18(5): p. 538-48.

113. Pai, M., et al., Gamma interferon release assays for detection of Mycobacterium tuberculosis infection. Clinical microbiology reviews, 2014. 27(1): p. 3-20.

114. Raja, S., et al., Technology for automated, rapid, and quantitative PCR or reverse transcription-PCR clinical testing. Clinical chemistry, 2005. 51(5): p. 882-90. 
115. Moore, D.A., et al., Microscopic-observation drug-susceptibility assay for the diagnosis of TB. The New England journal of medicine, 2006. 355(15): p. 1539-50.

116. Lawn, S.D., Point-of-care detection of lipoarabinomannan (LAM) in urine for diagnosis of HIVassociated tuberculosis: a state of the art review. BMC infectious diseases, 2012. 12: p. 103.

117. Pillay, M. and A.W. Sturm, Evolution of the extensively drug-resistant F15/LAM4/KZN strain of Mycobacterium tuberculosis in KwaZulu-Natal, South Africa. Clinical infectious diseases : an official publication of the Infectious Diseases Society of America, 2007. 45(11): p. 1409-1414.

118. Bell, L., et al., Paradoxical reactions and immune reconstitution inflammatory syndrome in tuberculosis. International Journal of Infectious Diseases, 2015. 32: p. 39-45.

119. Wallis, R.S., et al., Tuberculosis--advances in development of new drugs, treatment regimens, host-directed therapies, and biomarkers. The Lancet. Infectious diseases, 2016. 16(4): p. e34-46.

120. Rybniker, J., et al., Anticytolytic Screen Identifies Inhibitors of Mycobacterial Virulence Protein Secretion. Cell Host \& Microbe, 2014. 16(4).

121. Mascart, F. and C. Locht, Integrating knowledge ofMycobacterium tuberculosispathogenesis for the design of better vaccines. Expert Review of Vaccines, 2015.

122. Fine, P.E., Variation in protection by BCG: implications of and for heterologous immunity. Lancet (London, England), 1995. 346(8986): p. 1339-1345.

123. Trunz, B.B., P. Fine, and C. Dye, Effect of BCG vaccination on childhood tuberculous meningitis and miliary tuberculosis worldwide: a meta-analysis and assessment of cost-effectiveness. Lancet (London, England), 2006. 367(9517): p. 1173-1180.

124. Ottenhoff, T., D. Kumararatne, and J.-L. Casanova, Novel human immunodeficiencies reveal the essential role of type-1 cytokines in immunity to intracellular bacteria. Immunology Today, 1998. 19(11): p. 491-494.

125. Cooper, A.M., et al., Disseminated tuberculosis in interferon gamma gene-disrupted mice. The Journal of experimental medicine, 1993. 178(6): p. 2243-2247.

126. Flynn, J.L., et al., An essential role for interferon gamma in resistance to Mycobacterium tuberculosis infection. The Journal of experimental medicine, 1993. 178(6): p. 2249-2254.

127. Kagina, B.M., et al., Specific $T$ cell frequency and cytokine expression profile do not correlate with protection against tuberculosis after bacillus Calmette-Guérin vaccination of newborns. American Journal of Respiratory and Critical Care Medicine, 2010. 182(8): p. 1073-1079.

128. McShane, H., et al., Recombinant modified vaccinia virus Ankara expressing antigen $85 A$ boosts BCGprimed and naturally acquired antimycobacterial immunity in humans. Nature medicine, 2004. 10(11): p. $1240-1244$.

129. Scriba, T.J., et al., Modified vaccinia Ankara-expressing Ag85A, a novel tuberculosis vaccine, is safe in adolescents and children, and induces polyfunctional CD4+T cells. European Journal of Immunology, 2010. 40(1): p. 279-290.

130. Tameris, M.D., et al., Safety and efficacy of MVA85A, a new tuberculosis vaccine, in infants previously vaccinated with BCG: a randomised, placebo-controlled phase $2 b$ trial. Lancet (London, England), 2013. 381(9871): p. 1021-1028.

131. Bottai, D., et al., Increased protective efficacy of recombinant BCG strains expressing virulence-neutral proteins of the ESX-1 secretion system. Vaccine, 2015. 33(23): p. 2710-2718.

132. da Costa, A., et al., Recombinant BCG: Innovations on an Old Vaccine. Scope of BCG Strains and Strategies to Improve Long-Lasting Memory. Frontiers in immunology, 2014. 5.

133. Grode, L., et al., Increased vaccine efficacy against tuberculosis of recombinant Mycobacterium bovis bacille Calmette-Guerin mutants that secrete listeriolysin. The Journal of clinical investigation, 2005. 115(9): p. 2472-9.

134. da Costa, C., B. Walker, and A. Bonavia, Tuberculosis Vaccines - state of the art, and novel approaches to vaccine development. International Journal of Infectious Diseases, 2015. 32: p. 5-12.

135. Kleinnijenhuis, J., R. van Crevel, and M.G. Netea, Trained immunity: consequences for the heterologous effects of $B C G$ vaccination. Transactions of the Royal Society of Tropical Medicine and Hygiene, 2015. 
136. Benoit, M., B. Desnues, and J.L. Mege, Macrophage polarization in bacterial infections. Journal of immunology, 2008. 181(6): p. 3733-9.

137. Guilliams, M., et al., Alveolar macrophages develop from fetal monocytes that differentiate into long-lived cells in the first week of life via GM-CSF. The Journal of experimental medicine, 2013. 210(10): p. 1977-92.

138. Hashimoto, D., et al., Tissue-Resident Macrophages Self-Maintain Locally throughout Adult Life with Minimal Contribution from Circulating Monocytes. Immunity, 2013. 38(4): p. 792-804.

139. Hussell, T. and T.J. Bell, Alveolar macrophages: plasticity in a tissue-specific context. Nature reviews. Immunology, 2014. 14(2): p. 81-93.

140. Mattila, J.T., et al., Microenvironments in tuberculous granulomas are delineated by distinct populations of macrophage subsets and expression of nitric oxide synthase and arginase isoforms. Journal of Immunology, 2013. 191(2): p. 773-84.

141. Marino, S., et al., Macrophage polarization drives granuloma outcome during Mycobacterium tuberculosis infection. Infection and immunity, 2015. 83(1): p. 324-38.

142. Pathak, S.K., et al., Direct extracellular interaction between the early secreted antigen ESAT-6 of Mycobacterium tuberculosis and TLR2 inhibits TLR signaling in macrophages. Nature immunology, 2007. 8(6): p. 610-8.

143. Huang, Z., et al., Mycobacterium tuberculosis-Induced Polarization of Human Macrophage Orchestrates the Formation and Development of Tuberculous Granulomas In Vitro. PLoS One, 2015. 10(6): p. $\mathrm{e} 0129744$.

144. Gordon, S., Alternative activation of macrophages. Nat Rev Immunol, 2003. 3(1): p. 23-35.

145. Torrelles, J.B. and L.S. Schlesinger, Diversity in Mycobacterium tuberculosis mannosylated cell wall determinants impacts adaptation to the host. Tuberculosis, 2010. 90(2): p. 84-93.

146. Fratti, R.A., et al., Mycobacterium tuberculosis glycosylated phosphatidylinositol causes phagosome maturation arrest. Proceedings of the National Academy of Sciences, 2003. 100(9): p. 5437-5442.

147. Kang, P.B., et al., The human macrophage mannose receptor directs Mycobacterium tuberculosis lipoarabinomannan-mediated phagosome biogenesis. The Journal of experimental medicine, 2005. 202(7): p. 987-999.

148. Maeda, N., et al., The cell surface receptor DC-SIGN discriminates between Mycobacterium species through selective recognition of the mannose caps on lipoarabinomannan. The Journal of biological chemistry, 2003. 278(8): p. 5513-5516.

149. Geurtsen, J., et al., Identification of Mycobacterial a-Glucan As a Novel Ligand for DC-SIGN: Involvement of Mycobacterial Capsular Polysaccharides in Host Immune Modulation. The Journal of Immunology, 2009. 183(8): p. 5221-5231.

150. Cywes, C., et al., Nonopsonic binding of Mycobacterium tuberculosis to complement receptor type 3 is mediated by capsular polysaccharides and is strain dependent. Infection and immunity, 1997. 65(10): p. 4258-66.

151. Guirado, E., L.S. Schlesinger, and G. Kaplan, Macrophages in tuberculosis: friend or foe. Seminars in immunopathology, 2013. 35(5): p. 563-583.

152. Chan, J., et al., Killing of virulent Mycobacterium tuberculosis by reactive nitrogen intermediates produced by activated murine macrophages. The Journal of experimental medicine, 1992. 175(4): p. 1111-1122.

153. Ng, V.H., et al., Role of KatG catalase-peroxidase in mycobacterial pathogenesis: countering the phagocyte oxidative burst. Molecular Microbiology, 2004. 52(5): p. 1291-1302.

154. Russell, D.G., Mycobacterium tuberculosis and the intimate discourse of a chronic infection. Immunological Reviews, 2011. 240(1): p. 252-68.

155. Gaynor, C.D., et al., Pulmonary surfactant protein A mediates enhanced phagocytosis of Mycobacterium tuberculosis by a direct interaction with human macrophages. Journal of immunology (Baltimore, Md. : 1950), 1995. 155(11): p. 5343-5351. 
156. Ferguson, J.S., et al., Surfactant protein D inhibition of human macrophage uptake of Mycobacterium tuberculosis is independent of bacterial agglutination. Journal of immunology (Baltimore, Md. : 1950), 2002. 168(3): p. 1309-1314.

157. Ferguson, J.S., et al., Surfactant protein D increases fusion of Mycobacterium tuberculosis-containing phagosomes with lysosomes in human macrophages. Infection and immunity, 2006. 74(12): p. 70057009.

158. Schwab, U., et al., Transcriptional responses of Mycobacterium tuberculosis to lung surfactant. Microbial pathogenesis, 2009. 46(4): p. 185-93.

159. Wang, Z., et al., Peripheral cell wall lipids of Mycobacterium tuberculosis are inhibitory to surfactant function. Tuberculosis, 2008. 88(3): p. 178-86.

160. Chimote, G. and R. Banerjee, Lung surfactant dysfunction in tuberculosis: effect of mycobacterial tubercular lipids on dipalmitoylphosphatidylcholine surface activity. Colloids and surfaces. B, Biointerfaces, 2005. 45(3-4): p. 215-223.

161. Lemos, M.P., J. McKinney, and K.Y. Rhee, Dispensability of Surfactant Proteins A and D in Immune Control of Mycobacterium tuberculosis Infection following Aerosol Challenge of Mice. Infection and immunity, 2011. 79(3): p. 1077-1085.

162. Sánchez, D., et al., Role of TLR2- and TLR4-mediated signaling in Mycobacterium tuberculosis-induced macrophage death. Cellular immunology, 2010. 260(2): p. 128-136.

163. Liu, P.T., et al., Toll-like receptor triggering of a vitamin D-mediated human antimicrobial response. Science (New York, N.Y.), 2006. 311(5768): p. 1770-1773.

164. Brooks, M.N., et al., NOD2 controls the nature of the inflammatory response and subsequent fate of Mycobacterium tuberculosis and M. bovis BCG in human macrophages. Cellular Microbiology, 2011. 13(3): p. 402-418.

165. Killick, K.E., et al., Receptor-mediated recognition of mycobacterial pathogens. Cellular Microbiology, 2013. 15(9): p. 1484-1495.

166. Mishra, B.B., et al., Mycobacterium tuberculosis protein ESAT-6 is a potent activator of the NLRP3/ASC inflammasome. Cellular microbiology, 2010. 12(8): p. 1046-63.

167. Mayer-Barber, K.D., et al., Host-directed therapy of tuberculosis based on interleukin-1 and type I interferon crosstalk. Nature, 2014. 511(7507): p. 99-103.

168. Eklund, D., et al., Human gene variants linked to enhanced NLRP3 activity limit intramacrophage growth of Mycobacterium tuberculosis. The Journal of infectious diseases, 2014. 209(5): p. 749-53.

169. Watson, R.O., et al., The Cytosolic Sensor cGAS Detects Mycobacterium tuberculosis DNA to Induce Type I Interferons and Activate Autophagy. Cell Host \& Microbe, 2015. 17(6): p. 811-9.

170. Wassermann, R., et al., Mycobacterium tuberculosis Differentially Activates cGAS- and InflammasomeDependent Intracellular Immune Responses through ESX-1. Cell Host \& Microbe, 2015. 17(6): p. 799810.

171. Collins, A.C., et al., Cyclic GMP-AMP Synthase Is an Innate Immune DNA Sensor for Mycobacterium tuberculosis. Cell Host \& Microbe, 2015. 17(6): p. 820-8.

172. Freeman, S.A. and S. Grinstein, Phagocytosis: receptors, signal integration, and the cytoskeleton. Immunological Reviews, 2014. 262(1): p. 193-215.

173. Weiss, G. and U.E. Schaible, Macrophage defense mechanisms against intracellular bacteria. Immunological Reviews, 2015. 264(1): p. 182-203.

174. Sturgill-Koszycki, S., et al., Lack of acidification in Mycobacterium phagosomes produced by exclusion of the vesicular proton-ATPase. Science, 1994. 263(5147): p. 678-81.

175. Vergne, I., J. Chua, and V. Deretic, Tuberculosis toxin blocking phagosome maturation inhibits a novel Ca2+/calmodulin-PI3K hVPS34 cascade. The Journal of experimental medicine, 2003. 198(4): p. 653-9.

176. Vergne, I., et al., Mechanism of phagolysosome biogenesis block by viable Mycobacterium tuberculosis. Proceedings of the National Academy of Sciences of the United States of America, 2005. 102(11): p. 4033-4038. 
177. Fratti, R.A., et al., Mycobacterium tuberculosis glycosylated phosphatidylinositol causes phagosome maturation arrest. Proceedings of the National Academy of Sciences of the United States of America, 2003. 100(9): p. 5437-42.

178. Bach, H., et al., Mycobacterium tuberculosis virulence is mediated by PtpA dephosphorylation of human vacuolar protein sorting 33B. Cell Host \& Microbe, 2008. 3(5): p. 316-22.

179. Wong, D., et al., Mycobacterium tuberculosis protein tyrosine phosphatase (PtpA) excludes host vacuolarH+-ATPase to inhibit phagosome acidification. Proceedings of the National Academy of Sciences of the United States of America, 2011. 108(48): p. 19371-19376.

180. Walburger, A., et al., Protein kinase $G$ from pathogenic mycobacteria promotes survival within macrophages. Science, 2004. 304(5678): p. 1800-4.

181. Jayachandran, R., et al., Survival of mycobacteria in macrophages is mediated by coronin 1-dependent activation of calcineurin. Cell, 2007. 130(1): p. 37-50.

182. Tan, T., et al., The ESAT-6/CFP-10 secretion system of Mycobacterium marinum modulates phagosome maturation. Cellular Microbiology, 2006. 8(9): p. 1417-1429.

183. Majlessi, L., et al., Release of mycobacterial antigens. Immunological Reviews, 2015. 264(1): p. 25-45.

184. Simeone, R., et al., Cytosolic access of Mycobacterium tuberculosis: critical impact of phagosomal acidification control and demonstration of occurrence in vivo. PLoS Pathogens, 2015. 11(2): p. e1004650.

185. Via, L.E., et al., Effects of cytokines on mycobacterial phagosome maturation. Journal of Cell Science, 1998. 111 ( Pt 7): p. 897-905.

186. Schaible, U.E., et al., Cytokine activation leads to acidification and increases maturation of Mycobacterium avium-containing phagosomes in murine macrophages. Journal of immunology (Baltimore, Md. : 1950), 1998. 160(3): p. 1290-1296.

187. Lamb, C.A., T. Yoshimori, and S.A. Tooze, The autophagosome: origins unknown, biogenesis complex. Nature Reviews Molecular Cell Biology, 2013. 14(12): p. 759-774.

188. Singh, S.B., et al., Human IRGM Induces Autophagy to Eliminate Intracellular Mycobacteria. Science, 2006. 313(5792): p. 1438-1441.

189. Wessling-Resnick, M., Nramp1 and Other Transporters Involved in Metal Withholding during Infection. Journal of Biological Chemistry, 2015. 290(31): p. 18984-18990.

190. Romagnoli, A., et al., ESX-1 dependent impairment of autophagic flux by Mycobacterium tuberculosis in human dendritic cells. Autophagy, 2012. 8(9): p. 1357-70.

191. Castillo, E.F., et al., Autophagy protects against active tuberculosis by suppressing bacterial burden and inflammation. Proceedings of the National Academy of Sciences of the United States of America, 2012. 109(46): p. 76.

192. Andersson, A.-M., et al., Autophagy induction targeting mTORC1 enhances Mycobacterium tuberculosis replication in HIV co-infected human macrophages. Scientific reports, 2016. 6: p. 28171.

193. Duprez, L., et al., Major cell death pathways at a glance. Microbes and infection / Institut Pasteur, 2009. 11(13): p. 1050-1062.

194. Hmama, Z., et al., Immunoevasion and immunosuppression of the macrophage by Mycobacterium tuberculosis. Immunological Reviews, 2015. 264(1): p. 220-32.

195. Keane, J., H.G. Remold, and H. Kornfeld, Virulent Mycobacterium tuberculosis strains evade apoptosis of infected alveolar macrophages. Journal of immunology (Baltimore, Md. : 1950), 2000. 164(4): p. 2016-2020.

196. Behar, S.M., et al., Apoptosis is an innate defense function of macrophages against Mycobacterium tuberculosis. Mucosal immunology, 2011. 4(3): p. 279-287.

197. Divangahi, M., et al., Mycobacterium tuberculosis evades macrophage defenses by inhibiting plasma membrane repair. Nature immunology, 2009. 10(8): p. 899-906.

198. Schaible, U.E., et al., Apoptosis facilitates antigen presentation to Tlymphocytes through MHC-I and CD1 in tuberculosis. Nature medicine, 2003. 9(8): p. 1039-1046.

199. Butler, R.E., et al., The balance of apoptotic and necrotic cell death in Mycobacterium tuberculosis infected macrophages is not dependent on bacterial virulence. PLoS One, 2012. 7(10). 
200. Andersson, H., et al., Apoptotic neutrophils augment the inflammatory response to Mycobacterium tuberculosis infection in human macrophages. PLoS One, 2014. 9(7).

201. Chen, M., H. Gan, and H.G. Remold, A mechanism of virulence: virulent Mycobacterium tuberculosis strain H37Rv, but not attenuated H37Ra, causes significant mitochondrial inner membrane dismption in macrophages leading to necrosis. Journal of immunology (Baltimore, Md. : 1950), 2006. 176(6): p. 3707-3716.

202. Welin, A., et al., Human Macrophages Infected with a High Burden of ESAT-6-Expressing M. tuberculosis Undergo Caspase-1- and Cathepsin B-Independent Necrosis. PLoS One, 2011. 6(5): p. e20302.

203. Repasy, T., et al., Intracellular bacillary burden reflects a burst size for Mycobacterium tuberculosis in vivo. PLoS pathogens, 2013. 9(2): p. e1003190.

204. Velmurugan, K., et al., Mycobacterium tuberculosis nuoG is a virulence gene that inhibits apoptosis of infected host cells. PLoS Pathogens, 2007. 3(7).

205. Blomgran, R., et al., Mycobacterium tuberculosis inhibits neutrophil apoptosis, leading to delayed activation of naive CD4 T cells. Cell Host \& Microbe, 2012. 11(1): p. 81-90.

206. Andersen, P., et al., Recall of long-lived immunity to Mycobacterium tuberculosis infection in mice. Journal of Immunology, 1995. 154(7): p. 3359-72.

207. Pym, A.S., et al., Recombinant BCG exporting ESAT-6 confers enhanced protection against tuberculosis. Nature medicine, 2003. 9(5): p. 533-9.

208. Lewis, K.N., et al., Deletion of RD1 from Mycobacterium tuberculosis mimics bacille Calmette-Guerin attenuation. The Journal of infectious diseases, 2003. 187(1): p. 117-23.

209. Guinn, K.M., et al., Individual RD1-region genes are required for export of ESAT-6/CFP-10 and for virulence of Mycobacterium tuberculosis. Molecular microbiology, 2004. 51(2): p. 359-70.

210. Hsu, T., et al., The primary mechanism of attenuation of bacillus Calmette-Guerin is a loss of secreted lytic function required for invasion of lung interstitial tissue. Proceedings of the National Academy of Sciences of the United States of America, 2003. 100(21): p. 12420-5.

211. Leake, E.S., Q.N. Myrvik, and M.J. Wright, Phagosomal membranes of Mycobacterium bovis BCGimmune alveolar macrophages are resistant to disruption by Mycobacterium tuberculosis $H 37 R v$. Infection and immunity, 1984. 45(2): p. 443-6.

212. Harriff, M.J., G.E. Purdy, and D.M. Lewinsohn, Escape from the Phagosome: The Explanation for MHC-I Processing of Mycobacterial Antigens? Frontiers in immunology, 2012. 3: p. 40.

213. Welin, A. and M. Lerm, Inside or outside the phagosome? The controversy of the intracellular localization of Mycobacterium tuberculosis. Tuberculosis, 2012. 92(2): p. 113-120.

214. Russell, D.G., The ins and outs of the Mycobacterium tuberculosis-containing vacuole. Cellular Microbiology, 2016. 18(8): p. 1065-1069.

215. van der Wel, N., et al., M. tuberculosis and M. leprae translocate from the phagolysosome to the cytosol in myeloid cells. Cell, 2007. 129(7): p. 1287-98.

216. Houben, D., et al., ESX-1-mediated translocation to the cytosol controls virulence of mycobacteria. Cellular microbiology, 2012. 14(8): p. 1287-98.

217. Simeone, R., et al., Phagosomal rupture by Mycobacterium tuberculosis results in toxicity and host cell death. PLoS pathogens, 2012. 8(2): p. e1002507.

218. Wong, K.W. and W.R. Jacobs Jr, Critical role for NLRP3 in necrotic death triggered by Mycobacterium tuberculosis. Cellular microbiology, 2011.

219. Derrick, S.C. and S.L. Morris, The ESAT6 protein of Mycobacterium tuberculosis induces apoptosis of macrophages by activating caspase expression. Cellular Microbiology, 2007. 9(6): p. 1547-55.

220. Aguilo, N., et al., ESX-1-induced apoptosis during mycobacterial infection: to be or not to be, that is the question. Frontiers in cellular and infection microbiology, 2013. 3: p. 88.

221. Sreejit, G., et al., The ESAT-6 Protein of Mycobacterium tuberculosis Interacts with Beta-2Microglobulin ( $\beta 2 M)$ Affecting Antigen Presentation Function of Macrophage. PLoS Pathogens, 2014. 10(10). 
222. Kumar, P., et al., ESAT6 differentially inhibits IFN-gamma-inducible class II transactivator isoforms in both a TLR2-dependent and -independent manner. Immunology and Cell Biology, 2012. 90(4): p. 411-20.

223. Singh, V., et al., M. tuberculosis Secretory Protein ESAT-6 Induces Metabolic Flux Perturbations to Drive Foamy Macrophage Differentiation. Scientific reports, 2015. 5: p. 12906.

224. Ganguly, N., et al., Mycobacterium tuberculosis secretory proteins CFP-10, ESAT-6 and the CFP10:ESAT6 complex inhibit lipopolysaccharide-induced NF- $\kappa$ B transactivation by downregulation of reactive oxidative species (ROS) production. Immunology and Cell Biology, 2007. 86(1).

225. Welin, A., et al., CFP-10 from Mycobacterium tuberculosis selectively activates human neutrophils through a pertussis toxin-sensitive chemotactic receptor. Infection and immunity, 2015. 83(1): p. 20513 .

226. Lillebaek, T., et al., Molecular Evidence of Endogenous Reactivation ofMycobacterium tuberculosisafter 33 Years of Latent Infection. The Journal of Infectious Diseases, 2002. 185(3): p. 401-404.

227. Lillebaek, T., et al., Stability of DNA patterns and evidence of Mycobacterium tuberculosis reactivation occurring decades after the initial infection. The Journal of Infectious Diseases, 2003. 188(7): p. 10321039.

228. Opie, E.L., Pathology of the Tuberculosis of Childhood and Its Bearing on Clinical Work. British medical journal, 1927. 2(3493): p. 1130-5.

229. Stewart, G.R., B.D. Robertson, and D.B. Young, Tuberculosis: a problem with persistence. Nature reviews. Microbiology, 2003. 1(2): p. 97-105.

230. Feldman, W.H. and A.H. Baggenstoss, The residual infectivity of the primary complex of tuberculosis. The American journal of pathology, 1938. 14(4): p. 473-490.

231. Elkington, P.T. and J.S. Friedland, Permutations of time and place in tuberculosis. The Lancet infectious diseases, 2015.

232. Arriaga, A.K., et al., Immunological and pathological comparative analysis between experimental latent tuberculous infection and progressive pulmonary tuberculosis. Clinical and experimental immunology, 2002. 128(2): p. 229-37.

233. Seiler, P., et al., Cell-wall alterations as an attribute of Mycobacterium tuberculosis in latent infection. The Journal of infectious diseases, 2003. 188(9): p. 1326-31.

234. Barrios-Payan, J., et al., Extrapulmonary locations of mycobacterium tuberculosis DNA during latent infection. The Journal of infectious diseases, 2012. 206(8): p. 1194-205.

235. Neyrolles, O., et al., Is adipose tissue a place for Mycobacterium tuberculosis persistence? PLoS One, 2006. 1: p. e43.

236. Garcia-Perez, B.E., N.S. Castrejon-Jimenez, and J. Luna-Herrera, The Role of Non-Phagocytic Cells in Mycobacterial Infections, in Understanding Tuberculosis - Analyzing the Origin of Mycobacterium Tuberculosis Pathogenicity, P.-J. Cardona, Editor 2012, InTech.

237. Pethe, K., et al., The heparin-binding haemagglutinin of $M$. tuberculosis is required for extrapulmonary dissemination. Nature, 2001. 412(6843): p. 190-194.

238. Lerner, T.R., et al., Lymphatic endothelial cells are a replicative niche for Mycobacterium tuberculosis. Journal of Clinical Investigation, 2016. 126(3): p. 1093-1108.

239. Das, B., et al., CD271(+) bone marrow mesenchymal stem cells may provide a niche for dormant Mycobacterium tuberculosis. Science translational medicine, 2013. 5(170).

240. Raghuvanshi, S., P. Sharma, and S. Singh, Mycobacterium tuberculosis evades host immunity by recruiting mesenchymal stem cells. Proceedings of the ..., 2010.

241. Beamer, G., et al., Bone Marrow Mesenchymal Stem Cells Provide an Antibiotic-Protective Niche for Persistent Viable Mycobacterium tuberculosis that Survive Antibiotic Treatment. The American journal of pathology, 2014. 184(12): p. 3170-3175.

242. Behr, M.A. and R.W. Waters, Is tuberculosis a lymphatic disease with a pulmonary portal? The Lancet infectious diseases, 2013.

243. Bishai, W.R., Rekindling old controversy on elusive lair of latent tuberculosis. Lancet, 2000. 356(9248): p. 2113-4. 
244. Schnappinger, D., et al., Transcriptional Adaptation of Mycobacterium tuberculosis within Macrophages: Insights into the Phagosomal Environment. The Journal of experimental medicine, 2003. 198(5): p. 693-704.

245. Rohde, K.H., R.B. Abramovitch, and D.G. Russell, Mycobacterium tuberculosis invasion of macrophages: linking bacterial gene expression to environmental cues. Cell Host \& Microbe, 2007. 2(5): p. 352-64.

246. Gengenbacher, M. and S.H. Kaufmann, Mycobacterium tuberculosis: success through dormancy. FEMS Microbiology Reviews, 2012. 36(3): p. 514-32.

247. Vandal, O.H., et al., A membrane protein preserves intrabacterial $p H$ in intraphagosomal Mycobacterium tuberculosis. Nature medicine, 2008. 14(8): p. 849-854.

248. Abramovitch, R.B., et al., aprABC: a Mycobacterium tuberculosis complex-specific locus that modulates pH-driven adaptation to the macrophage phagosome. Molecular microbiology, 2011. 80(3): p. 678-94.

249. Baker, J.J., B.K. Johnson, and R.B. Abramovitch, Slow growth of Mycobacterium tuberculosis at acidic $p H$ is regulated by phoPR and host-associated carbon sources. Molecular Microbiology, 2014. 94(1): p. 56-69.

250. MacMicking, J.D., G.A. Taylor, and J.D. McKinney, Immune Control of Tuberculosis by IFN- $\gamma-$ Inducible $L R G-47$. Science, 2003. 302(5645): p. 654-659.

251. MacMicking, J.D., et al., Identification of nitric oxide synthase as a protective locus against tuberculosis. Proceedings of the National Academy of Sciences of the United States of America, 1997. 94(10): p. 5243-5248.

252. Landes, M.B., et al., Role for NOD2 in Mycobacterium tuberculosis-induced iNOS expression and NO production in human macrophages. Journal of Leukocyte Biology, 2015. 97(6): p. 1111-1119.

253. Thomas, A.C. and J.T. Mattila, "Of Mice and Men": Arginine Metabolism in Macrophages. Frontiers in immunology, 2014. 5: p. 479.

254. Gross, T.J., et al., Epigenetic Silencing of the Human NOS2 Gene: Rethinking the Role of Nitric Oxide in Human Macrophage Inflammatory Responses. The Journal of Immunology, 2014. 192(5): p. 23262338.

255. Schön, T., et al., Local production of nitric oxide in patients with tuberculosis. The international journal of tuberculosis and lung disease : the official journal of the International Union against Tuberculosis and Lung Disease, 2004. 8(9): p. 1134-1137.

256. Choi, H.-S., et al., Analysis of nitric oxide synthase and nitrotyrosine expression in human pulmonary tuberculosis. American Journal of Respiratory and Critical Care Medicine, 2002. 166(2): p. 178-186.

257. Nicholson, S., et al., Inducible nitric oxide synthase in pulmonary alveolar macrophages from patients with tuberculosis. The Journal of experimental medicine, 1996. 183(5): p. 2293-2302.

258. Schön, T., et al., Arginine as an adjuvant to chemotherapy improves clinical outcome in active tuberculosis. The European respiratory journal, 2003. 21(3): p. 483-488.

259. Ralph, A.P., et al., L-arginine and Vitamin D Adjunctive Therapies in Pulmonary Tuberculosis: A Randomised, Double-Blind, Placebo-Controlled Trial. PLoS One, 2013. 8(8).

260. Möller, M. and E.G. Hoal, Current findings, challenges and novel approaches in buman genetic susceptibility to tuberculosis. Tuberculosis, 2010. 90(2): p. 71-83.

261. Singh, R., et al., PA-824 kills nonreplicating Mycobacterium tuberculosis by intracellular NO release. Science (New York, N.Y.), 2008. 322(5906): p. 1392-1395.

262. Bustamante, J., et al., Germline CYBB mutations that selectively affect macrophages in kindreds with Xlinked predisposition to tuberculous mycobacterial disease. Nature immunology, 2011. 12(3): p. 213221.

263. Ehrt, S. and D. Schnappinger, Mycobacterial survival strategies in the phagosome: defence against host stresses. Cellular Microbiology, 2009. 11(8): p. 1170-1178.

264. Raynaud, C., et al., Extracellular enzyme activities potentially involved in the pathogenicity of Mycobacterium tuberculosis. Microbiology, 1998. 144 ( Pt 2): p. 577-87.

265. Shin, D.-M., et al., Mycobacterium tuberculosis Eis Regulates Autophagy, Inflammation, and Cell Death through Redox-dependent Signaling. PLoS Pathogens, 2010. 6(12). 
266. Lee, W.L., et al., Mycobacterium tuberculosis expresses methionine sulphoxide reductases $A$ and $B$ that protect from killing by nitrite and hypochlorite. Molecular Microbiology, 2009. 71(3): p. 583-593.

267. Gandotra, S., et al., In vivo gene silencing identifies the Mycobacterium tuberculosis proteasome as essential for the bacteria to persist in mice. Nature medicine, 2007. 13(12): p. 1515-1520.

268. Park, H.D., et al., Rv3133cldosR is a transcription factor that mediates the hypoxic response of Mycobacterium tuberculosis. Molecular microbiology, 2003. 48(3): p. 833-43.

269. Voskuil, M.I., et al., Inhibition of respiration by nitric oxide induces a Mycobacterium tuberculosis dormancy program. J Exp Med, 2003. 198(5): p. 705-13.

270. Kumar, A., et al., Mycobacterium tuberculosis DosS is a redox sensor and Dos $T$ is a hypoxia sensor. Proceedings of the National Academy of Sciences, 2007. 104(28): p. 11568-11573.

271. Rustad, T.R., et al., The Enduring Hypoxic Response of Mycobacterium tuberculosis. PLoS One, 2008. $3(1)$.

272. Rohde, K.H., et al., Linking the transcriptional profiles and the physiological states of Mycobacterium tuberculosis during an extended intracellular infection. PLoS pathogens, 2012. 8(6): p. e1002769.

273. Tailleux, L., et al., Probing host pathogen cross-talk by transcriptional profiling of both Mycobacterium tuberculosis and infected human dendritic cells and macrophages. PLoS One, 2008. 3(1): p. e1403.

274. Boon, C. and T. Dick, Mycobacterium bovis BCG response regulator essential for hypoxic dormancy. Journal of Bacteriology, 2002. 184(24): p. 6760-6767.

275. Beste, D.J.V., et al., Transcriptomic Analysis Identifies Growth Rate Modulation as a Component of the Adaptation of Mycobacteria to Survival inside the Macrophage. Journal of Bacteriology, 2007. 189(11): p. 3969-3976.

276. Neyrolles, O., et al., Mycobacteria, metals, and the macrophage. Immunological Reviews, 2015. 264(1): p. 249-263.

277. Luo, M., E.A. Fadeev, and J.T. Groves, Mycobactin-mediated iron acquisition within macrophages. Nature chemical biology, 2005. 1(3): p. 149-153.

278. Jones, C.M. and M. Niederweis, Mycobacterium tuberculosis Can Utilize Heme as an Iron Source. Journal of Bacteriology, 2011. 193(7): p. 1767-1770.

279. Botella, H., et al., Mycobacterial P1-Type ATPases Mediate Resistance to Zinc Poisoning in Human Macrophages. Cell Host \& Microbe, 2011. 10(3): p. 248-259.

280. Wolschendorf, F., et al., Copper resistance is essential for virulence of Mycobacterium tuberculosis. Proceedings of the National Academy of Sciences, 2011. 108(4): p. 1621-1626.

281. Liu, P.T., et al., Cutting Edge: Vitamin D-Mediated Human Antimicrobial Activity against Mycobacterium tuberculosis Is Dependent on the Induction of Cathelicidin. The Journal of Immunology, 2007. 179(4): p. 2060-2063.

282. Martineau, A.R., et al., IFN-gamma- and TNF-independent vitamin D-inducible human suppression of mycobacteria: The role of cathelicidin LL-37. Journal of Immunology, 2007.

283. Wilkinson, R.J., et al., Influence of vitamin D deficiency and vitamin D receptor polymorphisms on tuberculosis among Gujarati Asians in west London: a case-control study. Lancet, 2000. 355(9204): p. 618-21.

284. Martineau, A.R., et al., High-dose vitamin D3 during intensive-phase antimicrobial treatment of pulmonary tuberculosis: a double-blind randomised controlled trial. The Lancet, 2011. 377(9761): p. 242-250.

285. Salamon, H., et al., Cutting Edge: Vitamin D Regulates Lipid Metabolism in Mycobacterium tuberculosis Infection. The Journal of Immunology, 2014. 193(1): p. 30-34.

286. Russell, D.G., et al., Mycobacterium tuberculosis wears what it eats. Cell Host \& Microbe, 2010. 8(1): p. 68-76.

287. Neyrolles, O., Mycobacteria and the greasy macrophage: getting fat and frustrated. Infection and immunity, 2014. 82(2): p. 472-475.

288. Caire-Brändli, I., et al., Reversible lipid accumulation and associated division arrest of Mycobacterium avium in lipoprotein-induced foamy macrophages may resemble key events during latency and reactivation of tuberculosis. Infection and immunity, 2014. 82(2): p. 476-490. 
289. Deb, C., et al., A Novel Lipase Belonging to the Hormone-sensitive Lipase Family Induced under Starvation to Utilize Stored Triacylglycerol in Mycobacterium tuberculosis. Journal of Biological Chemistry, 2006. 281(7): p. 3866-3875.

290. Daniel, J., et al., Induction of a novel class of diacylglycerol acyltransferases and triacylglycerol accumulation in Mycobacterium tuberculosis as it goes into a dormancy-like state in culture. J Bacteriol, 2004. 186(15): p. 5017-30.

291. McLaren, J.E., et al., Cytokines, macrophage lipid metabolism and foam cells: Implications for cardiovascular disease therapy. Progress in lipid research, 2011. 50(4): p. 331-347.

292. Gleeson, L.E., et al., Cutting Edge: Mycobacterium tuberculosis Induces Aerobic Glycolysis in Human Alveolar Macrophages That Is Required for Control of Intracellular Bacillary Replication. The Journal of Immunology, 2016. 196(6): p. 2444-2449.

293. Shi, L., et al., Infection with Mycobacterium tuberculosis induces the Warburg effect in mouse lungs. Scientific reports, 2015. 5: p. 18176.

294. Skoura, E., A. Zumla, and J. Bomanji, Imaging in tuberculosis. International Journal of Infectious Diseases, 2015. 32: p. 87-93.

295. Singh, V., et al., Mycobacterium tuberculosis-driven targeted recalibration of macrophage lipid homeostasis promotes the foamy phenotype. Cell Host \& Microbe, 2012. 12(5): p. 669-81.

296. Pandey, A.K. and C.M. Sassetti, Mycobacterial persistence requires the utilization of host cholesterol. Proceedings of the National Academy of Sciences, 2008. 105(11): p. 4376-4380.

297. Munoz-Elias, E.J. and J.D. McKinney, Mycobacterium tuberculosis isocitrate lyases 1 and 2 are jointly required for in vivo growth and virulence. Nat Med, 2005. 11(6): p. 638-44.

298. Eoh, H. and K.Y. Rhee, Methylcitrate cycle defines the bactericidal essentiality of isocitrate lyase for survival of Mycobacterium tuberculosis on fatty acids. Proceedings of the National Academy of Sciences, 2014. 111(13): p. 4976-4981.

299. Ganapathy, U., et al., Two enzymes with redundant fructose bisphosphatase activity sustain gluconeogenesis and virulence in Mycobacterium tuberculosis. Nature communications, 2015. 6: p. 7912.

300. Via, L.E., et al., Tuberculous granulomas are hypoxic in guinea pigs, rabbits, and nonhuman primates. Infection and immunity, 2008. 76(6): p. 2333-40.

301. Lenaerts, A., C.E. Barry, and V. Dartois, Heterogeneity in tuberculosis pathology, microenvironments and therapeutic responses. Immunological Reviews, 2015. 264(1): p. 288-307.

302. Kramnik, I., et al., Genetic control of resistance to experimental infection with virulent Mycobacterium tuberculosis. Proceedings of the National Academy of Sciences, 2000. 97(15): p. 8560-8565.

303. Harper, J., et al., Mouse model of necrotic tuberculosis granulomas develops hypoxic lesions. The Journal of infectious diseases, 2012. 205(4): p. 595-602.

304. Daniel, J., et al., Mycobacterium tuberculosis Uses Host Triacylglycerol to Accumulate Lipid Droplets and Acquires a Dormancy-Like Phenotype in Lipid-Loaded Macrophages. PLoS Pathogens, 2011. 7(6).

305. Rohde, K., et al., Mycobacterium tuberculosis and the environment within the phagosome. Immunological reviews, 2007. 219: p. 37-54.

306. Daniel, J., et al., Mycobacterium tuberculosis Uses Host Triacylglycerol to Accumulate Lipid Droplets and Acquires a Dormancy-Like Phenotype in Lipid-Loaded Macrophages. PLoS pathogens, 2011. 7(6): p. e1002093.

307. Bhatt, A., et al., Deletion of kasB in Mycobacterium tuberculosis causes loss of acid-fastness and subclinical latent tuberculosis in immunocompetent mice. Proceedings of the National Academy of Sciences of the United States of America, 2007. 104(12): p. 5157-62.

308. Fenhalls, G., et al., In situ detection of Mycobacterium tuberculosis transcripts in human lung granulomas reveals differential gene expression in necrotic lesions. Infection and immunity, 2002. 70(11): p. 63306338.

309. Boshoff, H.I. and C.E. Barry, 3rd, Tuberculosis - metabolism and respiration in the absence of growth. Nature reviews. Microbiology, 2005. 3(1): p. 70-80. 
310. Elkington, P.T., C.A. Ugarte-Gil, and J.S. Friedland, Matrix metalloproteinases in tuberculosis. European Respiratory Journal, 2011. 38(2): p. 456-464.

311. Harris, J. and J. Keane, How tumour necrosis factor blockers interfere with tuberculosis immunity. Clinical \& Experimental Immunology, 2010. 161(1): p. 1-9.

312. Brassard, P., A. Kezouh, and S. Suissa, Antirheumatic drugs and the risk of tuberculosis. Clinical infectious diseases : an official publication of the Infectious Diseases Society of America, 2006. 43(6): p. 717-722.

313. Tobin, D.M., et al., The lta4h Locus Modulates Susceptibility to Mycobacterial Infection in Zebrafish and Humans. Cell, 2010. 140(5): p. 717-730.

314. Green, J.A., et al., Dexamethasone, Cerebrospinal Fluid Matrix Metalloproteinase Concentrations and Clinical Outcomes in Tuberculous Meningitis. PLoS One, 2009. 4(9).

315. Vilaplana, C., et al., Ibuprofen Therapy Resulted in Significantly Decreased Tissue Bacillary Loads and Increased Survival in a New Murine Experimental Model of Active Tuberculosis. Journal of Infectious Diseases, 2013. 208(2): p. 199-202.

316. Tobin, D.M. and L. Ramakrishnan, TB: the Yin and Yang of lipid mediators. Current Opinion in Pharmacology, 2013. 13(4): p. 641-645.

317. Orme, I.M., R.T. Robinson, and A.M. Cooper, The balance between protective and pathogenic immune responses in the TB-infected lung. Nature immunology, 2015. 16(1): p. 57-63.

318. Marakalala, M.J., et al., Inflammatory signaling in human tuberculosis granulomas is spatially organized. Nature medicine, 2016. 22(5): p. 531-538.

319. Garton, N.J., et al., Cytological and transcript analyses reveal fat and lazy persister-like bacilli in tuberculous sputum. PLoS medicine, 2008. 5(4): p. e75.

320. Walter, N.D., et al., Transcriptional Adaptation of Drug-tolerant Mycobacterium tuberculosis During Treatment of Human Tuberculosis. Journal of Infectious Diseases, 2015. 212(6).

321. Sirakova, T.D., et al., Identification of a diacylglycerol acyltransferase gene involved in accumulation of triacylglycerol in Mycobacterium tuberculosis under stress. Microbiology, 2006. 152(Pt 9): p. 2717-25.

322. Garton, N.J., et al., Intracellular lipophilic inclusions of mycobacteria in vitro and in sputum. Microbiology, 2002. 148(Pt 10): p. 2951-8.

323. Kayigire, X.A., et al., Simultaneous staining of sputum smears for acid-fast and lipid-containing Myobacterium tuberculosis can enhance the clinical evaluation of antituberculosis treatments. Tuberculosis (Edinburgh, Scotland), 2015.

324. Sloan, D.J., et al., Pharmacodynamic Modeling of Bacillary Elimination Rates and Detection of Bacterial Lipid Bodies in Sputum to Predict and Understand Outcomes in Treatment of Pulmonary Tuberculosis. Clinical Infectious Diseases, 2015. 61(1): p. 1-8.

325. Mukamolova, G.V., et al., Resuscitation-promoting factors reveal an occult population of tubercle Bacilli in Sputum. American Journal of Respiratory and Critical Care Medicine, 2010. 181(2): p. 174-80.

326. Turapov, O., et al., Phenotypically Adapted Mycobacterium tuberculosis Populations from Sputum Are Tolerant to First-Line Drugs. Antimicrobial Agents and Chemotherapy, 2016. 60(4): p. 2476-2483.

327. Markova, N., et al., Cell wall deficiency and its effect on methicillin heteroresistance in Staphylococcus aureus. International journal of antimicrobial agents, 2008. 31(3): p. 255-60.

328. Ghosh, J., et al., Sporulation in mycobacteria. Proceedings of the National Academy of Sciences of the United States of America, 2009. 106(26): p. 10781-6.

329. Traag, B.A., et al., Do mycobacteria produce endospores? Proceedings of the National Academy of Sciences of the United States of America, 2010. 107(2): p. 878-81.

330. Singh, B., et al., Growth, cell division and sporulation in mycobacteria. Antonie van Leeuwenhoek, 2010. 98(2): p. 165-77.

331. Shleeva, M.O., et al., Dormant ovoid cells of Mycobacterium tuberculosis are formed in response to gradual external acidification. Tuberculosis, 2011. 91(2): p. 146-54.

332. Kana, B.D., et al., The resuscitation-promoting factors of Mycobacterium tuberculosis are required for virulence and resuscitation from dormancy but are collectively dispensable for growth in vitro. Molecular Microbiology, 2008. 67(3): p. 672-684. 
333. Bagramyan, K., et al., Formation and resuscitation of 'non-culturable' cells of Rhodococcus rhodochrous and Mycobacterium tuberculosis in prolonged stationary phase. Microbiology, 2002. 148(5): p. 15811591.

334. Chao, M.C. and E.J. Rubin, Letting sleeping dos lie: does dormancy play a role in tuberculosis? Annual Review of Microbiology, 2010. 64: p. 293-311.

335. Turapov, O., et al., The in vivo environment accelerates generation of resuscitation-promoting factordependent mycobacteria. American Journal of Respiratory and Critical Care Medicine, 2014. 190(12): p. $1455-1457$.

336. Biketov, S., et al., Culturability of Mycobacterium tuberculosis cells isolated from murine macrophages: a bacterial growth factor promotes recovery. FEMS immunology and medical microbiology, 2000. 29(4): p. 233-240.

337. Davies, A.P., et al., Resuscitation-promoting factors are expressed in Mycobacterium tuberculosis-infected human tissue. Tuberculosis (Edinburgh, Scotland), 2008. 88(5): p. 462-468.

338. Manina, G., N. Dhar, and J.D. McKinney, Stress and host immunity amplify Mycobacterium tuberculosis phenotypic heterogeneity and induce nongrowing metabolically active forms. Cell Host \& Microbe, 2015. 17(1): p. 32-46.

339. Julian, E., et al., Microscopic cords, a virulence-related characteristic of Mycobacterium tuberculosis, are also present in nonpathogenic mycobacteria. Journal of bacteriology, 2010. 192(7): p. 1751-60.

340. Indrigo, J., R.L. Hunter, Jr., and J.K. Actor, Cord factor trehalose 6,6'-dimycolate (TDM) mediates trafficking events during mycobacterial infection of murine macrophages. Microbiology, 2003. 149(Pt 8): p. 2049-59.

341. Welsh, K.J., R.L. Hunter, and J.K. Actor, Trehalose 6,6'-dimycolate--a coat to regulate tuberculosis immunopathogenesis. Tuberculosis, 2013. 93 Suppl: p. S3-9.

342. Sakamoto, K., et al., Mycobacterial trehalose dimycolate reprograms macrophage global gene expression and activates matrix metalloproteinases. Infection and immunity, 2013. 81(3): p. 764-776.

343. Bernut, A., et al., Mycobacterium abscessus cording prevents phagocytosis and promotes abscess formation. Proceedings of the National Academy of Sciences of the United States of America, 2014. 111(10): p. E943-52.

344. Ackart, D.F., et al., Expression of antimicrobial drug tolerance by attached communities of Mycobacterium tuberculosis. Pathogens and Disease, 2014.

345. Ojha, A.K., et al., Growth of Mycobacterium tuberculosis biofilms containing free mycolic acids and harbouring drug-tolerant bacteria. Molecular Microbiology, 2008. 69(1): p. 164-174.

346. Wang, F., et al., Identification of a small molecule with activity against drug-resistant and persistent tuberculosis. Proceedings of the National Academy of Sciences of the United States of America, 2013. 110(27): p. 7.

347. Hunter, R.L., et al., Multiple roles of cord factor in the pathogenesis of primary, secondary, and cavitary tuberculosis, including a revised description of the pathology of secondary disease. Annals of clinical and laboratory science, 2006. 36(4): p. 371-386.

348. Stokes, R.W., et al., The glycan-rich outer layer of the cell wall of Mycobacterium tuberculosis acts as an antiphagocytic capsule limiting the association of the bacterium with macrophages. Infection and immunity, 2004. 72(10): p. 5676-86.

349. Gagliardi, M., et al., Cell wall-associated alpha-glucan is instrumental for Mycobacterium tuberculosis to block CD1 molecule expression and disable the function of dendritic cell derived from infected monocyte. Cellular Microbiology, 2007. 9(8): p. 2081-2092.

350. Sambou, T., et al., Capsular glucan and intracellular glycogen of Mycobacterium tuberculosis: biosynthesis and impact on the persistence in mice. Molecular Microbiology, 2008. 70(3): p. 762-774.

351. Koliwer-Brandl, H., et al., Metabolic Network for the Biosynthesis of Intra- and Extracellular aGlucans Required for Virulence of Mycobacterium tuberculosis. PLoS Pathogens, 2016. 12(8).

352. Schwebach, J.R., et al., Expression of a Mycobacterium tuberculosis arabinomannan antigen in vitro and in vivo. Infection and immunity, 2001. 69(9): p. 5671-8. 
353. Schwebach, J.R., et al., Glucan is a component of the Mycobacterium tuberculosis surface that is expressed in vitro and in vivo. Infect Immun, 2002. 70(5): p. 2566-75.

354. Ortalo-Magne, A., et al., Identification of the surface-exposed lipids on the cell envelopes of Mycobacterium tuberculosis and other mycobacterial species. Journal of Bacteriology, 1996. 178(2): p. 456-61.

355. Day, T.A., et al., Mycobacterium tuberculosis strains lacking surface lipid phthiocerol dimycocerosate are susceptible to killing by an early innate host response. Infection and immunity, 2014. 82(12): p. 521422.

356. Leisching, G., et al., The Host Response to a Clinical MDR Mycobacterial Strain Cultured in a Detergent-Free Environment: A Global Transcriptomics Approach. PLoS One, 2016. 11(4): p. e0153079.

357. Singhal, A., et al., Modulation of gamma interferon receptor 1 by Mycobacterium tuberculosis: a potential immune response evasive mechanism. Infection and immunity, 2007. 75(5): p. 2500-10.

358. Nalpas, N.C., et al., RNA sequencing provides exquisite insight into the manipulation of the alveolar macrophage by tubercle bacilli. Sci Rep, 2015. 5: p. 13629.

359. Prados-Rosales, R., et al., The Type of Growth Medium Affects the Presence of a Mycobacterial Capsule and Is Associated With Differences in Protective Efficacy of BCG Vaccination Against Mycobacterium tuberculosis. The Journal of infectious diseases, 2016. 214(3): p. 426-37.

360. Yu, X., et al., Comparative evaluation of profiles of antibodies to mycobacterial capsular polysaccharides in tuberculosis patients and controls stratified by HIV status. Clinical and vaccine immunology : CVI, 2012. 19(2): p. 198-208.

361. Ortalo-Magne, A., A.B. Andersen, and M. Daffe, The outermost capsular arabinomannans and other mannoconjugates of virulent and avirulent tubercle bacilli. Microbiology, 1996. 142 ( $\mathrm{Pt} 4$ ): p. 927-35.

362. Balaban, N.Q., Persistence: mechanisms for triggering and enhancing phenotypic variability. Current Opinion in Genetics \& Development, 2011. 21(6): p. 768-775.

363. Balaban, N.Q., et al., Bacterial persistence as a phenotypic switch. Science, 2004. 305(5690): p. 16225.

364. Orman, M.A. and M.P. Brynildsen, Dormancy Is Not Necessary or Sufficient for Bacterial Persistence. Antimicrobial Agents and Chemotherapy, 2013. 57(7): p. 3230-3239.

365. Wayne, L.G. and L.G. Hayes, An in vitro model for sequential study of shiftdown of Mycobacterium tuberculosis through two stages of nonreplicating persistence. Infection and immunity, 1996. 64(6): p. 2062-9.

366. Wakamoto, Y., et al., Dynamic persistence of antibiotic-stressed mycobacteria. Science, 2013. 339(6115): p. 91-5.

367. de Steenwinkel, J.E.M., et al., Time-kill kinetics of anti-tuberculosis drugs, and emergence of resistance, in relation to metabolic activity of Mycobacterium tuberculosis. Journal of Antimicrobial Chemotherapy, 2010. 65(12): p. 2582-2589.

368. Szumowski, J.D., et al., Pathogenesis of Mycobacterium tuberculosis and its Interaction with the Host Organism. Current topics in microbiology and immunology, 2013. 374: p. 81-108.

369. Malherbe, S.T., et al., Persisting positron emission tomography lesion activity and Mycobacterium tuberculosis $m R N A$ after tuberculosis cure. Nature medicine, 2016.

370. Voskuil, M.I., K.C. Visconti, and G.K. Schoolnik, Mycobacterium tuberculosis gene expression during adaptation to stationary phase and low-oxygen dormancy. Tuberculosis, 2004. 84(3-4): p. 218-27.

371. Iona, E., et al., Infection of human THP-1 cells with dormant Mycobacterium tuberculosis. Microbes and infection / Institut Pasteur, 2012. 14(11): p. 959-67.

372. Mariotti, S., et al., Dormant Mycobacterium tuberculosis fails to block phagosome maturation and shows unexpected capacity to stimulate specific human T lymphocytes. Journal of Immunology, 2013. 191(1): p. 274-82.

373. Betts, J.C., et al., Evaluation of a nutrient starvation model of Mycobacterium tuberculosis persistence by gene and protein expression profiling. Molecular microbiology, 2002. 43(3): p. 717-31. 
374. Deb, C., et al., A novel in vitro multiple-stress dormancy model for Mycobacterium tuberculosis generates a lipid-loaded, drug-tolerant, dormant pathogen. PLoS One, 2009. 4(6): p. e6077.

375. Sala, C., et al., Simple model for testing drugs against nonreplicating Mycobacterium tuberculosis. Antimicrobial Agents and Chemotherapy, 2010. 54(10): p. 4150-4158.

376. Estrella, J.L., et al., A Novel in vitro Human Macrophage Model to Study the Persistence of Mycobacterium tuberculosis Using Vitamin D(3) and Retinoic Acid Activated THP-1 Macrophages. Frontiers in microbiology, 2011. 2: p. 67.

377. Vogt, G. and C. Nathan, In vitro differentiation of human macrophages with enhanced antimycobacterial activity. The Journal of clinical investigation, 2011. 121(10): p. 3889-901.

378. Adams, K.N., et al., Drug tolerance in replicating mycobacteria mediated by a macrophage-induced efflux mechanism. Cell, 2011. 145(1): p. 39-53.

379. Viveiros, M., et al., Isoniazid-Induced Transient High-Level Resistance in Mycobacterium tuberculosis. Antimicrobial Agents and Chemotherapy, 2002. 46(9): p. 2804-2810.

380. Gumbo, T., et al., Isoniazid's Bactericidal Activity Ceases because of the Emergence of Resistance, Not Depletion of Mycobacterium tuberculosis in the Log Phase of Growth. Journal of Infectious Diseases, 2007. 195(2): p. 194-201.

381. Liu, Y., et al., Immune activation of the host cell induces drug tolerance in Mycobacterium tuberculosis both in vitro and in vivo. The Journal of experimental medicine, 2016. 213(5): p. 809-825.

382. Guirado, E. and L.S. Schlesinger, Modeling the Mycobacterium tuberculosis Granuloma - the Critical Battlefield in Host Immunity and Disease. Frontiers in immunology, 2013. 4: p. 98.

383. Kapoor, N., et al., Human granuloma in vitro model, for TB dormancy and resuscitation. PLoS One, 2013. 8(1): p. e53657.

384. Parasa, V.R., et al., Modeling Mycobacterium tuberculosis early granuloma formation in experimental human lung tissue. Disease models \& mechanisms, 2014. 7(2): p. 281-8.

385. Guirado, E., et al., Characterization of Host and Microbial Determinants in Individuals with Latent Tuberculosis Infection Using a Human Granuloma Model. mBio, 2015. 6(1): p. 14.

386. Davis, J.M. and L. Ramakrishnan, The role of the granuloma in expansion and dissemination of early tuberculous infection. Cell, 2009. 136(1): p. 37-49.

387. Clay, H., H.E. Volkman, and L. Ramakrishnan, Tumor necrosis factor signaling mediates resistance to mycobacteria by inhibiting bacterial growth and macrophage death. Immunity, 2008. 29(2): p. 283-94.

388. McCune, R.M., Jr., W. McDermott, and R. Tompsett, The fate of Mycobacterium tuberculosis in mouse tissues as determined by the microbial enumeration technique. II. The conversion of tuberculous infection to the latent state by the administration of pyrazinamide and a companion drug. The Journal of experimental medicine, 1956. 104(5): p. 763-802.

389. Muñoz-Elías, E., et al., Replication dynamics of Mycobacterium tuberculosis in chronically infected mice. Infection and immunity, 2005. 73(1): p. 546-551.

390. Gill, W.P., et al., A replication clock for Mycobacterium tuberculosis. Nature medicine, 2009. 15(2): p. 211-4.

391. Flynn, J.L., et al., Immunology studies in non-human primate models of tuberculosis. Immunological Reviews, 2015. 264(1): p. 60-73.

392. Diedrich, C.R., et al., Reactivation of Latent Tuberculosis in Cynomolgus Macaques Infected with SIV Is Associated with Early Peripheral T Cell Depletion and Not Virus Load. PLoS One, 2010. 5(3).

393. Lin, P., et al., Tumor necrosis factor neutralization results in disseminated disease in acute and latent Mycobacterium tuberculosis infection with normal granuloma structure in a cynomolgus macaque model. Arthritis \& Rheumatism, 2010. 62(2): p. 340-350.

394. Johnson, J.L., et al., Shortening treatment in adults with noncavitary tuberculosis and 2-month culture conversion. American Journal of Respiratory and Critical Care Medicine, 2009. 180(6): p. 558-563.

395. Jindani, A., et al., High-dose rifapentine with moxifloxacin for pulmonary tuberculosis. The New England journal of medicine, 2014. 371(17): p. 1599-1608.

396. Dartois, V., The path of anti-tuberculosis drugs: from blood to lesions to mycobacterial cells. Nature reviews. Microbiology, 2014. 12(3): p. 159-167. 
397. Zhang, Y., et al., Mechanisms of Pyrazinamide Action and Resistance. Microbiology spectrum, 2014. 2(4).

398. Hu, Y., A.R. Coates, and D.A. Mitchison, Sterilising action of pyrazinamide in models of dormant and rifampicin-tolerant Mycobacterium tuberculosis. The international journal of tuberculosis and lung disease : the official journal of the International Union against Tuberculosis and Lung Disease, 2006. 10(3): p. 317-322.

399. Balaban, N.Q., et al., A problem of persistence: still more questions than answers? Nature reviews. Microbiology, 2013. 11(8): p. 587-591.

400. Warrier, T., et al., Identification of Novel Anti-mycobacterial Compounds by Screening a Pharmaceutical Small-Molecule Library against Nonreplicating Mycobacterium tuberculosis. ACS infectious diseases, 2015. 1(12): p. 580-5.

401. Brodin, P., et al., High Content Phenotypic Cell-Based Visual Screen Identifies Mycobacterium tuberculosis Acyltrehalose-Containing Glycolipids Involved in Phagosome Remodeling. PLoS Pathogens, 2010. 6(9).

402. Mauvezin, C. and T.P. Neufeld, Bafilomycin A1 disrupts autophagic flux by inhibiting both V-ATPasedependent acidification and Ca-P60A/SERCA-dependent autophagosome-lysosome fusion. Autophagy, 2015. 11(8): p. 1437-1438.

403. Jung, J.-Y. and C.M. Robinson, IL-12 and IL-27 regulate the phagolysosomal pathway in mycobacteriainfected human macrophages. Cell Communication and Signaling, 2014. 12(1): p. 1-14.

404. Kim, B.-H.H., et al., A family of IFN- $\gamma$-inducible 65-kD GTPases protects against bacterial infection. Science (New York, N.Y.), 2011. 332(6030): p. 717-721.

405. Eklund, D., et al., Validation of a medium-throughput method for evaluation of intracellular growth of Mycobacterium tuberculosis. Clin Vaccine Immunol, 2010. 17(4): p. 513-7.

406. Redford, P.S., P.J. Murray, and A. O'Garra, The role of IL-10 in immune regulation during M. tuberculosis infection. Mucosal immunology, 2011. 4(3): p. 261-270.

407. Honeyborne, I., et al., Profiling persistent tubercule bacilli from patient sputa during therapy predicts early drug efficacy. BMC medicine, 2016. 14: p. 68.

408. Jung, Y.J., et al., The Intracellular Environment of Human Macrophages that Produce Nitric Oxide Promotes Growth of Mycobacteria. Infection and immunity, 2013.

409. Queval, C.J., et al., STAT3 Represses Nitric Oxide Synthesis in Human Macrophages upon Mycobacterium tuberculosis Infection. Scientific reports, 2016. 6: p. 29297.

410. Kinhikar, A.G., et al., Potential role for ESAT6 in dissemination of M. tuberculosis via human lung epithelial cells. Molecular Microbiology, 2010. 75(1): p. 92-106.

411. Chen, J.M., et al., Phenotypic Profiling of Mycobacterium tuberculosis EspA Point Mutants Reveals that Blockage of ESAT-6 and CFP-10 Secretion In Vitro Does Not Always Correlate with Attenuation of Virulence. Journal of Bacteriology, 2013. 195(24): p. 5421-5430.

412. Kennedy, G.M., et al., A novel ESX-1 locus reveals that surface-associated ESX-1 substrates mediate virulence in Mycobacterium marinum. Journal of Bacteriology, 2014. 196(10): p. 1877-1888.

413. BoseDasgupta, S. and J. Pieters, Striking the Right Balance Determines TB or Not TB. Frontiers in immunology, 2014. 5: p. 455. 


\section{Acknowledgements}

There is a long list of people that contributed in one way or another to this thesis, big thanks to all of you!

Most of all, to Maria, my main supervisor and mentor, for giving me the opportunity to be part of your group for so many years, I truly enjoyed it. Thank you for your endless energy and optimism, which was much needed at times! And for always giving me the freedom and encouragement to try things, as well as sharing your exceptional enthusiasm for research in general and for TB in particular.

To my co-supervisor Olle, for always taking the time to read what I wrote, as well as for your advice of not unnecessarily complicating things.

To my co-supervisor Vesa, for being so refreshingly straightforward, for all your input on my molecular biology and microscopy work and for introducing me to "the Vivatome", I now understand what all the fuss is about.

Huge thanks to the colleagues that got to take care of me during my first months at MedMikro and introduced me to everything, from BSL-3 lab work to Swedish language and beyond: To Amanda, for always sharing your huge knowledge and answering my thousands of questions. To Danne, for help in the lab, great humor and cheerful company.

A lot of work in Paper 2 was done by our postdoc Elsje, thanks for your huge efforts during these long experiments, when bacteria behaved weirdly and for being such a patient English language teacher. I'll never forget that Nebraska wedding, too! Baie dankie vir alles, dit was 'n groot plesier en ek mis jou!

Thanks to all other group members through all the years! To Clara, for being so laid-back, Deepti, for sushi, books and encouragement, Sadaf, my fellow phenotype colleague, for discussing all aspects of life, Ramana, for always sharing your theoretical and practical knowledge, to Hansi, for being such a fun German, and to Nina, for challenging me with clinical perspectives and tough questions about TB. Thanks to all of you for proof-reading!

To Robban, for challenging me with many discussions on results 'där vi har nördat ner oss rejält', and for always viewing things from a different perspective, Anna-Maria, for being a cheerful fellow fighter during long hours in the TB lab, Susmita, for being so positive and for brightening up the TB-lab with Bollywood music. To Blanka, for being such a powerful 
person and for sharing my passion for Knödel, and to Henrik, for all your input on how to analyze data and optimize statistics.

To the 'TB ladies' (Ann-Marie, Britt-Marie, Eva, Maria, Michaela, Sara, Slavica, Vita) in the clinical lab, for putting up with us in the old and also the new lab.

To Angelika, for being my $\mathrm{PhD}$ student colleague and friend, for all discussions on microscopy and picture analysis and everything else!

To all the people at MedMikro, a work place that I enjoyed very much! Thank you, Tony, for all the good times when teaching in the student lab and for being helpful with all small things, Katarina, for teaching me the perfect isoleringsutstryk and a lot more about microbiology when I was new. To Mary and Christina for outstanding support in (often lastminute) inquiries. To Maggan, for sharing your experiences of life. To Alejandro, Manuel, Maite, Stéphanie, Heli, Andrea for discussions and all activities outside of work. To all the others, Jonna, Ebba, Thommie, Anders, Fanny, Olena, Atik, Björn, Pontus, Lena, Kajsa, Elisabet, Martin, Åsa, Elena, Kalle, Per-Eric, Tommy, Heriberto and many more for all the nice talks during fika breaks.

To Magali, Johan, Fredrik, Rico, Marlen and Daniel for all the fun outside of work.

To all my friends in Austria, to Angie, Chrissy, Evi, Karin, Loisl, Mau, Verena... To Lise, for help with the figures, and to all the other Unimädels. Thanks to you all for your friendship and for great times during my summer and winter vacations back home!

To my family, above all to Mama, Papa and my siblings Iris, Jakob and Julia, for love and encouragement. To Peter, for your love and support, it means a lot! 


\section{Papers}

The articles associated with this thesis have been removed for copyright reasons. For more details about these see:

http://urn.kb.se/resolve?urn=urn:nbn:se:liu:diva-132321 